\title{
THESIS
}

\section{IS THE “GRASS” GREENER? \\ OCCUPATIONAL WELLNESS IN THE COLORADO CANNABIS INDUSTRY}

\author{
Submitted by \\ Kevin M. Walters \\ Department of Psychology
}

\author{
In partial fulfillment of the requirements \\ For the Degree of Master of Science \\ Colorado State University \\ Fort Collins, Colorado
}

Spring 2016

Master's Committee:

Advisor: Gwenith Fisher

Bryan Dik

Kurt Kraiger

Stephen Reynolds 
Copyright by Kevin Michael Walters 2016

All Rights Reserved 


\begin{abstract}
IS THE “GRASS” GREENER?

OCCUPATIONAL WELLNESS IN THE COLORADO CANNABIS INDUSTRY
\end{abstract}

This study is the first occupational safety and health evaluation of the cannabis industry of Colorado from an Occupational Health Psychology (OHP) perspective. Qualitative pilot data and common OHP theories provide a framework for project development, design, and rationale. This study investigated the following among cannabis industry workers: potential stressors, perceptions and awareness of physical safety hazards, strain outcomes, and organizational supports that might buffer relations between stressors and strain outcomes. Study results provide a first glimpse at the demographics of the cannabis industry and suggest that workers generally experience low strain and high levels of organizational supports in the presence of various physical and psychological stressors and hazards. However, results also suggest heterogeneous health and safety training, awareness, and regulation in the cannabis industry. Future research directions and practical implications for cannabis industry workers are provided. 


\section{ACKNOWLEDGMENTS}

This thesis represents several years of work - work that I could never have accomplished without the help and guidance of many others. As such, I have a number of people that I would like to acknowledge and thank.

First, thank you to my advisor, Dr. Gwen Fisher - where do I even begin? Put simply, thank you for everything. Your guidance, positive attitude, and expertise have been pivotal to the completion of this project (and my own occupational well-being along the way). Your ability to motivate and lead by example is inspiring and unwavering - from the first time I ever walked into your office, to the time we sat at your office table together writing a grant proposal into the wee morning hours, to my thesis defense, and beyond - thank you, thank you, thank you.

Second, thank you to my thesis committee, Drs. Kurt Kraiger, Bryan Dik, and Steve Reynolds. You are all truly brilliant individuals, and I feel incredibly fortunate to view each of you as a role model. Kurt - thank you for being a mentor and friend to me, both in and out of the classroom. Bryan - thank you for your enthusiasm and for enabling me to think about this project from a broader perspective and become a more well-rounded student of psychology. Steve - thank you for providing so much expertise from a different perspective and for your tremendous support.

Third, thank you to Lili Tenney, the last (but certainly not least) member of our project team. Your positive attitude, experiences, and ideas have contributed to this project from the very beginning - ever since we went on a site visit to the pilot organization, we've been in this together every step along the way. Thank you also for your tremendous help in marketing the project. 
Fourth, I would like to thank Dr. Lee Newman, Dr. Lorann Stallones, the NIOSH Mountains and Plains Education and Research Center (MAP ERC), the NIOSH MAP ERC Pilot Program, and NIOSH as a whole. Lee - you helped to turn the idea for this project into a reality. Without you, this project would never have happened. Lorann - thank you for many helpful suggestions regarding this project and your support through the MAP ERC. Thank you, the MAP ERC, and NIOSH for all of the financial support for this project and my occupational health education and training.

Fifth, I would like to thank the partners in the cannabis industry who played such a key role in this project. These partners supported and assisted with the development and the administration of the survey in various ways that made this project possible. Thank you for your generous support, expertise, and input. Finally, thank you to the countless anonymous individuals in the industry who completed this survey or contributed in one way or another.

Sixth, thank you to Chloe Wilson for being the best research assistant imaginable. You have a bright future ahead of you in psychology, and I'm so fortunate to have worked with you these past couple of years. Throughout all the behind-the-scenes work, you always keep a smile and a positive attitude. Thank you also to Alyssa Ortiz, Jiaxing Wu, and the entire CSU OHP Research Team for additional assistance on this project.

Seventh, thank you to James Weston, Megan Naude, Samantha Stelman, and Steve Raymer. Ever since our bright-eyed, bushy-tailed first day of grad school, I'm proud to be a member of "Team First-Year" for life. James - ever since we almost accidentally opened a joint bank account together, you have been one of the best friends I've ever had the privilege of knowing. Megan - it's amazing how well you can get to know a person just by sharing an office together for several years, and I'll always cherish the random conversations that we've had over 
the years (even if you always point out my weird pronunciations of things). Sam - without you and your positive energy, I would never have discovered how much my knees really do like dancing. Steve - the Air Force is lucky to have you. I suppose pirates aren't meant to stay cooped up in one place for too long, but we all miss your presence, personality, and "dad jokes" around the office.

Eighth, thank you to Kyle Sandell, Charlie Heidrick, and Drew Lindley. Never in my life could I have expected to meet people who love bears as much as you all do. Kyle - thank you for being a great friend and role model to me over the years, and thank you for your help throughout the extent of this project. I could always count on you for moral support, life advice, and help with reviewing my work. Life in Fort Collins truly hasn't been the same ever since you graduated. Charlie - thank you for just being you. You're an incredible friend and roommate, and an even better person. Drew - thank you for being a great friend, and for always having a positive attitude and a fresh perspective. Grad school always seems a little less stressful with your voice and ukulele in the background.

Ninth, thank you to Kyla Holcombe and Lauren Menger. Kyla - thank you for your help with reviewing my thesis, and for all the life advice you've given me throughout this project and throughout all of grad school. You are an incredible person and role model to follow - I think the world would be a better place if we could all learn to channel our own "inner Kyla". Lauren thank you for your help reviewing countless presentations of mine and for providing insightful help, input, and support throughout this project. I've been lucky to have you as an example these past few years and to work together on the scale development involved in this project. I sincerely hope that our paths continue to cross in the future. 
Tenth, thank you to the I/O faculty members and students at CSU that I haven't yet acknowledged. I am so proud to be a part of this incredible program, and I feel as if I could write an entire essay describing the many ways you have each had a positive impact on my life. Over the years, I have learned and continue to learn a great deal about psychology (and life in general) from each of you.

Eleventh, thank you to my once-advisors and forever-mentors, Dr. Tori Culbertson and Dr. YoungAh Park. Tori - you were my first true mentor, and I will always cherish our time spent working together at K-State. Beyond that, you are an incredible person and friend. I am so fortunate to know you, and I owe my entire journey into I/O Psychology to you. YoungAh - at a time when I hardly knew what Occupational Health Psychology was, you took me under your wing. Thank you for providing me with the foundation on which all of my OHP experience has been built, and thank you for being a great friend and mentor.

Finally, to Mom and Dad - words could never thank you enough for all that you do and have ever done for me. I sincerely appreciate all of your support throughout the years - this thesis represents your accomplishments far more than it represents any of my own. 


\section{DEDICATION}

This thesis is dedicated to Ryan, Marcy, Matthew, Ashley, and Alex.

You are the best siblings that anyone could ever ask for-I'll never stop learning from you. Thank you for putting up with my weird expressions and one-liners over the years. 


\section{TABLE OF CONTENTS}

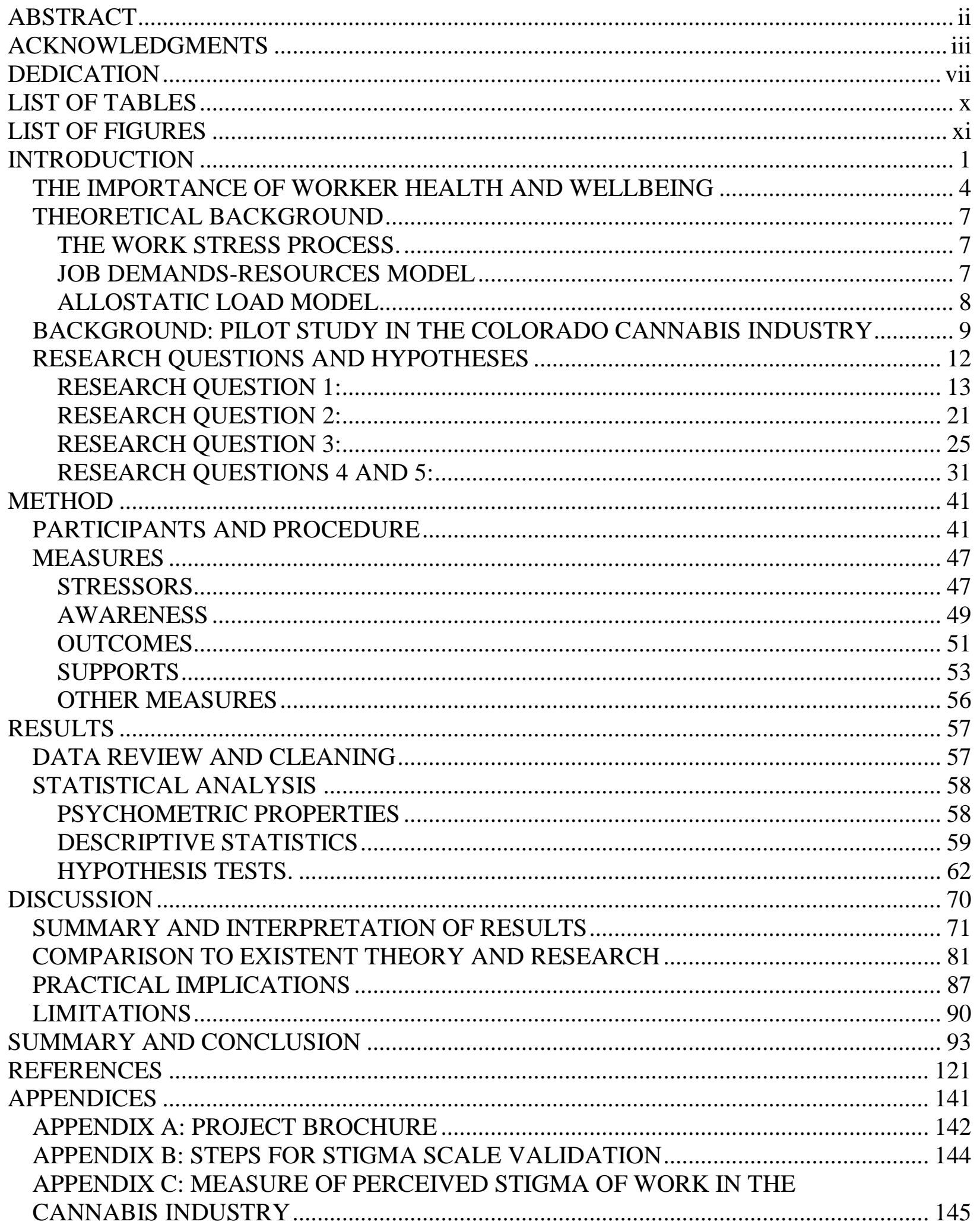


APPENDIX D: JOB INSECURITY SCALE ……………………………………….......... 146

APPENDIX E: BREAUGH \& COLIHAN ROLE AMBIGUITY SCALE ............................. 147

APPENDIX F: MEASURE OF LONG WORKING HOURS .......................................... 148

APPENDIX G: NEAL \& GRIFFIN SAFETY CLIMATE MEASURE ………………........ 149

APPENDIX H: MEASURE OF PERCEPTIONS OF PHYSICAL SAFETY IN THE

CANNABIS INDUSTRY 150

APPENDIX I: MICHIGAN ORGANIZATIONAL ASSESSMENT QUESTIONNAIRE

JOB SATISFACTION SUBSCALE

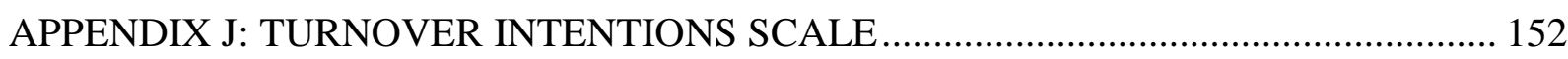

APPENDIX K: AFFECTIVE COMMITMENT SCALE ................................................. 153

APPENDIX L: COPENHAGEN WORK BURNOUT INVENTORY …………………...... 154

APPENDIX M: JOB CONTROL - DECISION AUTHORITY ……………………............ 155

APPENDIX N: SURVEY OF PERCEIVED ORGANIZATIONAL SUPPORT ………….... 156

APPENDIX O: WORK AS MEANING INVENTORY …………………………........... 157

APPENDIX P: MEASURE OF PERCEIVED EMPLOYABILITY ................................... 158

APPENDIX Q: NEGATIVE AFFECTIVITY SCALE ………………........................... 159

APPENDIX R: DEMOGRAPHICS AND CANNABIS USE ............................................. 160

APPENDIX S: DESCRIPTION OF “HACKER” RESPONSE IDENTIFICATION

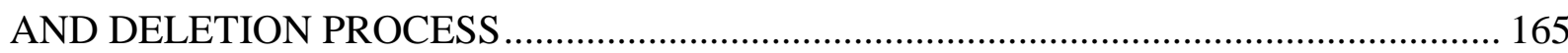




\section{LIST OF TABLES}

TABLE 1 - DEMOGRAPHICS: PARTICIPANTS ......................................................... 95

TABLE 2 - DEMOGRAPHICS: PARTICIPANTS' JOBS ................................................. 96

TABLE 3 - DEMOGRAPHICS: PARTICIPANTS' ORGANIZATIONS ............................... 97

TABLE 4 - DEMOGRAPHICS: PARTICIPANTS' CANNABIS USE ................................. 98

TABLE 5 - DESCRIPTIVE STATISTICS FOR ALL STUDY VARIABLES ........................99

TABLE 6 - CORRELATIONS FOR ALL STUDY VARIABLES .................................... 100

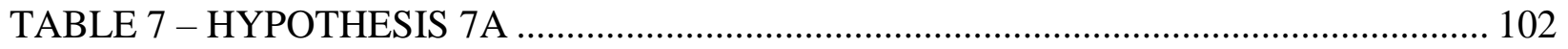

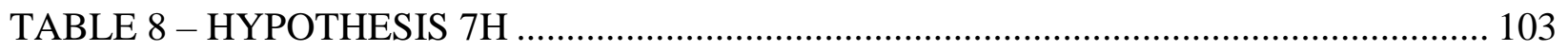

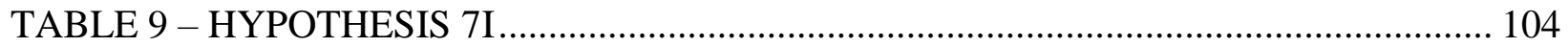

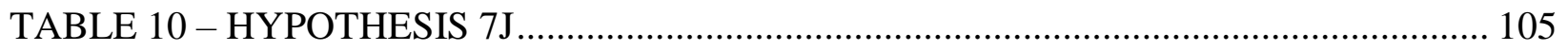

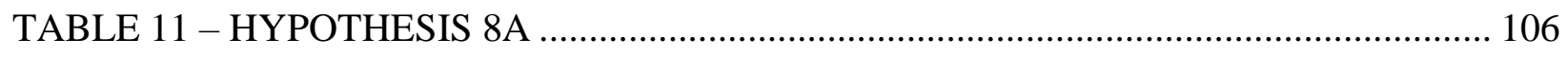

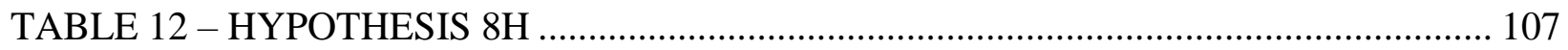

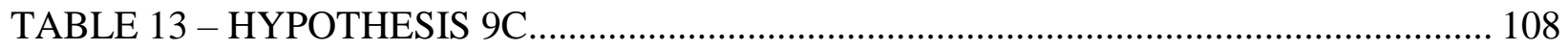

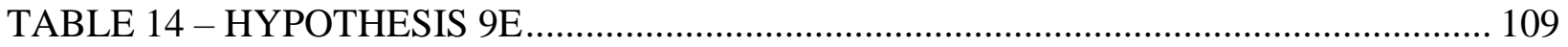

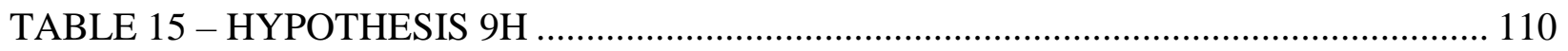




\section{LIST OF FIGURES}

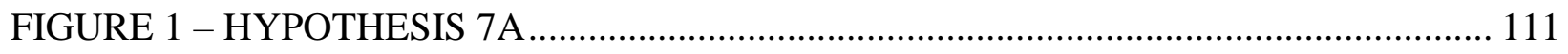

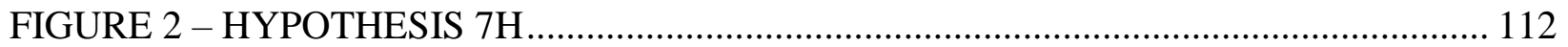

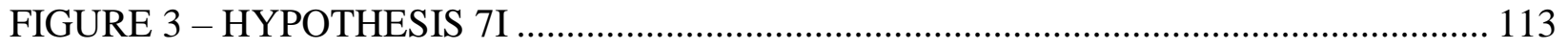

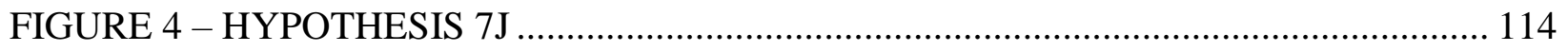

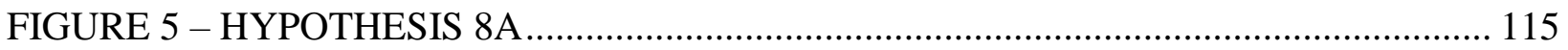

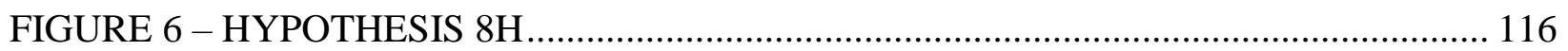

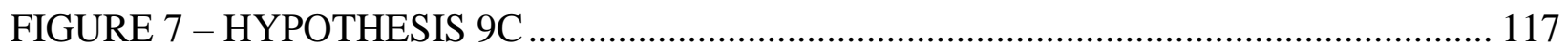

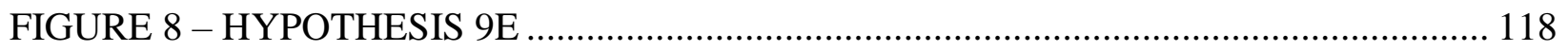

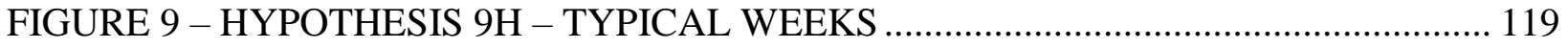

FIGURE 10 - HYPOTHESIS 9H - BUSY WEEKS ................................................ 120 


\section{Introduction}

Throughout the Western culture of the United States, an ever-growing trend towards social acceptance of lifestyle differences was first identified by Giddens (1991). One such lifestyle choice gaining prevalence and legal acceptance is the legalization and decriminalization of cannabis. As of February 2016, growth and usage of cannabis is legal in some form or another in a total of 27 states and Washington, D.C. Four states report only decriminalization laws (for all citizens, possession of small amounts will not be subject to criminal charges); eight states report only medical cannabis laws (use is legal only with a physician-prescribed medical cannabis card); an additional 11 states report both decriminalization and medical cannabis laws; and four states and Washington, D.C. report total legal recreational usage for individuals at a minimum 21 years of age (National Organization for the Reformation of Marijuana Laws [NORML], 2016). Colorado is currently one of these four states to allow for recreational cannabis use. The cannabis laws of Colorado first changed in November 2000 with the legalization of medical cannabis. In November 2012, Colorado voters again ruled to change the legislation with the passing of Amendment 64, this time legalizing cannabis for recreational use and also allowing for the retail sale of recreational cannabis at dispensaries beginning January 1, 2013. As of February 1, 2016, the Colorado Marijuana Enforcement Division (MED) reported that there were 517 licensed medical cannabis centers in Colorado (i.e., where licensed medical cardholders can purchase cannabis products), 754 licensed medical cannabis cultivation centers (i.e., where medical cannabis may be grown), and 204 licensed medical cannabis infused product manufacturers (i.e., where products such as edibles, lotions, oils, transdermal patches, and others are manufactured; Colorado Department of Revenue [CDOR], 2016a). Additionally, the MED reported a total of 426 licensed retail cannabis stores (i.e., dispensaries where cannabis may be 
purchased), 501 licensed retail cultivations, 168 licensed product manufacturers, and 16 licensed testing facilities (CDOR, 2016a). These cannabis organizations, which are nearly all operating as small businesses, are an economic asset to the state of Colorado. Specifically, first-year recreational cannabis sales (i.e., 2014 sales) generated over $\$ 52$ million in tax revenue for the state of Colorado (CDOR, 2016b).

With the liberalization of cannabis laws comes the birth and growth of an entirely new industry and population of workers, which are almost entirely uninvestigated. The goal of this study is to examine work-related psychosocial issues and occupational health and well-being among cannabis industry workers. In particular, this project aims to:

1. Identify potential health, safety, and psychosocial work stressors.

2. Assess employees' level of awareness of occupational safety and health issues.

3. Identify sources of workplace support in place to protect the health and well-being of employees within the cannabis industry of Colorado.

This project follows an important shift in the field of Occupational Health Psychology and other occupational health disciplines to examine specific industrial sectors individually. Specifically, the National Institute for Occupational Safety and Health (NIOSH), which is part of the U.S. Centers for Disease Control and Prevention (CDC), has identified the need to look at industrial sector and occupation-specific hazards. Given the diversity of job and industries in the United States, investigating specific industries and occupations can provide guidance for moving research to practice in workplaces among the entire occupational safety and health field (National Institute for Occupational Safety and Health [NIOSH], 2013). NIOSH has organized its variety of occupational safety and health activities into a NIOSH program portfolio that is divided further into sector and cross-sector programs. There are currently ten National 
Occupational Research Agenda (NORA) sector programs, each of which represents a specific industry: agriculture, forestry, and fishing; construction; healthcare and social assistance; manufacturing; mining; oil and gas extraction; public safety; services; transportation, warehousing, and utilities; and wholesale and retail trade (Rogers, 2006; Sorerholm, 2006). NORA was first established in 1996 by NIOSH as a partnership program to guide research and workplace practices for the nation (Rogers, 2006; Sorerholm, 2006). In a 2006 review of the first decade of NORA, NIOSH first identified its sector-based approach with the goal of moving research to practice among workplaces in the ten identified sectors (Rogers, 2006). Each sector is represented by a sector research council which outlines strategic goals for researching and implementing programs to protect worker health and well-being. The importance of NORA lies in its sector-based approach; rather than focusing strictly on specific businesses, NIOSH emphasizes the need to focus on entire industrial sectors to improve occupational safety, health, and well-being. The rationale for a sector-based approach is that research can more easily be shifted to practice within workplaces via industrial examinations of the demographics of at-risk workers, the severity of the potential risk, and the probability that new approaches can make a difference (NIOSH, 2013). Essentially, through this focus on industrial sectors, the sector-based approach can compensate for possible situations in which occupational health and safety evaluations of one organization might not reflect occupational health and safety trends within an entire industry.

Given the novelty of the cannabis industry, this industry is not currently housed within a specific sector program but can be likened to the relevant sector programs of agriculture, forestry, and fishing (e.g., cultivating cannabis crops); manufacturing (e.g., manufacturing cannabis products, such as extracts, baked goods, concentrates, etc.); and wholesale and retail 
trade (e.g., the sale of cannabis products by cashiers and sales clerks). The goal of this project aligns with many strategic goals of these relevant NORA Sector Research Councils such as: enhancing existing employment demographic data (for which there is currently none in the cannabis industry); reducing occupational health issues among understudied and vulnerable populations; reducing occupational health issues among small businesses; enhancing knowledge related to emerging occupational health and safety risks; moving proven health and safety strategies into workplaces through collaborative efforts; expanding the availability and use of effective interventions to reduce occupational health issues; improving the health and well-being of workers; and disseminating solutions and guidelines throughout the industry (see National Agriculture, Forestry, and Fishing Agenda, 2008; National Manufacturing Agenda, 2010; National Wholesale and Retail Trade Agenda, 2009). This thesis project was part of a larger project with these overlapping goals. Specifically, this publication was supported by Grant Number T42OH009229-08 from CDC NIOSH Mountains and Plains Education and Research

Center. Its contents are solely the responsibility of the author and do not necessarily represent the official views of the CDC NIOSH and MAP ERC.

\section{The Importance of Worker Health and Wellbeing}

Occupational Health Psychology (OHP) is a field of psychology focused on the development and promotion of the psychological health, safety, and well-being of employees and their families (Tetrick \& Quick, 2011). Occupational Health Psychology was developed by integrating knowledge and research across disciplines, including multiple areas of psychology (e.g., Health Psychology and Industrial/Organizational (I/O) Psychology) as well as ergonomics, preventive medicine, public health, epidemiology and engineering, among others (Tetrick \& Quick, 2011). Research in OHP, which has grown exponentially during the past 30 years, has 
demonstrated that psychosocial factors at work (e.g., the social environment, organizational aspects, and job tasks) are important for employee health and well-being (Sauter, Murphy, \& Hurrell, 1990). For example, in an analysis of the 2002 National Study of the Changing Workforce, Thompson and Prottas (2006) found that psychosocial factors such as job autonomy, availability of family benefits, and organizational support were associated with such employee well-being outcomes as stress, life satisfaction, and turnover intentions. OHP addresses many aspects of workers' experiences, including positive (e.g., well-being and job satisfaction) and negative (e.g., psychosocial work stress, lack of support) issues at work. OHP is generally based on a scientist-practitioner model; researchers and practitioners often work in conjunction with industry leaders and workers to protect and promote worker health and well-being while broadening scientific knowledge. In support of the scientist-practitioner model, Adkins (1999) identified OHP as an evolving practice with aims to work with organizations to develop preventive stress management procedures.

Within the cannabis industry there is a need for occupational health research, evaluations, and interventions to optimize worker health and well-being. The lack of occupational health research in the cannabis industry is problematic, in that 'old' (i.e., existing) occupational health problems often occur in new industries, and 'new' (i.e., previously unidentified) problems are constantly created as the global economy evolves (Rantanen, 2011). For example, Raja and Bhasin (2014) began empirical investigations of worker health and well-being among call-center employees in India, who were was labeled as an emerging and understudied occupational group. Raja and Basin identified a number of potential hazards to worker health and well-being that have been identified in other literature, including low sleep quality levels, reported poor eating habits, imbalance between work and family life, and high rates of mental and physical ailments. 
This investigation by Raja and Basin is similar to my examination of the cannabis industry, because a new occupational group and industry has emerged with a need for occupational health assessment and evaluation. However, the cannabis industry is unique because it cannot be directly compared to similar industries elsewhere in the world; this is the first legal cannabis growth and retail industry in existence. In the process of developing and recommending legalization practices and procedures, the cannabis industry has been compared from a public health standpoint to the alcohol and tobacco industries, both of which are currently legislated in the United States for production, sale, and consumption (e.g., Pacula, Kilmer, Wagenaar, Chaloupka, \& Caulkins, 2014). Alcohol and tobacco production also involve work characteristics across a variety of sectors, such as agricultural and horticulture, manufacturing, and retail sales. Alcohol and tobacco are also examples of stigmatized industries. However, direct comparisons between cannabis and alcohol and/or tobacco cannot and should not be made without extensive empirical investigations of the industry. Previously collected pilot study data has suggested potential unique stressors in the cannabis industry, such as unique safety concerns and job insecurity issues. In short, there is a need for occupational health research in all industries where work is being performed by individuals. The cannabis industry represents a new industry with potentially unique characteristics. This project aims to apply the scientist-practitioner model via an assessment of the cannabis industry across multiple organizations.

This paper is organized as follows: First, I describe the theoretical background to guide this research project. Second, I discuss previously collected pilot study data. Third, I individually present and discuss research questions and hypotheses for this project. Fourth, I describe the research methodology used in this project. Fifth, I report and discuss the results of this study. Sixth, I discuss this project's implications and contributions to research literature, compare 
results to existent research, and describe the general limitations of this study. Finally, I conclude this paper with a brief summary and conclusion.

\section{Theoretical Background}

The work stress process. In order to provide a theoretical background for this study, it is first necessary to understand the work stress process. Colloquially, "stress" is often considered to be the physiological or psychological experience of individuals in response to a stimulus, which is often viewed in a negative context. However, a response to the stress process is actually referred to in OHP literature as "strain," and it might be either positive (eustress) or negative (distress; Nelson \& Simmons, 2011). The physical or psychological stimuli to which an individual is exposed can be considered as a stressor (sometimes referred to as a demand; Nelson \& Simmons, 2011). Within the organizational context, stressors might have origins in one's work roles and role capacities, social and/or environmental settings, the physical nature of the job, and job characteristics.

Job demands-resources model. As OHP has developed beyond an understanding of the stress process, a variety of theories and models have been offered and empirically examined to increase our understanding of negative and positive aspects of the intersection between work, worker health, and worker well-being. The first of such theories I will discuss is the job-demands resources model (JDR), which suggests that workers experience a certain degree of demands from their job and roles which they can fulfill through the use of resources (Demerouti, Bakker, Nachreiner, \& Schaufeli, 2001). These demands refer to various components of the job (i.e., physical, social, or organizational) that require a certain degree of sustained mental or physical effort by the worker, thus relating to a certain degree of psychological or physiological cost to the worker (Demerouti et al., 2001). Given this cost, research suggests that there are aspects of 
the job that operate in a way that is protective of worker health, allowing workers to meet and cope with job demands. These aspects are referred to as resources. For example, Richter and Hacker (1998) distinguished resources as either external (e.g., organizational and social) or internal (e.g., cognitive characteristics and actions within the person). Given variability and fluctuations in individual internal resources, literature tends to focus on work-related resources, such as job control, task variety, and participation in organizational decision making (Demerouti et al., 2001). According to the JDR, strain occurs when there is an imbalance between the demands of the job and the resources that the worker has to cope with those demands (Demerouti et al., 2001). In a review of the JDR, Schaufeli and Taris (2014) found empirical support for the proposition in the JDR that high levels of job demands lead to strain and health impairment, whereas high levels of resources lead to higher levels of worker motivation and productivity. I applied the JDR to cannabis industry workers as a theoretical framework to aid in identifying relations between demands and resources experienced by these workers. In other words, the JDR framework of strain resulting from imbalances between demands (e.g., stressors) and resources (e.g., sources of workplace support) can be applied to this industry because identifying such imbalances provides insight into strain outcomes for cannabis industry workers.

Allostatic load model. Another approach to the study of work stress is the allostatic load model (McEwen, 1998). This model was developed in response to early theories of stress, which focused primarily on physiological strain as a result of external stimuli (e.g., Cannon, 1932). Cannon's writings focused on the concept of homeostasis, which Ganster and Perrewé (2011) described as the concept of the body's physiological systems maintaining steady states, such as the human body sweating in response to exposure to a hot desert environment (Sapolsky, 1994). Selye (1955) argued that the human body is only finitely capable of adapting to external stimuli 
in the environment; for example, in a hot desert environment, the body will eventually become dehydrated and will die. Recent researchers have noticed the limitations of the homeostatic approach, such as the overly simplification of the body's regulation systems, which prompted Sterling and Eyer (1988) to propose the idea of allostasis, or 'stability through change'. Ganster and Perrewé further described allostasis as a process in which various response systems (e.g., cardiovascular, neuroendocrine, etc.) adjust to cope with stimuli that challenge homeostatic systems, whether those challenges are real or imagined. For example, in a hot desert environment, the body will not only sweat but will also alter kidney function, mucous membrane secretion, and vein and arterial function, among others (Sapolsky, 1994). When response systems are over-activated, such as due to repeated chronic stressors, systematic "set points" can be altered and changed; this is referred to as an allostatic state (Ganster \& Perrewé, 2011). Finally, allostatic load (pathological psychological and physiological symptoms) can result from a chronic, repeated allostatic state (Ganster \& Perrewé, 2011; Ganster \& Rosen, 2013). This model applies broadly to the cannabis industry, in that allostatic load might result if the industry workers experience chronic psychological stressors. Although homeostatic and allostatic models can provide a foundation for predictions of occupational strain for cannabis industry workers, a comprehensive evaluation of the industry is necessary to fully understand how these models do (or do not) relate to the industry. When I developed research questions and hypotheses for an evaluation of these models within the cannabis industry, previously collected pilot data served as a framework and basis for understanding additional research questions.

\section{Background: Pilot Study in the Colorado Cannabis Industry}

In fall 2013, I worked with one community partner organization in Colorado's cannabis industry as part of an interdisciplinary occupational health team to perform an occupational 
health and safety assessment. The objective of this project was to assess the organization's current setting and best practices regarding worker safety and health. Through informal qualitative interviews and observations with approximately 10-15 workers (all at the one organization), my project team identified numerous potential physical safety and psychological hazards in the workplace. For example, reported and observed physical environmental stressors included the overall physical safety and security of employees, as well as a lack of emergency preparedness for potential violence and/or theft. Workers reported concerns about their respiratory health, due to the processes involved in growing cannabis plants and exposure to particular strains of cannabis which may produce allergens, as well as environmental exposure to harmful substances (such as carbon dioxide, carbon monoxide, and various pesticides). Additionally, we identified potential for ergonomic injuries that could result from performing repetitive tasks (e.g. trimming plants) for up to 8-10 hours per day.

The main psychological stressors reported by workers in the pilot study organization included repetitive tasks, long working hours, ambiguous roles and task loads, and general role overload (having insufficient time to fulfill job demands; Hecht, 2001) during peak work periods (e.g., harvesting). Within this particular organization, there was also a high degree of workplace support to alleviate those stressors. Qualitatively, all workers, including the organization's leaders as well as lower-level workers, reported high levels of perceived organizational support, social support, and job autonomy (as was possible within reason, given the nature of the tasks and job demands). However, it is worth noting that all of these findings were based only on observational data gathered through facility tours, observation of job tasks and work space, and unstructured interviews and discussions with a subset of workers. 
The pilot work in this one organization identified a clear need to conduct more thorough, systematic empirical investigations across many growhouses and dispensaries. First, given that most, if not all, Colorado cannabis dispensaries operate as small businesses, there are hundreds of organizations and the potential for variability among these growhouses and dispensaries in terms of working conditions, policies, and tasks supportive of employee psychological wellbeing. Second, there was a need to conduct a systematic employee-level assessment. The transactional model of stress and coping (i.e., the "transactional model"), developed by Lazarus and Folkman (1984), suggests that strain is not a product of strictly a person or his or her environment; rather, it is the interaction of the two that results in subjective strain. Lazarus and Folkman further posited the importance of cognitive appraisals (i.e., either conscious or unconscious) and coping strategies (i.e., emotion-focused or problem-focused coping; HulbertWilliams, Morrison, Wilkinson, \& Neal, 2013). Lazarus and Folkman emphasized the importance of subjective perceptions in the stress process. In other words, certain individuals might perceive or experience strain from particular stressors, while other individuals in the same job or environmental conditions might not. An employee-level evaluation in the cannabis industry could provide a method for assessing individual employees' perceptions and provide a broader view of the stressors and strains experienced by cannabis industry workers than has previously been considered.

The purpose of the present study is to take the first step toward fulfilling the need for empirical investigations of the occupational and environmental safety and health of the cannabis industry, with an emphasis on worker psychological health and well-being. By conducting a preliminary systematic evaluation of workers in this industry, I aim to create a foundation to serve as the basis for future empirical research and practice. I developed a number of relevant 
research questions and hypotheses based on the JDR model, allostatic load model, and transactional model of stress, as well as the discussed pilot data.

\section{Research Questions and Hypotheses}

As described previously, Lazarus and Folkman's (1984) transactional model of stress and coping suggests the potential for fluctuations and variability in individual perceptions of stressors and strains. Given such variability, as well as the lack of prior empirical investigations of the cannabis industry, I hereby established a goal of descriptively investigating and reporting general levels of perceived stressors and outcomes without specific a priori hypotheses. In other words, throughout this introduction I reference pilot data, prior research in other industries, and general OHP models to introduce specific stressors and outcomes and also discuss possible levels of those perceived stressors and outcomes, especially with regard to how such levels might influence relations between variables and/or their influence on buffering (i.e., moderating) effects. However, I do not specifically state hypotheses regarding expected levels of stressors and outcomes (although these findings are included in the results), and instead focused my explicit hypotheses on the relations between stressors and outcomes, as well as potential buffering effects of workplace supports on those relations. The buffering effects to which I refer throughout this paper could be conceptualized as moderation effects on the relation between stressors and outcomes among cannabis industry workers. For example, a cannabis industry worker exposed to high levels of workplace stressors may experience less negative outcomes when there are workplace supports in place at their organization (as opposed to a worker without such supports, who may experience more negative outcomes). Previously collected pilot study data and existent literature provided insights into all hypothesized relations, and I accordingly reference specific stressors, outcomes, and supports in various hypotheses. 


\section{Research question 1:}

What are the potential work-related psychological stressors for cannabis industry workers?

There are a number of potential psychological stressors relevant to the population of cannabis industry workers. Based on the job demands-resources model (JDR), one can expect

physiological and psychological variability in job demands given the nature of growhouse work; cannabis plants are grown in cyclical schedules, with fluctuating levels of maintenance and tasks depending on the stage in the growing cycle. Additionally, job demands likely differ among workers across different jobs, such as growhouse workers, retail shop workers, and organizational administration, given necessary job tasks. Within organizations, work-related resources (e.g., task variety and job autonomy) might serve to protect worker health and wellbeing. If the levels of job demands and job resources are found to fluctuate between individual workers or between organizations, one could expect variability in the levels of perceived stressors and outcomes. Based on the JDR model and pilot data, I identified stigma, job insecurity, role ambiguity, and long working hours as potentially influential stressors in the context of the cannabis industry. I next describe stressors of interest and the relevant outcomes to which I expected them to relate.

Stigma. The first potential work-related stressor considered here is perceived stigma of working in the cannabis industry. Perceived stigma can be defined as negative thoughts, feelings, or actions towards a group of workers who perform a particular type of work that is typically based on the perceived social, physical, or moral taint (i.e., "dirtiness") of their work, such as sex workers or those in the global arms industry (Hathaway, Comeau \& Erickson, 2011). For example, research has indicated that stigma has the most negative effects on individuals in jobs 
with high levels of both breadth (how much of the job is 'dirty') and depth (an individual's involvement with the dirty work; Ashforth \& Kreiner, 2013). In situations in which the depth (i.e., one's involvement) is high but the breadth (i.e., dirtiness or degree of taint) is low, or even vice versa, the stigma is easier to dismiss (Ashforth \& Kreiner, 2013).

Hughes (1951) described the realm of "dirty work," which Ashforth and Kreiner (1999) further described as consisting of social, physical, or moral taint. Among these, moral taint is typically viewed as more evil than necessary for society and thus possesses the most potential for stigma (Ashforth \& Kreiner, 1999). Depending on the psychological and behavioral characteristics of workers who may perceive stigma, research has indicated the potential for negative individual outcomes, such as intent to leave one's job and reduced overall well-being (Hathaway et al., 2011; Mishra \& Bhatnagar, 2010). Within the context of cannabis industry workers, perceived stigma may occur as a result of the work being viewed as "morally tainted," given that members of the general public might view the industry as more evil than necessary (Ashforth \& Kreiner, 1999).

The majority of psychological research regarding stigma and cannabis primarily has focused on stigma associated with the use of cannabis, either medically and/or recreationally (Hathaway et al., 2011). For example, research emphasized that stigma of cannabis users is prevalent, despite the previously mentioned trends towards legal acceptance (Hathaway et al., 2011). Regarding cannabis in organizational contexts, research is limited to social acceptance of medical cannabis policies. For example, Truxillo, Cadiz, Bauer, and Erdogan (2013) conducted two studies among students with work experience and nurses to examine attitudes towards workplace drug-free, prescription drug, and medical cannabis policies. Truxillo et al. found no conditions in which workers reacted positively or acceptingly towards fellow workers' use of 
medical cannabis. The stigma of medical cannabis use was likely associated with negative views toward cannabis as a recreational drug, criminal sanctions in place at the time of the study (which was conducted in Canada), and the stigmatizing vulnerability of the cannabis users given already-present disabilities and illnesses (Bottorff, Bissell, Balneaves, Oliffe, Capler, \& Buxton, 2013).

Although research has not touched upon perceived stigma of cannabis workers, pilot study data provide some insight into these workers' stigma perceptions. In my pilot, virtually all workers at the one organization possessed medical cannabis cards and reported regularly using cannabis for medical purposes (recreational cannabis was not yet legal for sale at the time of pilot data collection). Frequency of cannabis usage varied, but daily use at and outside of work was common. Based on existent literature regarding stigma, open discussion and use of cannabis could be considered a form of accommodation, in that the workers are open towards their use and strive towards societal transformation of the stigma (Hathaway et al., 2011). Internalizing behaviors (i.e., behaviors directed towards oneself) that act contrary to societal transformation of the stigma (such as concealing or stopping use, concealing the nature of one's job, etc.) could then be considered a form of assimilation (Hathaway et al., 2011). Hathaway et al. (2011) further compared accommodation and assimilation to Goffman's (1963) concepts of normification and normalization. Specifically, normification could be considered much like assimilation, in that it involves individuals performing socially acceptable behaviors to keep social interactions fluid, such as denying or concealing one's employment within the cannabis industry (Hathaway et al., 2011). Per the JDR, strain might result for cannabis industry workers engaged in assimilation or normification behaviors if the behaviors require excessive use of available resources. Normalization (i.e., parallel to accommodation), conversely, compares to societal transformation 
of a stigmatized individual; this concept is understood to occur when others are completely accepting of a stigmatized individual, to the point where the individual is treated as if there is no stigma present (Hathaway et al., 2011). In this context, normalization could be understood as a cannabis industry worker openly discussing one's employment within the cannabis industry such that others outside of the industry treat the individual as they would anyone else.

Given these indications of research among stigmatized individuals, there was potential for a buffering (i.e., moderating) effect of the use of cannabis on the levels of perceived stigma among cannabis industry workers. When cannabis industry workers report openly using cannabis and engaging in normalizing behaviors (i.e., not concealing their use of cannabis or job status to others), I expect that they experience and perceive lower levels of stigma than those industry workers who do not use or who engage in normification behaviors (i.e., concealing their use or job status).

Hypothesis 1: Personal use of cannabis (either medical or recreational) will buffer perceptions of stigma among cannabis industry workers, such that workers who use cannabis will report lower levels of stigma than those who do not use cannabis.

Job Insecurity. The next potential stressor I consider is job insecurity. Job insecurity can be broadly defined as an experienced overall apprehension of the continuation of one's current job (Keim, Landis, Pierce, \& Earnest, 2014). In the years since Greenhalgh and Rosenblatt's (1984) seminal article on job insecurity and call for empirical psychometric and construct-related investigations of job insecurity, a meta-analysis by Keim et al. (2014) indicated a plethora of articles focusing on potential predictors and consequences relevant to the construct. Sverke and Hellgren's (2002) model of job insecurity discussed both the objective situation and subjective characteristics of one's job (e.g., perceived threats to one's job) as predictors of perceived job 
insecurity. Sparks, Faragher, and Cooper (2001) argued that the available research suggests that perceived job insecurity has negative effects on employee well-being, which can then negatively impact organizations. Within the cannabis industry, the objective security and stability of one's job might be obscure, given possible changes in the political climate regarding legalization of cannabis sale and use. Additionally, given that cannabis dispensaries and growhouses operate as small businesses, potential instability of managerial and organizational factors (such as early in the organization's development, given the continuous establishment of new cannabis organizations in the industry) might negatively influence perceptions of job insecurity (Headd, 2001). Essentially, the job demands associated with working in the cannabis industry include ambiguities of working in a federally illegal industry among newly-created small businesses without established financial stability. If these newly-created businesses are unstable and cannot offer ample resources to employees, job insecurity might occur due to the imbalance between demands and resources as per the JDR model. Research literature supports this notion and has indicated relations between job insecurity and various outcomes. Two meta-analyses indicated a negative relation between job insecurity and job satisfaction (Cheng \& Chan, 2008; Sverke, Hellgren, \& Naswall, 2002). The same meta-analyses also indicated a positive relation between job insecurity and turnover intentions among employees.

Among cannabis industry workers, I descriptively analyzed levels of employee job insecurity without specific a priori hypotheses. I present specific hypotheses involving relations of job insecurity with potential outcomes, as well as a variety of buffering effects therein, with upcoming research questions.

Role ambiguity. The next work-related psychological stressor I consider is role ambiguity. Role ambiguity refers to a perceived lack of the information one needs to adequately 
perform one's role (Rizzo, House, \& Lirtzman, 1970). Kahn, Wolfe, Quinn, Snoek, and Rosenthal (1964) were among the first to identify sources of role stress when they described unclear role expectations as an organizational stressor which might lead to low levels of job satisfaction. In a meta-analysis, Abramis (1994) identified widespread support for this significant negative relation between role ambiguity and job satisfaction. Beyond individual strain outcomes, Jackson and Schuler (1985) identified negative outcomes of role ambiguity for organizations as well, such as poor employee performance. Additionally, Good, Sisler, and Gentry (1988) identified role ambiguity as an antecedent to turnover intentions among retail management personnel. Role ambiguity has also been identified as an antecedent to low organizational commitment, as discussed in a review by Reichers (1985).

Breaugh and Colihan (1994) suggested three aspects of role ambiguity: work method ambiguity, scheduling ambiguity, and performance criteria ambiguity. Given that cannabis dispensaries and growhouses within Colorado primarily operate as small businesses, the organization of work within these small businesses may result in each worker performing a variety of different tasks (e.g., at various stages of the grow cycle and at sales roles) that may lack role clarity. While role ambiguity was not reported in pilot study data, the particular organization maintained a reputation and status as a leader in Colorado's cannabis industry, abiding by and exceeding necessary regulations and practices. Organizational leaders reported vast fluctuation in operations among other cannabis organizations in Colorado; while some organizations maintained similar reputations and practices, other organizations were reported to operate using less structured procedures that might increase demands on employees, resulting in problematic imbalances between demands and resources in the context of the JDR model. As such, there was potential for perceptions of role ambiguity among cannabis industry workers. 
Among cannabis industry workers, I descriptively analyzed levels of role ambiguity without specific a priori hypotheses. I present specific hypotheses involving relations of role ambiguity with potential outcomes, as well as a variety of buffering effects therein, with upcoming research questions.

Long working hours. Another potential psychological stressor to be considered is long working hours by cannabis workers. Concern over the number of hours spent working, as well as how it relates to worker health, is no new phenomenon. Bosch (1999) discussed the changes in worldwide working hours that developed over the $20^{\text {th }}$ century, demonstrating incredible fluctuation among both full-time and part-time working hour policies between countries. The United States has seen a drop in working hours from the early 1900s; whereas 16-hour days were common at that time, eight-hour workday policies are now the general norm (Johnson \& Lipscomb, 2006). That said, a 2002 NIOSH report indicated that long working hours have increased over the past two decades, while the research literature on the effects of long working hours has moved considerably slower (Johnson \& Lipscomb, 2006). Long working hours have been interpreted ambiguously in existent research. For example, Spurgeon, Harrington, and Cooper (1997) identified a weakness of many studies that relate long working hours to health with a focus on only working time beyond 50 hours per week. Given this weakness, as well as uncertainty regarding work week schedule variability among cannabis industry workers, I likened long working hours among cannabis industry workers as an average of 41 or more hours per week, similar to Shields' (1999) categorization of long working hours in the National Population Health Survey in Canada.

The available research literature pointed toward a variety of negative health outcomes associated with long working hours. For example, Caruso et al. (2006) discussed positive 
associations of long working hours with stress, fatigue, sleep disorders, adverse health behaviors, mental illness, and other disorders (e.g., cardiovascular, gastrointestinal, and musculoskeletal). Such negative effects of long working hours have been demonstrated across cultures as well. One example occurs in Japan, where the term Karoshi refers to sudden death among working professionals due to overwork (Uehata, 1991). Johnson and Lipscomb (2006) further discussed that quantity of time spent working might not be the only factor at play; rather, it might be a combination of work time patterns, intensity of work, availability of breaks, and individual job autonomy.

Among workers in the cannabis industry, pilot study data suggested that a number of working hour factors can be considered potential stressors. The data revealed an average grow cycle for cannabis plants of roughly 120-140 days. However, within the pilot study organization, a rotating grow cycle allotted for a new batch of plants being readily available to harvest every 45 days. Workers in the growhouse reported that peak stressor periods generally occur at harvest time as a result of long working hours, repetitive tasks, and excessive job demands to cultivate large quantities of cannabis plants within a short time window. This demonstrates that the factors mentioned by Johnson and Lipscomb (2006) are readily applicable, as cannabis industries can be expected to have patterns of intense working periods with long hours. The JDR model would suggest peak levels of job demands at this time, which could be problematic for workers if job resource availability is limited. Additionally, I suggest that strain might occur if workers experience allostatic load due to inability to return to set points in the periods between harvests, as discussed in the allostatic load model (Ganster \& Perrewe, 2011).

Although an interesting question arises regarding work schedule fluctuation in the cannabis industry (i.e., what are between- and within-person discrepancies among various jobs in 
the industry?), answering such an inquiry would necessitate an understanding of various job types for workers. Given that this is the first empirical investigation of the cannabis industry of Colorado, I do not limit my hypothesis to one specific job type (e.g., cannabis growhouse workers) and instead aim to first establish a general understanding of work schedule fluctuations among cannabis industry workers.

Hypothesis 2: Cannabis industry workers will report working longer hours during busy weeks than during typical weeks.

\section{Research question 2:}

To what extent are workers aware of potential occupational health and safety issues?

In order to provide recommendations to the cannabis industry about optimizing physical and psychological health of its workers, it is necessary to first understand employees' perceptions regarding their environment and the impact it has on their safety and health (Ringen $\&$ Stafford, 1996). This is especially true among worker populations without previous exposure to interventions, such as cannabis industry workers (Kortum \& Leka, 2014). Although this project does not constitute intervention research, it shares an overlapping goal of informing potential interventions and improving occupational health, both now and in the future (Quick, Quick, Nelson, \& Hurrell, 1997). As such, there is a focus on developing further awareness of the identified occupational health risk factors, such as work load/pace, work scheduling, role stressors, job security, interpersonal relations at work, job content and job tasks, and other potential intervening variables (Sauter, Murphy, \& Hurrell, 1990). Additionally, self-reports of workplace safety hazards can provide a framework for recommendations on future occupational health and safety policies in general. In short, this project's primary assessment of cannabis 
industry workers' awareness of occupational health and safety issues may serve as a starting point from which to base interventions.

Certain occupational health fields focus primarily on the physical work environment, utilizing objective assessments of the workplace (e.g., Industrial Hygiene, Ergonomics; Stellman, 1998). Although these fields' contributions to employee safety and physical health are of vital importance, they do little to directly assess and improve upon workers' psychological well-being. Sauter et al. (1990) described health as an adjustment process between the individual and the environment, in which imbalances between the individual and the environment result in manifestations of psychological disturbances such as strain. OHP serves to bridge this gap between workers' environments and their related psychological health; there are numerous articles and frameworks in the OHP literature that support such an objective, such as the previously described transactional model of stress and coping (Lazarus \& Folkman, 1984).

Similar to Sauter et al. (1990), the transactional model incorporates stress as a subjective process. Therefore, the perception of stress is in the eye of the beholder, with potential for variability in strain perceptions between individual workers. In the same context, perceptions of strain might be influenced by differing perceptions of job demands and resources, in that one worker's cognitive appraisal of a lack of resources or excess in demands as a strain might occur whereas another worker might not perceive such a lack in resources or excess in demands. The same could be presumed regarding perceptions of occupational health and safety. Specifically, what one individual perceives to be an occupational hazard or stressor, another individual might perceive entirely differently and consider a safe and non-stressful norm. Due to this potential for individual variability in perceptions of stressors, hazards, and threats to safety, it is necessary to 
examine these perceptions among a large sample of cannabis industry workers to aggregate and determine overall safety and health perceptions in a generalizable way.

A large body of OHP research has focused on safety climate (or perceived safety climate) within organizations. Safety climate refers to perceptions of workplace policies, procedures, and practices related to safety (Neal \& Griffin, 2006). For example, a common focus of safety climate assessments and applications is the construction industry, which researchers have identified as having high numbers of accidents and a historically poor safety climate (e.g., Mohamed, 2002; Dedobbeleer \& Béland, 1991). Safety climate can exist at either the individual or group level. Individual levels are typically analyzed within groups, accounting for individual differences through incorporation of all individual scores in analyses and ignoring clustering of scores (Krull \& MacKinnon, 2001). Group levels can be operationalized via Chan's (1998) direct consensus model, which aggregates individual perceptions to form a group-level safety climate. Neal and Griffin found positive top-down and bottom-up effects of safety climate within organizations by measuring perceptions of safety climate, motivation, and behavior at two separate time points and linking the perceptions to accident levels over a five-year period. Topdown effects can be considered from a functionalist perspective that serves the imperatives of the higher-level controlling group within an organization, whose behaviors and perceptions influence the lower levels of the organization (Glendon \& Stanton, 2000). Bottom-up effects, conversely, can be considered as an interpretive perspective which identifies possible subcultures in organizations in which individual or sub-group behaviors and perceptions influence higher levels within the organization (Glendon \& Stanton, 2000). Within their study, Neal and Griffin found that aggregate levels of safety climate predicted changes in individual safety motivation, which was found to be associated with changes in self-reported safety behavior. 
Additionally, improving levels of safety behavior within groups was associated with a subsequent reduction in accidents at the group level (Neal \& Griffin, 2006).

Collectively, these findings on occupational safety, health, and well-being need to be replicated among cannabis industry workers for multiple reasons. First, descriptive assessments of individual- and group-level safety climate can provide a basic understanding of cannabis industry workers' safety motivations and behaviors to provide insight into workplace safety practices. Additionally, descriptively measuring and assessing cannabis industry workers' selfreported awareness of their physical work environment, including awareness of potential safety hazards and stressors, can provide insight into physical occupational safety and health practices within organizations. With this combined understanding of the psychological and physical safety environments of workplaces, future occupational safety and health recommendations to the industry can focus on addressing safety hazards and improving safety climate, given its associations with increased safety behavior and decreased accidents.

Specific levels of safety climate and awareness are difficult to generalize a priori across the cannabis industry. The pilot study organization qualitatively described individual- and grouplevel focus on safety in that particular workplace, and also provided insight into overall industry standards surrounding workplace safety practices. In order to avoid federal repercussions due to the current federal illegality of cannabis, the organization followed a several-hundred-page document on federal- and state-level operational guidelines (including safety behaviors). The organization's leaders reported that these guidelines were necessary for all cannabis industry organizations. However, I hesitate to assume that all organizations will adhere to these guidelines, and do not hypothesize specific levels of safety climate or awareness of physical 
workplace hazards. Rather, I descriptively assess levels of both safety climate and awareness of physical workplace hazards in this context.

\section{Research question 3:}

To what extent do these work-related psychological stressors relate to psychological outcomes for cannabis industry workers?

Relevant outcomes. Next I provide a brief discussion of expected relevant outcomes as a reference for operationally defining and understanding these outcomes. After this discussion, I present relevant hypothesized relations between stressors and these outcomes based on OHP models and pilot data.

Job satisfaction. Job satisfaction was first discussed by Hoppock (1935) as the satisfaction that workers experience as a result of combinations of psychological, physiological, and environmental circumstances. In the years since Hoppock's initial discussion of job satisfaction, the construct has become one of the most widely researched topics in industrial/organizational psychology (Judge, Parker, Colbert, Heller, \& Ilies, 2002). Locke (1976) described job satisfaction as a positive evaluation regarding an overall appraisal of one's job, as well as one's job tasks, pay, and coworkers. In a review of job satisfaction literature, Aziri (2011) discussed discrepancies in the literature regarding a specific, agreed-upon definition or explanation of job satisfaction. However, the literature presents a recurring theme of job satisfaction as a positive attitude towards one's job, similar to Locke's conceptualization of the construct (Aziri, 2011). Thus, low job satisfaction (or job dissatisfaction) represents a lack of positive attitudes or a presence of negative attitudes toward one's job.

Research has further indicated a discrepancy between facet job satisfaction and overall job satisfaction (Nagy, 2002). Facet job satisfaction focuses on assessing employees' attitudes 
towards various facets or aspects of the job via such measures as the Job Descriptive Index (e.g., facets include the work itself, supervision, pay, opportunities for promotion, and coworkers; Smith, Kendall, \& Hulin, 1969), whereas overall job satisfaction focuses on general attitudes towards the job as a whole (Nagy, 2002). Research has indicated the potential for facet-based measurements of job satisfaction to neglect certain job components which are important to the employee but are beyond the scope of the measures (Ironson, Smith, Brannick, Gibson, \& Paul, 1989). To avoid potentially overlooking certain components or facets of jobs within the cannabis industry, I focus on overall job satisfaction in my assessment. Although this approach may fail to differentiate between workers' satisfaction towards various facets of the job, the novelty of cannabis industry research makes it difficult to confidently determine all such relevant facets. In other words, I aimed to avoid the potential scenario of convoluted or non-comprehensive data (i.e., due to inadequate facet job satisfaction considerations) and instead prioritized a clear interpretation via overall job satisfaction. Within the context of the JDR model, if employees in the cannabis industry receive adequate resources from their organization to cope with job demands, I expect job satisfaction to be prevalent. Additionally, per the allostatic load model, satisfaction could occur if workers are able to return to set points outside of peak hours (such as during harvest time), rather than if allostatic load were to remain high due to continuous peak working hours.

Organizational commitment. The next outcome I consider is organizational commitment. In a review and conceptualization of organizational commitment, Meyer and Allen (1991) identified a three-component framework of the construct, which they describe as a psychological state that characterizes an employee's relation with his or her organization and also has implications for that employee's decision to continue or discontinue affiliation with that 
organization. The three components identified as part of this psychological state are affective, continuance, and normative organizational commitment (Allen \& Meyer 1990; Meyer \& Allen, 1991). Affective commitment refers to an employee's emotional attachment, identification, and involvement with his/her organization, in that the employee wants to remain employed with the organization. Continuance commitment refers to the need to remain with the organization due to the costs associated with leaving. Finally, normative commitment refers to a sense of obligation to remain with the organization (i.e., they ought to remain; Meyer \& Allen, 1991). In their review of relevant literature, Meyer and Allen further described commitment as negatively related to turnover, thus indicating negative implications for organizations if commitment is low. Pilot data indicated a likelihood for affective organizational commitment among cannabis industry workers, which has been shown to correlate to perceived organizational support in prior research (e.g., Vandenberghe, Bentein, \& Stinglhamaber, 2004). These experiences of support might serve as resources for cannabis industry workers within the context of the JDR model, allowing workers to meet job demands.

Turnover intentions. Turnover intentions can be understood as a worker's intent to leave his or her current job or industry (Hayes et al., 2006). Turnover intentions can be understood within Fishbein and Ajzen's (1975) model of the relation between behaviors and attitudes, which posits that beliefs lead to attitudes, which then lead to intentions, which can eventually influence a person's behavior. Thus, turnover intentions can be considered a psychological step in the process leading to turnover behaviors. In a literature review among nurses, Hayes et al. (2006) identified turnover intentions as either internal (i.e., job changes within an organization) or external (i.e., intentions to leave the organization). In this context, I focus primarily on external turnover intentions among cannabis industry workers because it is useful to predict who is likely 
to leave an organization to retain productive employees and avoid negative outcomes for organizations. These external turnover intentions can be further understood as employees' intent to quit their current job or intent to quit their respective field. In the cannabis industry, turnover intentions can then be specifically described as cannabis industry workers' intent to leave their current job (i.e., leave their current organization for another cannabis industry organization) or their intent to leave the entire cannabis industry.

In a meta-analysis, Steel and Ovalle (1984) reported turnover intentions as predictive of actual turnover and attrition. Therefore, low levels of turnover among cannabis industry workers are ideal. Avoiding turnover is of economic interest to organizations within the cannabis industry, given that high rates of turnover can lead to negative economic impacts on organizations (Hayes et al., 2006). In order to achieve these low levels, the JDR and allostatic load models can be referenced in providing insight into ideal working conditions. Specifically, a balance of job demands and resources, as well as opportunity to reduce allostatic load and return to set points outside of peak work times, could serve to reduce strain outcomes and turnover intentions among cannabis industry workers.

Burnout. Burnout refers to an individual response to prolonged stressor exposure (Maslach, Schaufeli, \& Leiter, 2001). In a review of the burnout literature, Maslach et al. (2001) described this conceptualization of burnout and outlined the historical and empirical development of the construct. Maslach and colleagues identified the three dimensions of burnout as exhaustion, cynicism, and inefficacy, each of which can be measured using the Maslach Burnout Inventory (MBI). Exhaustion is often the most commonly reported dimension of burnout, and generally refers to excessive feelings of fatigue or a lack of energy (Maslach et al., 2001). Cynicism, also referred to as depersonalization, refers to attempts to distance oneself from 
others, such as coworkers and clients. Finally, Maslach et al. described inefficacy as a perception of reduced personal accomplishment and capacity to achieve a sense of accomplishment. Through these three dimensions, burnout can consequently lead to further negative outcomes such as decreased motivation, increased negative attitudes and behaviors in the workplace, and reduced job performance (Kaur, Sambasivan, \& Kumar, 2013).

Despite the prevalence of Maslach's conceptualization and measurement of burnout, Kristensen, Borritz, Villadsen, and Christensen (2005) identified six primary concerns with the MBI. Specifically, Kristensen et al. discussed: 1) a circular argument among MBI literature that the MBI only applies to human services "people" work; 2) unclear relations between the MBI and the concept of burnout; 3) a mixture of a state, coping strategy, and affect (i.e., the three dimensions of exhaustion, cynicism, and inefficacy, respectively); 4) unacceptable questions which induce negative reactions; 5) lack of generalizability from the "generic" version of the MBI that is supposed to apply to other work sectors aside from "people" work; and, finally, 6) the MBI lies outside of public domain and the full measures are not available in most scientific literature. Given these concerns, I approach burnout in a manner similar to Kristensen et al., who generalize burnout to all populations through three dimensions: personal burnout, work-related burnout, and client-related burnout.

In the cannabis industry, pilot data indicated that many workers do not interact with clients (e.g., growhouse workers). As such, I conceptualize and measure burnout in this project via the dimensions of personal burnout and work-related burnout. In cannabis industry workers, I expect burnout to occur if chronic allostatic states are experienced, thus resulting in allostatic load in the form of burnout. Organizational resources, such as economic stability, flexible 
scheduling, and clear role descriptions could aid workers as they cope with the demands of their jobs in attempts to avoid and deter burnout.

\section{Hypothesized relations.}

Stigma.

Hypothesis 3: Perceived stigma will relate to important outcomes for cannabis industry workers. Specifically, perceived stigma will...

Hypothesis 3a: ...negatively relate to job satisfaction.

Hypothesis $3 b$ : ...positively relate to intent to quit one's job.

Job insecurity.

Hypothesis 4: Perceived job insecurity will relate to important outcomes among cannabis industry workers. Specifically, perceived job insecurity will...

Hypothesis 4a: ...negatively relate to job satisfaction.

Hypothesis 4b: ...negatively relate to organizational commitment.

Hypothesis 4c: ...positively relate to intent to quit one's job.

Hypothesis 4d: ...positively relate to burnout.

Role ambiguity.

Hypothesis 5: Role ambiguity will relate to important outcomes among cannabis industry workers. Specifically, perceived role ambiguity will...

Hypothesis 5a: ...negatively relate to job satisfaction.

Hypothesis 5b: ... negatively relate to organizational commitment.

Hypothesis 5c: ...positively relate to intent to quit one's job.

Hypothesis 5d: ...positively relate to burnout. 


\section{Long working hours.}

Hypothesis 6: Long working hours will relate to important outcomes among cannabis industry workers during both typical weeks and busy weeks. Specifically, long working hours will...

Hypothesis 6a: ...negatively relate to job satisfaction in typical weeks.

Hypothesis 6b: ...negatively relate to organizational commitment in typical weeks. Hypothesis 6c: ...positively relate to intent to quit one's job in typical weeks. Hypothesis 6d: ...positively relate to burnout in typical weeks.

Hypothesis 6e: ...negatively relate to job satisfaction in busy weeks.

Hypothesis 6f: ...negatively relate to organizational commitment in busy weeks.

Hypothesis 6g: ...positively relate to intent to quit one's job in busy weeks.

Hypothesis 6h: ...positively relate to burnout in busy weeks.

\section{Research questions 4 and 5:}

What sources of workplace supports are in place to protect the psychological health and well-being of employees within the cannabis industry of Colorado? Do sources of workplace support buffer the negative relation between work-related stressors and strains?

The job demands-resources model suggests that certain resources on the job serve to protect worker health and well-being as they meet and cope with the demands of their job (Demerouti et al., 2001). There are numerous psychosocial supports that may serve as resources to buffer the negative effects of job demands. For example, these supports might include having autonomy over one's work tasks, flexible work hours, job sharing, task rotation, organizational support for physical safety, social support from supervisors and/or coworkers, and a shared occupational identity. Research findings have indicated that such workplace supports may 
actually serve to buffer the negative impact of work-related stressors by moderating the relations between demands and negative outcomes (Scharlach, 2001; Viswesvaran, Sanchez, \& Fisher, 1999; Warren \& Johnson, 1995). For example, Grönlund (2007) described the buffering effect in terms of job control, in which she found that high levels of job control among Swedish women moderated the negative effects (e.g., work-family conflict) of high demands. Accordingly, the following two current research objectives regarding supports and buffering effects within the cannabis industry can stem from existent research. First, there is a need to identify specific sources of workplace support, to understand which sources of support are currently in place and which sources of support could be implemented in the future. Secondly, surveying cannabis industry workers about psychological workplace supports can provide a means to assess the extent to which those sources may serve as such a buffer for employee well-being. Finally, these findings can be communicated to industry leaders to both optimize workplace support policies and practices and communicate these support channels to employees. Pilot data provides insight into potential industry characteristics and, in conjunction with OHP models, provides a foundation for the following relevant hypotheses regarding resources and corresponding buffering effects among cannabis industry workers. In all hypotheses regarding buffer or buffering effects, such effects are conceptualized as a moderation effect on the relation between relevant stressors and outcomes.

Job control. Job control refers to the extent to which employees have a say over their job, such as in determining decisions, which tasks are performed, or how they do their work (Karasek \& Theorell, 1992; Brauchli, Bauer, \& Hämmig, 2014). Within the context of the JDR model, job control is one type of resource potentially available to workers. Simply speaking, job control may allow greater resources and opportunities for workers to make individual job-related 
decisions to cope with strain and negative demands (Bakker \& Demerouti, 2007). In a metaanalysis, Spector (1986) found associations between perceived control and high levels of job satisfaction, organizational commitment, involvement, performance, and motivation, as well as with low levels of physical health symptoms, turnover intentions, absenteeism, role stress, and emotional distress. Numerous research findings have supported a buffering effect via job control. Daniels and Guppy (1994) found that social support and job control may jointly buffer the effects of psychological work-related stressors on employee well-being. Similarly, Brauchli, Bauer, and Hämmig (2014) found that job control may serve as a buffer between work-to-life conflict and negative organizational outcomes, including turnover intention, job satisfaction, and organizational commitment.

In my pilot study, the organization's employees reported high levels of job control, despite job control being inevitably limited for many cannabis industry workers (e.g., given the nature of growhouse work). Due to repetitive tasks and a limited extent of task variety, growhouse workers at this organization were subjected to long shifts of required tasks. Therefore, prevalent job control existed in terms of their ability to take breaks when desired, rotate tasks, and voice concerns with administration and management in an unthreatening and safe manner to facilitate inclusive decision making. If cannabis industry organizations offer employees the resource of job control in a manner similar to that of the pilot organization, then workers might utilize job control to cope with demands, thus resulting in a buffer effect similar to those found in existent research.

Hypothesis 7: Job control will serve as a buffer against previously hypothesized relations of stressors and negative outcomes among cannabis industry workers. Specifically, job control will serve as a buffer in the hypothesized... 
Hypothesis 7a: ...negative relation between perceived stigma and job satisfaction. Hypothesis 7b: ...positive relation between perceived stigma and intent to quit one's job.

Hypothesis 7c: ...negative relation between perceived job insecurity and job satisfaction.

Hypothesis 7d: ...positive relation between perceived job insecurity and intent to quit one's job.

Hypothesis 7e: ...negative relation between role ambiguity and job satisfaction. Hypothesis 7f: ...positive relation between role ambiguity and intent to quit one's job.

Hypothesis 7g: ...negative relation between role ambiguity and organizational commitment.

Hypothesis 7h: ...negative relation between long working hours and job satisfaction. Hypothesis 7i: ...positive relation between long working hours and intent to quit one's job.

Hypothesis 7j: ...negative relation between long working hours and organizational commitment.

Hypothesis 7k: ...positive relation between long working hours and burnout. Perceived organizational support. Perceived organizational support (POS) refers to employees' perceptions of their respective organization in terms of the organization's policies, practices, and procedures oriented around their employees (Eisenberger, Armeli, Rexwinkel, Lynch, \& Rhoades, 2001). POS is based on the broader Organizational Support Theory (OST), which suggests that employees personify the organization and develop perceptions of 
organizational support as a response to organizations meeting employees' socio-emotional needs and to organizations rewarding employees' efforts on their (the organizations') behalf (Rhoades \& Eisenberger, 2002). Essentially, employees view their favorable or unfavorable treatment by the organization (in terms of the policies, norms, and culture) as indicative of the organization either favoring or disfavoring them (Rhoades \& Eisenberger, 2002). Employees who view their organization as favoring them could be considered to have high levels of POS. Conversely, employees who view their organization as disfavoring them could be considered to have low levels of POS. Although research has demonstrated multiple sources of support within organizations (e.g., the organization, supervisors, coworkers, and subordinates; Eisenberger, Huntington, Huntington, \& Sowa, 1986), Rhoades and Eisenberger identified POS as a single dimension construct in a meta-analysis of the POS literature.

Ongoing research literature has demonstrated a buffering effect of POS on relations between stressors and negative outcomes, resulting in positive organizational outcomes. In a review, Steele, Rupayana, Mills, Smith, Wefald, and Downey (2012) empirically assessed POS as one of four positive worker states (including job involvement, engagement, and vigor) that might predict such work-related outcomes as self-reported performance, customer service, turnover intentions, and job satisfaction. Steele and colleagues found that POS was the most consistent positive worker state predictor of such organizational outcomes. In another recent review of POS literature, Baran, Shanock, and Miller (2012) discussed empirically-supported relations between POS and such outcomes as improved overall health, a sense of accomplishment, decreased burnout and anger, and increased organization-based self-esteem.

In my pilot study, the organization's employees qualitatively reported high levels of perceived organizational support for both physical and psychological strains. Given the 
unstructured format of pilot data collection, workers anecdotally reported such trends as feeling supported and cared for by the organization and organizational leaders, organizational policies that were supportive of worker health and well-being, and the ability to talk to management about any problems that might arise (i.e., personal or work-related). At the administrative level, organizational leaders conveyed these perceptions as well, stating their care for employees as a high priority and providing similar anecdotal examples to support these statements.

Perceived organizational support might be prevalent throughout the cannabis industry, given the high potential for sub-cultures to develop around a united organizational identity (Ashforth \& Kreiner, 2013). Specifically, Ashforth and Kreiner identified workers within morally-tainted industries (such as the cannabis industry, as discussed previously) developing such sub-cultures in a united defense to socially buffer against outsider stigma. Thus, I expect such support among cannabis industry organizations to operate as a resource and buffer against negative stigma experiences (i.e., POS operating as a resource within the JDR model might correct imbalances between demands and resources).

Hypothesis 8: Perceived organizational support among cannabis industry workers will serve as a buffer between previously hypothesized relations of stressors and negative outcomes among cannabis industry workers. Specifically, perceived organizational support will serve as a buffer in the hypothesized...

Hypothesis 8a: ... negative relation between perceived stigma and job satisfaction. Hypothesis 8b: ...positive relation between perceived stigma and intent to quit one's job.

Hypothesis 8c: ...negative relation between perceived job insecurity and job satisfaction. 
Hypothesis 8d: ...positive relation between perceived job insecurity and intent to quit one's job.

Hypothesis 8e: ...negative relation between role ambiguity and job satisfaction.

Hypothesis 8f: ... positive relation between role ambiguity and intent to quit one's job.

Hypothesis $8 \mathrm{~g}:$...negative relation between role ambiguity and organizational commitment.

Hypothesis $8 \mathrm{~h}$ : ...negative relation between long working hours and job satisfaction. Hypothesis 8i: ...positive relation between long working hours and intent to quit one's job.

Hypothesis $8 \mathrm{j}$ : ...negative relation between long working hours and organizational commitment.

Hypothesis 8k: ...positive relation between long working hours and burnout.

Meaningfulness in work. As I described previously, work in the cannabis industry may be considered what Ashforth and Kreiner (1999) have labeled as "dirty" or morally-tainted work. Research suggests that, within such morally-tainted jobs, we can expect workers to exhibit strong, subjective sub-cultures in which they perceive their job as meaningful (Ashforth \& Kreiner, 2013). These sub-cultures among dirty occupations develop as defense mechanisms to reframe the meaning of "dirtiness", primarily due to salient perceptions of a shared threat (i.e., from society) and an "us versus them" worldview (Ashforth \& Kreiner, 1999). The perception of meaningful work (MW) could operate as a resource in the context of the JDR model, aiding workers in meeting job demands and resulting in positive individual outcomes. Recent positive psychological research has supported this relation and examined calling and MW among 
employees and related such experiences to worker well-being (Duffy \& Dik, 2013; Steger, Dik, \& Duffy, 2012). This meaningfulness is both subjective and socially constructed (Ashforth \& Kreiner, 2013). Among cannabis industry workers, high levels of perceived MW may be expected if workers feel as if their work (i.e., growing and distributing cannabis products) serves some sort of societal purpose. Examples of a "purpose" among cannabis industry workers can be seen in various periodicals and news articles discussing medical benefits to society from cannabis cultivation and use. For example, a strain of cannabis known as "Charlotte's Web" has attracted over 100 families to the Colorado Springs area, due to the strain's reported ability to control seizures among some epileptic children for whom traditional medical and prescription treatment has failed (Cordell, 2014).

Assessing cannabis industry workers' perceptions of the meaningfulness of their work can provide insight into potentially positive individual and organizational outcomes among this worker population. Specifically, literature has demonstrated a positive relation between meaningful work and job satisfaction (Kamdron, 2005; Sparks \& Schenk, 2001). Steger et al. (2012) also indicated positive relations between meaningful work and organizational commitment, as well as negative relations with rates and intentions of turnover.

Hypothesis 9: Meaningful work will serve as a buffer against previously hypothesized relations of stressors and negative outcomes among cannabis industry workers. Specifically, meaningful work will serve as a buffer in the hypothesized...

Hypothesis 9a: ...negative relation between perceived stigma and job satisfaction. Hypothesis 9b: ...positive relation between perceived stigma and intent to quit one's job. 
Hypothesis 9c: ...negative relation between perceived job insecurity and job satisfaction.

Hypothesis 9d: ...positive relation between perceived job insecurity and intent to quit one's job.

Hypothesis 9e: ...negative relation between role ambiguity and job satisfaction. Hypothesis 9f: ...positive relation between role ambiguity and intent to quit one's job.

Hypothesis 9g: ...negative relation between role ambiguity and organizational commitment.

Hypothesis 9h: ...negative relation between long working hours and job satisfaction. Hypothesis 9i: ...positive relation between long working hours and intent to quit one's job.

Hypothesis $9 \mathrm{j}:$...negative relation between long working hours and organizational commitment.

Hypothesis 9k: ...positive relation between long working hours and burnout.

Employability. The final source of support I consider is employability, described in the literature as an employee's perceptions of possessing the necessary skills and attributes to find and maintain a desired alternative job (Keim et al., 2014; Silla, De Cuyper, Gracia, Peiro, \& De Witte, 2009). Such employability perceptions, if prevalent, may reduce the negative consequences of job insecurity among cannabis industry workers. Pilot study data has suggested a high rate of job movement among cannabis industry workers, as organizations reportedly tend to employ workers from within the industry based on personal connections and experience. This job movement can be likened to Arthur and Rousseau's (2001) discussion of boundaryless 
careers, which postulated that employees in such careers move across organizational boundaries rather than linearly upwards through a single organization. Silla et al. further discussed employability as a potential predictor of employee well-being among workers in such boundaryless careers.

Research outside of the scope of boundaryless careers has also demonstrated relations between employability and health outcomes. Specifically, Berntson and Marklund (2007) found positive relations between perceived employability and overall health and well-being a year after data collection among the National Working Life Cohort in Sweden. Thus, there is the potential for perceptions of employability to operate as a personal resource in support of well-being among cannabis industry workers and buffer negative stress outcomes that result from job insecurity.

Hypothesis 10: Employability will serve as a buffer against previously hypothesized relations of stressors and negative outcomes among cannabis industry workers. Specifically, employability will serve as a buffer in the hypothesized...

Hypothesis 10a: ...negative relation between perceived job insecurity and job satisfaction.

Hypothesis 10b: ...positive relation between perceived job insecurity and intent to quit one's job. 


\section{Method}

\section{Participants and Procedure}

After data cleaning (which I describe in the results), study participants were 214 workers employed by approximately 20-40 Colorado cannabis businesses (estimated due to methodological restrictions; see results section) across various jobs within each organization (e.g., growers, as well as retail sales, production, packaging, and management-level employees). Among the 214 survey respondents, the sample was predominantly male (57\%), below the age of $30(66 \%)$, and Caucasian (76\%; Table 1). Forty percent of respondents reported having attended "some college" and another 39\% of respondents had a 2- or 4-year college degree (Table 1). Seventy-four percent of respondents received hourly wages, with $40 \%$ earning less than $\$ 25,000 /$ year and another $40 \%$ earning between $\$ 25-35,000 /$ year (Table 2 ). Thus, a majority of survey respondents were white, male, with at least some college education, and making less than $\$ 35,000 /$ year. Additionally, $80 \%$ of participants worked daytime shifts, and approximately threequarters of workers only held their one particular job in the cannabis industry (i.e., they did not have other jobs; Table 2). Respondents' organizations were all relatively young (less than 5 years in operation), which aligns with the novelty of the cannabis industry in the state of Colorado (Table 3). The majority of organizations also had both an indoor grow facility (77\%) and a cannabis dispensary (71\%), and most respondents worked at locations with at least one of these components. Specifically, 38\% worked at facilities with an indoor grow and 51\% worked at facilities with a dispensary (Table 3).

I also asked participants a variety of questions about their personal use of cannabis, as pilot data and anecdotal evidence suggested that a vast majority of workers in the industry were registered medical cannabis cardholders and/or used cannabis to some extent. Survey data 
supported these preconceptions, as $66 \%$ of participants were registered medical cannabis cardholders (Table 4). Additionally, $95 \%$ of respondents reported using cannabis, with $78 \%$ indicating that they used cannabis (in any form) at least daily (Table 4). Specifically, $21 \%$ of respondents used cannabis once daily, 28\% reported using cannabis 2-4 times/day, and 29\% reported using cannabis more than 4 times/day. Other participants reported using cannabis either 3-6 times/week (7\%), 1-2 times/week (5\%), once a week (1\%), less than weekly (1\%), or less than monthly (3\%). Additionally, $60 \%$ of respondents indicated that they first tried cannabis more than 10 years ago (Table 4). Given that a majority of workers were below the age of 30, this suggests that a proportion of workers in the cannabis industry likely began using cannabis in their teenage years or early twenties. However, $5 \%$ of respondents reported that they did not currently use cannabis, with only $2 \%$ of respondents indicated that they had never tried cannabis before.

Beyond general cannabis use, the survey also asked participants about their use of cannabis before, during, and after work, as well as while driving motor vehicles (Table 4). Thirty-seven percent of respondents reported never using before work (i.e., within two hours of starting work), although 9\% used 1-2 days/week, 17\% used 3-5 days/week, and 24\% used cannabis before work 6-7 days/week. A higher proportion (55\%) of participants did not use cannabis while at work (i.e., including on breaks and while working), with smaller proportions using at work 3-5 days/week (10\%) and 6-7 days/week (14\%). Interestingly, 11\% of participants used cannabis at work 1-3 days/month, with smaller proportions using less than monthly (4\%) and 1-2 days/week (5\%). Finally, 53\% of respondents reported using cannabis 6-7 days/week within two hours after the end of the workday, with $21 \%$ using 3-5 days/week, $11 \%$ using 1-2 days/week, and $8 \%$ never using within two hours after the end of work. With regard to cannabis 
use while driving, $21 \%(n=39)$ of participants reported that, during the work day, they drive while under the influence of cannabis. Interestingly, it appears that workers who do drive under the influence of cannabis tend to do so at multiple different times throughout the day. Specifically, of the 39 respondents who reported driving under the influence of cannabis, 33 indicated driving under the influence on the way to work, 18 indicated driving during the work day, and 27 indicated driving on the way home from work. Additionally, a higher proportion of respondents (43\%) reported driving under the influence of cannabis in their own personal nonwork time.

With the characteristics of study participants in mind, I next describe the two-stage recruitment strategy used in this study. Prior to data collection, information on cannabis businesses within Boulder, Denver, and Fort Collins was gathered through online cannabis business databases (e.g., WeedMaps.com). Additionally, I developed a recruitment survey for cannabis industry workers and organizational leaders that included questions regarding interest in participating in the study, availability of wireless internet access at their businesses, and questions gathering information on the aforementioned stratification criteria. Cannabis industry organizations were then recruited for participation using 1) the recruitment survey, and 2) convenience sampling, both of which I next describe in detail.

In the first stage of recruitment, I worked with industry partners to identify organizations to contact and recruit for participation in the study. I contacted previously established and yet-tobe-established industry partners via telephone, e-mail, and/or in-person meetings to solicit participation in the project. In the first contact I explained the project importance, objectives, methodology, and protocol. After initially explaining the project significance and protocol, I administered a follow-up preliminary recruitment survey online (via e-mail) to managers and/or 
organizational leaders. Additionally, I administered the recruitment survey to other cannabis industry members by using industry partners' online platforms. Specifically, I attended and presented at numerous industry events, wrote a guest blog post for the National Cannabis Industry Association's (NCIA; currently the only national cannabis trade association in existence) website, and partnered with executives at the NCIA and Marijuana Industry Group (MIG; a state cannabis trade association in Colorado) to include study recruitment postings in email blasts to each association's respective membership body. Through this process, I also gathered feedback from industry leaders regarding the survey content, such as through cognitive interviewing (Drennan, 2003), checking for accurate and industry-appropriate language, and general proofreading. Such feedback was beneficial throughout the duration of the study; for example, I was informed by one industry partner that the term "cannabis" was preferred to the term "marijuana", due to negative connotations associated with the latter term.

Based on preliminary recruitment survey results, businesses and their employees were stratified by multiple criteria: geographical location (Boulder, Denver, or Fort Collins); type of cannabis produced and/or sold (i.e., recreational, medical, or both); operations of the business (i.e., cannabis growth, sale, extraction, or manufacture of products such as baked goods and concentrates); organizational size (i.e., number of employees); membership in trade associations (such as the NCIA and/or MIG); demographics of employees (i.e., part-time or full-time, contracted or permanent workers, salaried or hourly pay rates); and the quality of the work environment and business reputation, as identified by industry leading partners and trade association leaders. I developed these stratification criteria through pilot data, coordination with industry partners, and coordination with experts in occupational health, safety, and well-being. I used these stratification criteria in an effort to sample businesses in a manner that represented 
heterogeneity in worksite characteristics across the cannabis industry. For example, if I only included participants at recreational extraction facilities in one city, the heterogeneity and generalizability of my findings would be less than those acquired through incorporation of organizations and workers across these criteria.

After gathering all preliminary recruitment interest and stratification criteria information, I generated a final list of individuals and organizations with willingness to participate in the study. This list was created with an aim to obtain heterogeneity across all aforementioned stratification criteria. After generating this list, I coordinated with industry partners and business owners to arrange the most convenient data collection strategy. I took two approaches to primary survey administration: 1) I coordinated with organizational leaders to come to their work sites with tablets and mobile Wi-Fi hotspots, so that employees could complete the survey in-person; and 2) I provided cannabis industry workers with a survey URL to complete the survey online at their own convenience (this was typically preferred by participants).

As survey data collection progressed after the first stage of recruitment, I soon realized the need for a second stage of data collection via convenience sampling. This was to achieve a higher sample size because reliance on the recruitment survey alone would not provide an adequate sample size despite the efforts by the research team and our industry contacts. Therefore, I enacted additional strategies to recruit participation in this study. Specifically, I created a project brochure (See Appendix A), which included information on the goals and methodologies of the project, members of the research team, answers to common participant questions, and contact information. Additionally, I printed hundreds of business cards displaying the survey URL to distribute to interested participants. I then traveled in-person to numerous cannabis organizations throughout Fort Collins, Boulder, and Denver to speak in-person to 
workers and management, solicit participation in the project, and provide additional study information in the form of brochures and URL business cards. I also welcomed potential participants to share this information with fellow co-workers and colleagues in the cannabis industry of Colorado. However, this too proved to be inadequate with regard to the sample size, as the number of responses remained consistently low. To address this, in accordance with social exchange theory and the norm of reciprocity (Emerson, 1976), I ordered 200 keychains (which displayed the "project logo"1) to give to potential participants before completing the survey (i.e., during recruitment visits to cannabis organizations). I then continued in-person recruitment and distributed keychains (while supplies lasted), project brochures, and newly-printed URL business cards (with modified wording for the addition of the keychain incentive) until data collection concluded on June 30,2015 , due to the end of the grant funding cycle. Through these recruitment trips, I personally visited a total of 11 cannabis organizations in Fort Collins, 19 in Boulder, and 74 in Denver (104 total).

All participants who successfully completed the survey received a $\$ 20$ incentive payment in the form of cash (in-person) or an Amazon.com gift-card (online) in exchange for their time and effort. The incentive was important for encouraging workers to participate in the survey and to yield a high response rate to facilitate obtaining a representative sample of workers.

Throughout this project and after completion, respondents' data have remained (and will remain) confidential. No names of workers or businesses or identifying information were collected. This study was reviewed and approved by the Colorado State University Institutional Review Board (IRB) to ensure compliance with federal regulations regarding research with human subjects.

\footnotetext{
${ }^{1}$ The "project logo" is an image of the Colorado state flag with a cannabis leaf, developed by New Zealand artist Bruce Stanfield and purchased for reproduction with project funding via Shutterstock.com. See the project brochure in Appendix A for an example.
} 


\section{Measures}

\section{Stressors.}

Perceived Occupational Stigma. Stigma was measured using a newly-created Measure of Perceived Occupational Stigma (Fisher, Walters, \& Menger, in preparation). This measure was generated by adapting items from the ten-item Stigma Consciousness Questionnaire (SCQ; Pinel, 1999); the Identity Threat measure (McGonagle \& Barnes-Farrell, 2013); and generating one new item. All item wording reflected stigma perceptions among cannabis industry workers from three possible sources of stigma. In other words, cannabis industry workers answered questions about the degree to which they perceived stigma from 1) family, 2) friends, and 3) society in general. The new scale indicated an acceptable reliability estimate for all three sources of stigma, including family (coefficient alpha $\alpha=.84$ ), friends $(\alpha=.81)$, and society $(\alpha=.79)$. Additionally, principal axis factoring (PAF) results indicated single-factor solutions for each of the three sources of stigma (I describe PAF in detail in the results section). All steps for scale validation can be seen in Appendix B. Pinel (1999) constructed and validated the SCQ through measuring stigma consciousness among such groups as women, gay men and lesbians (Pinel, 1999). Pinel found an acceptable reliability estimate for the SCQ among women (coefficient alpha $\alpha=.74$ ) and gay men and lesbians $(\alpha=.81)$. The Identity Threat measure was constructed and validated as a measure of perceptions of stigma at work because of chronic illness (McGonagle \& BarnesFarrell, 2013). McGonagle and Barnes-Farrell found an acceptable reliability estimate for the Identity Threat measure (coefficient alpha $\alpha=.84$ ). In the current study, participants responded via a five-point Likert-type scale ranging from "Strongly Agree” to "Strongly Disagree." Example items in the new Measure of Perceived Occupational Stigma in the cannabis industry were: "My family has a negative view of people who work in the cannabis industry," "I am 
concerned that my friends judge me for the type of work that I do," and "My choice to work in the cannabis industry has been scrutinized by people in general." See Appendix C for the full scale.

Job insecurity. Job insecurity was measured using the four-item Job Insecurity Scale (JIS; Vander Elst, De Witte, \& De Cuyper, 2014). Participants indicated the extent to which they agreedd or disagree with item using a five-point Likert-type scale ranging from "Strongly Agree" to "Strongly Disagree." An example item from the JIS was: "Chances are, I will soon lose my job." The JIS had an acceptable reliability estimate in this study $(\alpha=.78)$. Other research has indicated similarly acceptable reliability estimates for the English version of the JIS with a coefficient alpha $\alpha=.82(\alpha=.85$ for a total sample across Belgian, Dutch, Spanish, Swedish, and English versions; Vander Elst et al., 2014). Additionally, Virga (2015) reported acceptable reliability for the 4-item JIS $(\alpha=.89)$ and indicated validity support for the scale. For example, in the study by Virga, job insecurity weakly negatively correlated with job satisfaction $(r=-.21)$ and strongly positively correlated with qualitatively-measured job insecurity $(r=.86)$. See Appendix D for a full scale.

Role ambiguity. I measured role ambiguity using a shortened version of the Breaugh and Colihan Role Ambiguity Scale (Breaugh \& Colihan, 1994; Kath, Stichler, Ehrhart, \& Schultze, 2013). The role ambiguity scale consisted of six items assessing the level of role ambiguity perceived by respondents, such as: "I know what my supervisor considers satisfactory work performance," and "I know what is the best way (approach) to go about getting my work done." Respondents indicated the degree to which they agreed or disagreed with each item using a fivepoint Likert-type rating scale, ranging from "Strongly Agree" to "Strongly Disagree." Research has demonstrated an acceptable reliability estimate of the Breaugh and Colihan Role Ambiguity 
Scale ( $\alpha=.84$, Breaugh \& Colihan, 1994; $\alpha=.86$, Kath et al., 2013). Additionally, Kath et al. found that role ambiguity significantly predicted perceptions of overall work stress among nurse leaders $(\beta=.15, p<.05)$. In this study, the role ambiguity scale had an acceptable reliability estimate with a coefficient alpha $\alpha=.86$. The full scale is in Appendix E.

Long working hours. I measured long working hours in a manner similar to that of Shields (1999) and Golden and Wiens-Tuers (2005, 2006, 2008). Specifically, I utilized Shields' (1999) categorization of long working hours as an average of 41 or more hours per week and standard working hours as an average of 35 to 40 hours per week. Thus, I asked cannabis industry workers to report their average number of working hours in a typical week, as well as average number of working hours during a typical busy week. Additionally, I asked participants questions similar to Golden and Wiens-Tuers (2008), such as: "How many days per month do you work extra hours beyond your usual schedule?" and "When you work extra hours on your main job, is it mandatory (required by your employer)?" The scale is presented in Appendix F.

\section{Awareness.}

Safety climate. Safety climate was measured using the Safety Climate Measure developed by Neal, Griffin, and Hart (2000). Participants indicated the extent to which they agreed or disagreed with each item using a five-point Likert-type scale ranging from "Strongly Agree" to "Strongly Disagree." The Neal et al. safety climate measure included several relevant dimensions, including management values, training, communication, and physical safety. Relevant items for each dimension included: "Management is concerned for the safety of employees," (management values); "There is frequent communication about safety issues in this workplace," (communication); "Safety issues are given a high priority in training programs," (training); and, "There are significant dangers inherent in the workplace," (physical work 
environment). Research has indicated an acceptable reliability estimate for the Neal et al. safety measure, with a coefficient alpha $\alpha=.72$ for management values (Griffin $\&$ Neal, 2000); $\alpha=.73$ for training (Griffin \& Neal, 2000); $\alpha=.74$ for safety communication (Griffin \& Neal, 2000); and $\alpha=.71$ for physical work environment (Mohamed, Ali, \& Tam, 2009). In support of the validity of the Safety Climate Measure, Neal et al. also found that safety climate perceptions strongly positively correlated with safety knowledge $(r=.52)$ and moderately correlated with safety motivation $(r=.40)$, safety compliance $(r=.42)$, and safety participation $(r=.47)$. Acceptable reliability estimates were found in this study across all dimensions, including management values $(\alpha=.95)$, communication $(\alpha=.92)$, training $(\alpha=.94)$, and the physical work environment $(\alpha=.73)$. See Appendix $G$ for a full scale.

Perceptions of physical safety. Perceptions of physical safety were measured using a newly-generated scale including potential safety hazards identified in pilot study data. I consulted with an epidemiologist with experience researching workplace hazards and health effects among tobacco growers to further verify potential hazards for cannabis industry workers. Respondents were asked to rate the extent to which they agreed or disagreed that each hazard was a problematic issue in their workplace using a five-point Likert-type scale ranging from “Strongly Agree” to "Strongly Disagree.” Hazards included physical safety; air quality; respiratory issues; absorbing chemicals through skin; ergonomic issues; slips, trips, or fall hazards; temperature from lighting systems; and exposure to pesticides. Respondents were also asked an open-ended question regarding any other perceived hazardous characteristics of their workplaces. See Appendix H for the full scale. 


\section{Outcomes.}

Job satisfaction. Job satisfaction was measured using the three-item Michigan Organizational Assessment Questionnaire Job Satisfaction Subscale (MOAQ-JSS; Cammann, Fichman, Jenkins, \& Klesh, 1979, 1983). The MOAQ-JSS consisted of three items assessing the level of general job satisfaction perceived by respondents, such as: "All in all I am satisfied with my job." Respondents indicated the degree to which they agreed or disagreed with each item using a five-point Likert-type rating scale, ranging from "Strongly Agree" to "Strongly Disagree." Research has demonstrated an acceptable reliability estimate of these three items $(\alpha=$ .89; Harris, Wheeler, \& Kacmar, 2009). In a meta-analysis of the MOAQ-JSS, Bowling and Hammond (2008) investigated the psychometric properties of the scale and found widespread support for its validity as a measure of job satisfaction. For example, Bowling and Hammond reported that job satisfaction, measured via the MOAQ-JSS, moderately positively related to perceived organizational support (mean $r=.41$ ) and strongly negatively related to turnover intentions (mean $r=-.52$ ). In my study, the MOAQ-JSS had an acceptable reliability estimate with a coefficient alpha $\alpha=.78$. See Appendix I for the full scale.

Turnover intentions. Turnover intentions were measured using the three-item scale by Seashore, Lawler, Mirvis, and Cammann (1982), such as: "I have seriously thought about leaving my job.” In addition to asking workers about their intentions to quit their job, I initially intended to also assess workers' intentions to leave the cannabis industry as a whole by adapting the items from Seashore et al. However, upon completion of data collection I realized that the adapted scale, assessing intent to leave the cannabis industry, was not included in the survey content. As such, turnover intentions in this paper solely refer to workers' intentions to leave their specific job. Participants responded using a five-point Likert-type rating scale ranging from 
"Strongly Agree" to "Strongly Disagree." Research has demonstrated an acceptable reliability estimate of the Seashore Turnover Intentions Scale $(\alpha=.86$; George $\&$ Jones, 1996). In support of the validity of the three-item Seashore Turnover Intentions Scale, Meriac, Slifka, and LaBat (2015) found that turnover intentions strongly negatively correlated with job satisfaction ( $r=-$ .67). Additionally, Venkataramani, Labianca, and Grosser (2013) reported that turnover intentions (via the three-item scale) related strongly negatively with affective organizational commitment across two studies ( $r=-.60$ in Study $1 ; r=-.54$ in Study 2$)$. The Seashore Turnover Intentions Scale demonstrated an acceptable reliability estimate in my study $(\alpha=.86)$. See Appendix $\mathrm{J}$ for the full scale.

Organizational commitment. Affective organizational commitment was measured using a shortened version of the Affective Commitment Scale (ACS; Allen \& Meyer, 1990; Rhoades, Eisenberger, \& Armeli, 2001). Participants rated the extent to which they agree with each item using a five-point Likert-type scale ranging from "Strongly Agree" to "Strongly Disagree." Example items from the ACS were: "I would be happy to work at my organization until I retire," and "I really feel that problems faced by my organization are also my problems." Research has demonstrated an acceptable reliability estimate for the ACS $(\alpha=.87$, Allen \& Meyer, 1990; $\alpha=$ .85 , Rhoades et al., 2001). In a meta-analysis, Meyer, Stanley, Herscovitch, and Topolnytsky (2002) estimated true correlations $(\sigma)$ between affective commitment (measured via the ACS) and its various antecedents, correlates, and consequences to support the validity of the construct. For example, Meyer et al. (2002) found that affective commitment moderately negatively correlated with the role ambiguity (an antecedent of affective commitment; $\sigma=-.39$ ), strongly positively correlated with overall job satisfaction (a correlate; $\sigma=.65$ ), moderately positively correlated with the coworker (a correlate; $\sigma=.45$ ) and supervisor satisfaction (a correlate; $\sigma=$ 
.42 ), and weakly negatively correlated with job stress (a consequence; $\sigma=-.21$ ). The ACS demonstrated an acceptable reliability estimate in my study $(\alpha=.83)$. See Appendix $\mathrm{K}$ for the full scale.

Burnout. Burnout was measured using a shortened two-part version of the Copenhagen Work Burnout Inventory (CBI; Kristensen, Borritz, Villadsen, \& Christensen, 2005). In the first part of the CBI, participants responded using a five-point Likert-type scale ranging from "To a very high degree" to "To a very low degree." An example item from the first part of the CBI is, "Is your work emotionally exhausting?" In the second part of the CBI, participants responded to such items as "Do you feel worn out at the end of the working day?" using a five-point Likerttype scale ranging from "Always" to "Never/Almost never." Research has demonstrated an acceptable reliability estimate of the CBI $(\alpha=.85-.87$; Kristensen et al., 2005). Kristensen et al. also found that burnout (as measured by the $\mathrm{CBI}$ ) correlated with measures of fatigue and psychological well-being, and also significantly predicted future sickness absence, sleep problems, and turnover intentions. The CBI demonstrated an acceptable reliability estimate in my study, with a coefficient alpha $\alpha=.90$. See Appendix L for the full scale.

\section{Supports.}

Job control. Job control was measured using a shortened version of the Job Control Decision Authority measure (Smith, Tisak, Hahn, \& Schmieder, 1997). The job control measure consisted of three items regarding the perceptions of workers regarding their ability to make decisions about their job. Participants responded on a five-point Likert-type scale ranging from “Strongly Agree" to "Strongly Disagree." An example item was: "My job allows me to make a lot of decisions on my own." Research has indicated acceptable internal consistency reliability for the Job Control - Decision Authority measure $(\alpha=.77$; Kath et al., 2013). Additionally, Kath 
et al. provided validity evidence for job control as a significant moderator of the relations between stress perceptions and outcomes among nurse leaders, such that low job control related to greater negative outcomes when stress perceptions were higher. Internal consistency reliability in my study was acceptable with a coefficient alpha $\alpha=.86$ for three items. See Appendix M for the full scale.

Perceived organizational support. Perceived organizational support (POS) was measured using a shortened version of the Survey of Perceived Organizational Support (SPOS; Eisenberger, Huntington, Hutchinson, \& Sowa, 1986). Research had indicated an internal consistency reliability of the SPOS as $\alpha=.93$ (Eisenberger, Fasolo, \& Davis-LaMastro, 1990); similar acceptable reliability was also found in my study $(\alpha=.93)$. In a review of POS literature, Rhoades and Eisenberger (2002) describe extensive empirical support for the reliability, unidimensionality, and validity of the SPOS in both original and shortened versions. For example, Rhoades and Eisenberer described that POS (as measured by the SPOS) is related to, yet distinct from, affective organizational commitment and job satisfaction. The POS scale consisted of four items assessing the degree to which workers perceive that the organization cares about their overall well-being beyond the work that they do for the organization, such as: "My organization really cares about my well-being." Respondents indicated the extent to which they agreed or disagreed with each of the four items using a five-point Likert-type rating scale, ranging from "Strongly Agree” to "Strongly Disagree." See Appendix N for the full scale.

Meaningfulness in work. Meaningfulness in work was measured using the Work as Meaning Inventory (WAMI; Steger et al., 2012). The WAMI consisted of ten items to which participants responded via a five-point Likert-type rating scale, ranging from "Absolutely True" to "Absolutely Untrue." Respondents indicated the extent to which they agreed with the items, 
such as "I have found a meaningful career," "I view my work as contributing to my personal growth," and "My work really makes no difference in the world." Steger et al. indicated an acceptable reliability estimate, with a total scale coefficient alpha of $\alpha=.93$. Steger et al. also described validity evidence for the WAMI, and WAMI scores positively correlated to desirable work variables (e.g., organizational commitment, $r=.49$; job satisfaction, $r=.56$ ) and negatively correlated to undesirable work variables (e.g., withdrawal intentions, $r=-.35$ ). In my study, the WAMI demonstrated acceptable reliability with a coefficient alpha $\alpha=.95$. See Appendix O for the full scale.

Employability. Employability was measured using the Perceived Employability measure developed by Berntson and Marklund (2007), composed of five items such as: "I know of other organizations/companies where I could get work," and "My experience is in demand on the labour market." Berntson and Marklund found an acceptable reliability estimate for the measure of perceived employability, with a coefficient alpha $\alpha=.88$. In support of the construct's validity, De Cuyper, Bernhard-Oettel, Berntson, De Witte, and Alarco (2008) described that employability is important for worker well-being, either as a means to secure future jobs or as a buffer of negative consequences of job insecurity. Additionally, De Cuyper, Van der Heijden, and de Witte (2011) found that perceived employability was positively related to life satisfaction $(r=.13)$ and turnover intentions $(r=.12)$. The measure of perceived employability demonstrated an acceptable reliability coefficient alpha in my study $(\alpha=.84)$. Respondents indicated the extent to which they agreed or disagreed with each of the five items using a five-point Likert-type rating scale, ranging from "Strongly Agree" to "Strongly Disagree." See Appendix P for the full scale. 


\section{Other measures.}

Negative affectivity. I included a measure to control for negative affectivity. Negative affectivity was measured using the general negative affectivity portion of the Positive and Negative Affectivity Scale (PANAS; Watson, Clark, \& Tellegen, 1988). Respondents indicated how often they generally feel certain negative emotions using a five-point Likert-type scale ranging from "Never" to "Almost Always." Example emotions include "scared," "afraid," and "upset." Research had indicated an acceptable reliability estimate for the general negative affectivity portion of the PANAS with a coefficient alpha $\alpha=.87$ (Watson et al., 1988). In my study, the negative affectivity portion of the PANAS demonstrated acceptable reliability $(\alpha=$ .91). See Appendix Q for the full scale.

Demographics and cannabis use. In addition to the previous measures, I also asked participants a number of questions regarding demographics and cannabis use. See Appendix R for a list of demographic questions. 


\section{Results}

\section{Data Review and Cleaning}

Prior to analyzing the data, I reviewed and cleaned the data. Throughout data collection, I reviewed responses on a rolling basis to provide incentives (i.e., \$20 Amazon.com gift cards) to study participants. During this process, I encountered problematic and obscure responses early in the data collection process; similar problems continued to appear on a rolling basis. Specifically, I identified a total of 668 separate responses to the survey that I determined to be false responses across a number of criteria (see Appendix S for a full description of this process). Given that I provided a gift card as an incentive to each individual who successfully completed the survey, I determined that the individual (or small group of individuals) responsible for the false responses seemed to be "hacking" the survey in an attempt to take the survey countless times and receive multiple incentives. Fortunately, I manually provided electronic delivery of incentive payments on a case-by-case basis, so no incentives were ever provided to the individual(s) responsible. All false responses were removed from the dataset prior to data cleaning and analysis (see Appendix S).

After removing all fake "hacker" responses, I analyzed the dataset to examine patterns of missing data as recommended by Rubin and Little (2002). No random or nonrandom missing data patterns were found in the dataset; the only missing data appeared in 27 cases, in which respondents began the survey but dropped out prior to completing the entire surveys; I retained data from these participants to analyze all available data.

Next, I computed frequency distributions for each item to analyze the distribution of responses and identify outliers. Aguinis, Gotfredson, and Joo (2013) described three types of outliers: error outliers (resulting from inaccuracies), interesting outliers (accurately reported 
data points which still lie at a distance from others), and influential outliers (accurately reported data points which are not error or interesting outliers and affect conclusions). Among variables included in this study, only one outlier case was found in the "long working hours" variable. Specifically, one respondent reported working 190 hours in a typical week, and 205 hours in a

busy week. Although this is an ambitious work schedule, it is factually impossible (there are only 168 hours in a 7-day week). Thus, this outlier was most likely a data-entry error designated as an outlier and was replaced with a missing value indicator in the dataset.

Third, I examined the frequency distributions and investigate assumptions of normality, linearity, and homoscedasticity for all variables. I assessed normality by examining results about skewness and kurtosis. All variables were found to have skewness and kurtosis within the acceptable ranges identified by Curran, West, and Finch (1996). I next analyzed linearity and homoscedasticity through pairwise scatterplot analysis per the recommendations of Tabachnick and Fidell (2013); I did not find any problems among the study variables.

\section{Statistical Analysis}

After cleaning the data, I analyzed the data using a number of statistical methods. These methods included computing descriptive statistics to assess central tendency and variability, conducting psychometric analyses to assess the reliability and validity of survey measures, and conducting correlational, regression, and $t$-test analyses to test study hypotheses.

Psychometric properties. Prior to analyzing the data for hypotheses tests, I first conducted exploratory factor analyses of all measures (and their corresponding variables) to assess the factor structure of all scales. Specifically, I used principal axis factoring (PAF), given that it is based on the common factor model that postulates that measured variables are a function of common variance and unique variance (Fabrigar, Wegener, MacCallum, \& Strahan, 1999). As 
such, PAF accounts for random error by removing unique variance, as opposed to other approaches which do not account for unique variance (e.g., principal components analysis, which is not a "true" factor analysis; Fabrigar et al., 1999). Among all study variables, PAF results indicated single-factor measures as expected (e.g., one eigenvalue $>1$ with minimal additional incremental variance explained by other factors, scree plot analysis, acceptable factor loadings > .3 without cross-loading, etc.). After conducting factor analyses, I then computed estimates of internal consistency reliability (i.e., Cronbach's alpha) to assess scale reliability from a single test administration (e.g., Gliem \& Gliem, 2003; Rusbult, Martz, \& Agnew, 1998). As identified in the "measures" section, all scales demonstrated acceptable internal consistency reliability with alpha's greater than .70 (Cortina, 1993).

Descriptive statistics. Prior to conducting hypothesis tests, I assessed general descriptive statistics of the sample. I report these descriptive findings here to provide a general understanding and overview of this new industry. Note that across all study variables (with the exception of "long working hours"), scale scores were measured using a Likert-type response scale ranging from 1 to 5 . In the following sections, I briefly describe the descriptive results in regards to the workers' organizations, stressors, supports, and outcomes.

Respondents' organizations. The organizations represented by this sample had been in operation for an average of 4.7 years (with a range of 0-9 years) and had an average of 39 employees $(S D=69)$. However, given that these organizations primarily operate as small businesses, the number of employees at organizations was rather positively skewed (i.e., most organizations had small numbers of employees). Thus, I note that the organizations in this sample had a median of 20 employees (with a range of 1-500 employees). Although the study methodology did not facilitate an accurate estimate of how many specific organizations were 
represented by the sample (i.e., it was an anonymous survey to protect participant confidentiality), I estimate that participants represented approximately 20-40 unique organizations (i.e., due to the number of organizations I contacted and the rate of data collection). Of these organizations, $77 \%$ had an indoor grow facility (e.g., in a warehouse), 5\% had an outdoor grow facility, and $10 \%$ had a greenhouse grow operation. Seventy-one percent of organizations had a retail dispensary; of those organizations that had a dispensary, $86 \%$ sold both medical and recreational cannabis.

With organizational characteristics in mind, I now briefly describe the work environments of participants in the sample. Thirty-seven percent of respondents' specific work locations had an indoor grow facility, $3 \%$ of respondents worked at an outdoor grow facility, and $4 \%$ worked at a greenhouse grow facility. Eleven percent of respondents worked in a cannabis product manufacturing facility, and $9 \%$ worked at a facility with cannabinoid extractions in place. Finally, 52\% of respondents worked at any kind of dispensary; of these respondents working in dispensary settings, $89 \%$ worked a dispensary that sold both medical and recreational cannabis.

Stressors. Generally speaking, the sample reported moderate to low levels of workrelated stressors (Table 5). Stigma perceptions were gathered from respondents with regard to three potential sources: friends, family, and society in general. Respondents indicated highest perceptions of stigma from society $(M=2.90, S D=.90)$, followed by family $(M=2.06, S D=$ $.93)$ and friends $(M=1.52, S D=.67)$. Respondents also reported relatively low levels of both job insecurity $(M=1.65, S D=.72)$ and role ambiguity $(M=1.54, S D=.66)$. With regard to long working hours, respondents indicated the average number of hours worked on both typical weeks $(M=39.19, S D=9.17)$ and busy weeks $(M=44.58, S D=11.15)$. Approximately $27 \%$ of the 
sample $(n=58)$ reported working more than 40 hours in typical weeks, with 3 such participants (approximately 1\%) working more than 60 hours in typical weeks. Furthermore, a majority of the sample (112 participants; approximately 52\%) reported worked more than 40 hours in busy weeks, with 12 participants (approximately 6\%) working more than 60 hours in busy weeks. Interestingly, the "busiest" respondent indicated working as much as 82 hours in a typical week and 85 hours in a busy week. Additionally, respondents reported working extra hours an average of 4.7 days/month $(S D=6.25)$. Of those respondents working extra hours, $20 \%$ reported that working extra hours was mandatory (i.e., required) by their employer, with another $69 \%$ reporting that working extra hours was not mandatory and $11 \%$ reporting that they have never had to work extra hours at their jobs in the cannabis industry.

Supports. The sample generally reported moderate to high levels of supports (i.e., variables of interest hypothesized as buffers). Respondents indicated high levels of meaningfulness in work $(M=4.25, S D=.75)$, as well as moderate-to-high levels of perceived employability $(M=3.99, S D=.73)$, perceived organizational support $(M=3.92, S D=.99)$, and job control $(M=3.66, S D=.87$; Table 5).

Outcomes. Respondents reported low, moderate, and high levels of the outcomes of interest, due to the varying positive and negative directionality of the constructs (Table 5). Regarding positive individual and organizational outcomes, the sample demonstrated relatively high levels of job satisfaction $(M=4.40, S D=.73)$ and affective organizational commitment $(M$ $=4.22, S D=.84)$. Respondents demonstrated moderate levels of turnover intentions $(M=2.23$, $S D=1.13)$ and burnout $(M=2.36, S D=.91)$, both of which were below the scale midpoint. Of the variables included in the study, respondents indicated the highest degree of variability on turnover intentions, as demonstrated by the standard deviation of 1.13. 
Awareness. Awareness of health and safety among cannabis industry workers was measured in two ways: through assessments of safety climate, and assessments of general physical workplace hazards. Participants reported a relatively high overall safety climate in their organizations $(M=3.73, S D=0.85)$. Across the various dimensions of safety climate, respondents indicated the highest level of perceptions of safety climate with regard to management values $(M=4.01, S D=0.99)$, followed by communication $(M=3.79, S D=0.98)$, the physical work environment $(M=3.63, S D=0.84)$, and training $(M=3.47, S D=1.10)$. Other results also indicated lower regard for employee health and safety training, as 49 different participants indicated that they had never received health and safety training at their job in the cannabis industry. Additionally, participants who received health and safety training indicated heterogeneous responses, ranging from receiving "a piece of paper" to "two weeks paid (training)."

When asked about physical workplace hazards, participants expressed the most concern for ergonomics issues $(M=2.80, S D=1.32)$ and air quality $(M=2.48, S D=1.32)$, although these were all rated below " 3 " on the 1-5 Likert scale, indicating that respondents were more likely to disagree than agree that each was a hazard. Other hazards included physical safety $(M=$ $2.30, S D=1.27)$, respiratory issues $(M=2.26, S D=1.23)$, slips, trips, and fall hazards $(M=$ $2.22, S D=1.11)$, exposure to pesticides $(M=2.15, S D=1.23)$, temperature from lighting systems $(M=2.04, S D=1.09)$, and absorbing chemicals through skins $(M=2.01, S D=1.02)$.

\section{Hypothesis tests.}

Hypothesis 1. Hypothesis 1, which indicated that workers who use cannabis will report lower levels of stigma perceptions, was not supported for any of the three sources of stigma. I analyzed Hypothesis 1using an independent samples $t$-test to compare between-group means. 
Prior to conducting the analysis, I created a binary variable to distinguish between those who do not use/have never used cannabis (i.e., those who indicated they "don't use" cannabis on the response scale), and those who do currently use cannabis in varying degrees of frequency (i.e., from "Less than monthly" to "More than 4 times a day"; see Appendix R, Question \#16). I conducted separate $t$-tests for each source of stigma (i.e., family, friends, and society) to investigate significant mean differences in stigma perceptions between those who do and do not use cannabis. No support was found for stigma from family $(t(185)=-1.56, p=.12)$, friends $(t(185)=-.38, p=.71)$, or society $(t(185)=.32, p=.75)$. However, it is important to note that there was large discrepancy between the sample sizes of each specific group. 178 respondents indicated that they currently use cannabis in some frequency, whereas only 10 respondents indicated that they did not currently use cannabis at the time of the survey, so there was insufficient power to detect mean differences between groups.

Hypothesis 2. Hypothesis 2, which indicated that cannabis industry workers will report working longer hours during busy weeks than typical weeks, was supported by results from a paired-samples $t$-test to assess mean differences between typical weeks and busy weeks for all respondents. Results indicated that respondents worked significantly more hours during busy weeks than typical weeks $(t(199)=-11.36, p<.001)$.

Hypothesis 3. Hypothesis 3 indicated that perceived stigma will relate to job satisfaction (H3a) and turnover intentions (H3b) for cannabis industry workers. I assessed Hypothesis 3 by computing Pearson's $r$ product-moment correlations for all variables of interest. In all of my correlational analyses interpretations, small (or weak) correlations are considered as absolute values of $r$ between 0 and 0.30 , moderate correlations as absolute values of $r$ between 0.31 and 0.50, and large (or strong) correlations as absolute values of $r$ above 0.50 (Cohen, 1992). I found 
support for $\mathrm{H} 3 \mathrm{a}$ and $\mathrm{H} 3 \mathrm{~b}$ across all sources of stigma, although all correlations were small or weak $(r<0.30)$ aside from those involving stigma perceptions from friends (see Table 6). Specifically, stigma perceptions orienting from the "friends" source correlated moderately negatively with job satisfaction $(r=-.31, p<.001)$ and moderately positively correlated with turnover intentions $(r=.32, p<.001)$. Stigma perceptions from the "family" source correlated weakly negatively with job satisfaction $(r=-.17, p=.014)$ and weakly positively with turnover intentions $(r=.21, p=.003)$. I found similar weak correlations for stigma perceptions from "society" and both job satisfaction $(r=-.20, p=.005)$ and turnover intentions $(r=.28, p<.001)$.

Hypothesis 4. I found support for Hypothesis 4, which indicated that job insecurity will relate to individual and organizational outcomes for cannabis industry workers, across all variables of interest using Pearson's $r$ product-moment correlations. Specifically, the correlation between perceived job insecurity and both job satisfaction $(r=-.48, p<.001 ; \mathrm{H} 4 \mathrm{a})$ and affective organizational commitment $(r=-.40, p<.001 ; \mathrm{H} 4 \mathrm{~b})$ were moderately negative. Additionally, perceived job insecurity moderately positively correlated with both turnover intentions $(r=.34, p$ $<.001 ; \mathrm{H} 4 \mathrm{c})$ and burnout $(r=.43, p<.001 ; \mathrm{H} 4 \mathrm{~d})$ among cannabis industry workers.

Hypothesis 5. Hypothesis 5, which purported that role ambiguity will relate to individual and organizational outcomes, was supported across all variables of interest based on analysis of Pearson's $r$ product-moment correlations. Role ambiguity only moderately negatively correlated with job satisfaction $(r=-.33, p<.001 ; \mathrm{H} 5 \mathrm{a})$; all other correlations were small or weak in nature (Table 6). Specifically, role ambiguity was negatively correlated with affective organizational commitment $(r=-.24, p=.001 ; \mathrm{H} 5 \mathrm{~b})$ and positively correlated with both turnover intentions $(r=$ $.20, p=.004 ; \mathrm{H} 5 \mathrm{c})$ and burnout $(r=.30, p<.001 ; \mathrm{H} 5 \mathrm{~d})$. 
Hypothesis 6. Hypothesis 6 indicated that long working hours, conceptualized as working more than 40 hours per week, will relate to individual and organizational outcomes for cannabis industry workers. I tested this hypothesis using independent samples $t$-tests to compare mean scores on outcomes of interest between those who do work long hours compared to those who do not. Additionally, I conducted separate $t$-tests to compare mean scores between groups during both "typical weeks" and "busy weeks." In other words, I created two distinct binary variables to dichotomize individuals who did/did not work long hours during typical weeks, and also to dichotomize individuals who did/did not work long hours during busy weeks. Results indicated partial support for Hypothesis 6. For ease of interpretation, I first describe results for respondents during typical weeks then describe results for busy weeks.

Typical weeks. During typical weeks, I found significant mean differences between those who work long hours and those who work normal hours on levels of both job satisfaction and burnout. Specifically, H6a was supported and mean levels of job satisfaction significantly differed between those who work long hours $(M=4.17, S D=.88)$ and those who do not work long hours $(M=4.48, S D=.66)$ during typical weeks $(t(198)=-2.80, p=.006)$. Additionally, $\mathrm{I}$ found significant mean differences in levels of burnout for those who work long hours $(M=2.79$, $S D=1.04)$ and those who work normal hours $(M=2.20, S D=.81)$, indicating support for H6d $(t(198)=4.30, p=.000)$. However, no significant differences were found between groups in levels of affective organizational commitment $(t(198)=-.145, p=.885 ; \mathrm{H} 6 \mathrm{~b})$ and turnover intentions $(t(198)=1.92, p=.057 ; \mathrm{H} 6 \mathrm{c})$.

Busy weeks. During busy weeks, trends appeared similar to those found in typical weeks. Specifically, significant mean differences were found between groups on both job satisfaction and burnout. Hypothesis 6e was supported, as I found significant mean differences in job 
satisfaction between respondents who work long hours $(M=4.26, S D=.85)$ and those who work typical hours during busy weeks $(M=4.56, S D=.53), t(198)=-2.85, p=.000$. Additionally, H6h was supported, as I found significant mean differences on levels of burnout between those working long hours $(M=2.61, S D=.92)$ and those working normal hours $(M=2.07, S D=.83$; $t(198)=4.34, p=.000)$. However, similar to during typical weeks, no significant differences were found between groups on either affective organizational commitment $(t(198)=-.073, p=$ $.942 ; \mathrm{H6f})$ or turnover intentions $(t(198)=1.29, p=.199 ; \mathrm{H6g})$.

Hypothesis 7. Hypothesis 7, which indicated that job control will serve as a buffer between hypothesized relations between stressors and outcomes, was assessed using hierarchical multiple regression analyses. In all hypotheses assessing buffer effects (i.e., Hypotheses 7-10), I entered stressors at the first step of analyses and then entered buffer variables at the second step. At the third step, I entered the interaction effect to analyze for significance of interaction term effects and changes in $R^{2}$. In other words, at the third step I added the interaction term(s) of hypothesized buffer variables (i.e., workplace supports) and stressors in order to assess potential buffer effects. I considered hypotheses of buffer effects to be supported if the interaction explained a significant amount of the variance in the outcome. This was assessed by examining the change in $R^{2}$ and outcomes of an $F$-ratio and alpha $<.05$ to assess statistical significance. For ease of interpretation, for Hypotheses 7-10 I only describe results for each supported moderation sub-hypothesis individually, and then interpret all non-significant moderation hypotheses in the following discussion section. Hypothesis 7 received partial support for job control operating as a buffer on the hypothesized relation between stressors and outcomes. Specifically, I found support for Hypotheses 7a, 7h, 7i, and 7j, and Hypotheses 7b, 7c, 7d, 7e, 7f, 7g, and 7k were not supported $(p>.05)$. 
Hypothesis $7 a$. Hypothesis 7 a received partial support for job control operating as a buffer on the hypothesized relation between stigma perceptions and job satisfaction. I conducted separate hierarchical regressions for each source of stigma, with a significant buffer effect only evident for the relation between stigma perceptions from the "friends" source and job satisfaction $\left(\Delta R^{2}=.020, \Delta F(1,185)=4.62, p=.033\right.$; Table 7; Figure 1). I found no significant buffer effects in the relations between both stigma-family and stigma-society and job satisfaction.

Hypothesis $7 h$. I assessed Hypothesis $7 \mathrm{~h}$ for both typical and busy weeks, such that separate hierarchical regressions were assessed to assess for a buffering effect of job control on the relation between long working hours and job satisfaction in both a) typical weeks; and b) busy weeks. Hypothesis $7 \mathrm{~h}$ was partially supported, indicating that job control served as a significant buffer of the relation between long working hours and job satisfaction, but only during busy weeks $\left(\Delta R^{2}=.020, \Delta F(1,184)=4.54, p=.034\right.$; Table 8; Figure 2). I found no significant interaction effect during typical weeks.

Hypothesis 7i. I analyzed Hypothesis 7i with separate hierarchical regressions to assess for a buffering effect of job control on the relation between long working hours and turnover intentions in both typical and busy weeks, similar to H7h. Hypothesis 7i was partially supported, indicating a significant buffer effect of job control during busy weeks $\left(\Delta R^{2}=0.030, \Delta F(1,184)\right.$ $=6.16, p=.014$; Table 9; Figure 3). No significant interaction effect was found during typical weeks.

Hypothesis $7 \mathrm{j}$. Hypothesis $7 \mathrm{j}$ was partially supported in a manner similar to that of Hypotheses 7h and 7i. Specifically, I found a significant buffer effect of job control on the relation between long working hours and affective organizational commitment during busy 
weeks $\left(\Delta R^{2}=0.034, \Delta F(1,184)=8.00, p=.005\right.$; Table 10; Figure 4). However, I found no significant interaction effect during typical weeks.

Hypothesis 8. Hypothesis 8 indicated that perceived organizational support would serve as a buffer in the hypothesized relations between stressors and outcomes among cannabis industry workers. I conducted hierarchical multiple regressions for each buffer effect, and Hypothesis 8 was partially supported. Specifically, Hypotheses $8 \mathrm{a}$ and $8 \mathrm{~h}$ each received partial support. Hypotheses 8b, 8c, 8d, 8e, 8f, 8g, 8i, 8j, and 8k were not supported ( $p>.05$ ). Hypothesis $8 a$. Hypothesis $8 \mathrm{a}$ was partially supported, indicating that perceived organizational support significantly buffered the negative relation between perceived stigma and job satisfaction only for the "friends" source of stigma $\left(\Delta R^{2}=.020, \Delta F(1,185)=6.09, p=.015\right.$; Table 11; Figure 5). I found no significant interaction effects for either the "family" or "society" sources of stigma.

Hypothesis $8 h$. Hypothesis $8 \mathrm{~h}$ analyses assessed a buffering effect of perceived organizational support on the negative relation between long working hours and job satisfaction. I conducted separate hierarchical regression analyses for typical and busy weeks. Hypothesis $8 \mathrm{~h}$ was partially supported, in that I found a significant buffering effect during busy weeks $\left(\Delta R^{2}=\right.$ $0.016, \Delta F(1,184)=5.03, p=.026$; Table 12; Figure 6). Although alpha neared significance, I found no significant interaction effect during typical weeks $\left(\Delta R^{2}=0.012, \Delta F(1,184)=3.61, p=\right.$ $.059)$.

Hypothesis 9. Hypothesis 9 assessed meaningful work as a buffer of hypothesized relations between stressors and outcomes. I assessed all sub-hypotheses using hierarchical multiple regression analyses, and Hypothesis 9 was partially supported. Specifically, Hypothesis 
9c, 9e, and 9h were each supported. Hypotheses 9a, 9b, 9d, 9f, 9g, 9i, 9j, and 9k were each not supported $(p>.05)$.

Hypothesis $9 c$. Hypothesis $9 \mathrm{c}$ assessed meaningful work as a buffer on the hypothesized negative relation between job insecurity and job satisfaction. Hypothesis $9 \mathrm{c}$ was supported, as analyses revealed a significant interaction effect $\left(\Delta R^{2}=0.019, \Delta \mathrm{F}(1,185)=6.41, p=.012\right.$; Table 13; Figure 7).

Hypothesis $9 e$. Hypothesis 9e involved meaningful work buffering the hypothesized negative relation between role ambiguity and job satisfaction. Analyses indicated a significant interaction effect $\left(\Delta R^{2}=0.014, \Delta F(1,185)=4.08, p=.045\right.$; Table 14; Figure 8). Thus, I found support for $\mathrm{H} 9 \mathrm{e}$ and meaningful work significantly buffered the negative relation between role ambiguity and job satisfaction.

Hypothesis $9 h$. Hypothesis $9 \mathrm{~h}$ assessed a buffering effect of meaningful work on the hypothesized negative relation between long working hours and job satisfaction. I conducted separate hierarchical regression analyses for both typical and busy weeks, and results indicated support for $\mathrm{H} 9 \mathrm{~h}$ in both weeks. Specifically, meaningful work significantly buffered the relation between long working hours and job satisfaction in typical weeks $\left(\Delta R^{2}=0.031, \Delta F(1,184)=\right.$ $9.65, p=.002$; Table 15; Figure 9). Additionally, I found a significant interaction effect in busy weeks $\left(\Delta R^{2}=0.016, \Delta F(1,184)=4.94, p=.027\right.$; Table 15; Figure 10). Thus, H9h was supported for both typical and busy weeks.

Hypothesis 10. Hypothesis 10 indicated that perceived employability will buffer the hypothesized relations between perceived job insecurity and both job satisfaction (H10a) and turnover intentions (H10b). I assessed Hypothesis 10a and H10b using hierarchical multiple regression analyses and both were unsupported. 


\section{Discussion}

The aim of this study was to conduct the first occupational safety and health investigation of the Colorado cannabis industry, particularly from an OHP perspective. Specifically, I sought to: 1) identify potential health, safety, and psychosocial work stressors among Colorado cannabis industry workers; 2) assess workers' awareness of OSH issues; and 3) identify workplace supports which may protect and promote the health and well-being of cannabis industry workers. This project aligned with the sector-based approach proposed by NIOSH (NIOSH, 2013), which calls for researchers to investigate specific industries and occupations to practically apply research findings. Given an overwhelming lack of occupational health and safety research and practice in the cannabis industry, primarily due to the novelty of the industry, I developed this study by aligning project goals with NIOSH National Occupational Research Agenda goals (Rogers, 2006; Sorerholm, 2006), comparing the cannabis industry to similar industries (e.g., alcohol and tobacco; Pacula et al., 2014), and by using common OHP theories and models, in conjunction with previously collected pilot data, to inform study hypotheses and methodologies.

In general, my results provide a preliminary understanding of the demographics of cannabis industry workers and organizations. Additionally, my results suggest the presence of specific physical and psychological workplace hazards or stressors, as well workplace supports to protect worker health and well-being. In this section, I first synthesize and interpret the results of supported hypotheses. Second, I describe how these results align with psychological theories and empirical research. Third, I discuss the practical implications of this project. Fourth, I describe the limitations of this project in detail. Finally, I end this discussion with a general summary and conclusion. 


\section{Summary and Interpretation of Results}

My results first provided some general insight into the workers and organizations that comprise the cannabis industry of Colorado. Generally speaking, workers in this industry were predominantly Caucasian, male, below the age of 30, and had some college education. These workers primarily worked day shifts and only held jobs in the cannabis industry (i.e., a majority did not have other jobs), where they typically earn less than $\$ 35,000 /$ year. Cannabis businesses that employed the participants in this study included various types of cannabis operations (e.g., cannabinoid extractions, cannabis manufacturing, etc.), but a majority of organizations had an indoor grow facility and a retail cannabis dispensary to sell both recreational and medical cannabis. These organizations are all typically young, with an average of less than five years in operation at the time of data collection, which aligns with the novelty of the cannabis industry in general.

The study results also provided an initial understanding of physical and psychological workplace stressors for cannabis industry workers. Generally, respondents reported moderate to low levels of work-related stressors, which suggests that there were no exceptionally prevalent stressors among the variables in this study. Relatively speaking, workers perceived the highest degree of stigma from society in general, with lower perceptions of stigma from family or friends. Although purely speculative, this may simply be due to workers generally befriending individuals or family members with similar values and occupations, as I would not expect individuals to develop friendships with individuals who stigmatize or disagree with their employment decisions. Cannabis industry workers also indicated relatively low levels of job insecurity and role ambiguity. Thus, workers in the cannabis industry appeared to generally understand their roles at work and feel as if they are secure in their jobs. None of the average 
ratings of stressors in this study exceeded a value of "3" on the 1-5 Likert-type scales, which indicated that respondents typically were more likely to disagree that they experienced such stressors than they were to feel neutrally towards or agree with experiencing such stressors. Overall this is a positive finding, as low levels of stressors are certainly desirable.

Cannabis industry workers also reported favorable levels of individual and organizational outcomes, as well as workplace supports. My results suggested moderate to high levels of workplace supports in the cannabis industry, such as feeling that their work was meaningful, that they were highly employable at other jobs, that their organizations supported their overall wellbeing, and that they had a fair amount of control over their jobs. Additionally, respondents were highly satisfied with their jobs, had positive feelings toward their organizations, did not plan to leave their organization, and generally were not burned out. Thus, cannabis industry workers appeared to have a relatively positive and strong support system in their workplaces, which they reciprocated to the organization with high commitment and satisfaction. However, it is noteworthy that respondents' variability in turnover intentions was higher than for any other study variable, indicating that there was more heterogeneity in individuals' intent to leave their jobs than for any other worker perceptions.

Finally, cannabis industry workers also reported relatively high levels of safety climate in their organizations, with the highest perceptions that management values the health and safety of workers (as compared to the other dimensions of safety climate: communication, training, and the physical work environment). Generally speaking, this is good news for the cannabis industry and indicates that workers generally feel as if their employers and organizations care about their safety and well-being beyond simply what they bring to the job. Interestingly, however, participants reported the lowest safety climate perceptions with regard to employee training. That 
result was reflected in the data as 49 different participants reported that there was no health and safety training at their organization. Thus, although organizations may indeed care about the health and safety of their workers, the heterogeneity of health and safety training (or complete lack thereof in some cases) is cause for concern. Additionally, cannabis industry workers generally gave moderately low ratings of physical workplace hazards, indicating that they did not feel as if the hazards were problematic or concerning in their workplace. This may have been due to a genuine lack of existing hazards, but I hesitate to make such an interpretation of the data. Rather, I interpret the low ratings of physical workplace hazards as a lack of concern for or awareness of (rather than a lack of existence of) those hazards, as respondents might not have recognized such hazards due to inconsistent, inadequate, or non-existent health and safety training. For an anecdotal example, during data collection one participant asked me to explain term "ergonomic issues." Although this lack of understanding may not be representative of the sample as a whole, such clarifying questions were not uncommon. Additionally, the relatively high variability of physical hazard ratings (i.e., all standard deviations were greater than one on a 1-5 Likert scale) further supports the notion that Colorado cannabis businesses are heterogeneous regarding how they prevent or attend to physical workplace hazards. I will note that I make these interpretations with caution, and encourage future research involving on-site assessments and evaluations of physical workplace hazards to compare perceptions of workers to those of trained external observers and professionals (e.g., industrial hygienists and/or ergonomists, ideally also employing proper instruments to systematically measure such hazards).

After analyzing and assessing the general characteristics and perceptions of cannabis industry workers, I conducted various statistical analyses to test all hypotheses. First, I did not find any significant differences in stigma perceptions between respondents who personally use 
cannabis and those who do not (H1); this finding was consistent across all three sources of stigma (i.e., family, friends, and society). However, this result was most likely due to low statistical power, as the vast majority of survey participants reported being cannabis users. Specifically, only 10 respondents indicated that they did not currently use cannabis in some form (compared to 178 who did use cannabis). Although there is a large discrepancy in sample sizes between workers who do and do not use cannabis, there is also a lot of variability in frequency of usage among those respondents who report using cannabis. Cannabis users reported their usage frequency across a variety of response options (e.g., "Less than monthly," "Once a week," "Daily," and "More than 4 times a day"; see Appendix R, Question \#16). Thus, future analyses could involve creating sub-groups of cannabis industry workers based on self-reported cannabis use to assess differences in stigma perceptions across such sub-groups (i.e., are there differences in stigma perceptions between chronic daily users and those who use cannabis less often?). In addition, I draw another interesting interpretation of my results from the work of Ashforth and Kreiner (1999). Specifically, as I described previously in this paper, Ashforth and Kreiner suggested that workers in stigmatized, "dirty" jobs may develop unique sub-cultures to buffer against outsider stigma. Although speculative, I suggest that my results might be indicative of such a larger "united front" among cannabis industry workers, wherein stigma experiences are similar for all workers regardless of personal use of cannabis. For example, workers who do not use cannabis may perceive similar stigma as workers who do use cannabis, given the common cultural experiences of working in the cannabis industry. Thus, although my results suggest that personal use of cannabis does not moderate or relate to individuals' perceptions of stigma, additional research is necessary to accurately confirm this interpretation. However, my findings also suggest that there are very few cannabis industry workers who do not use cannabis in any 
form. Even with a follow-up investigation of this hypothesis, I anticipate that such knowledge may lack any practical application to improving the lives of cannabis industry workers.

When cannabis industry workers do experience stigma, my results indicate that these stigma experiences relate to both decreased job satisfaction and increased turnover intentions (H3). However, these correlations were small or weak $(r<0.30$; Cohen, 1992) except when the source of stigma was cannabis industry workers' friends. When workers' friends were the source of stigma, these correlations were moderate in nature, suggesting that workers who perceive stigma from friends are less satisfied with their jobs and more intent on leaving their jobs. This finding is especially interesting because respondents actually reported the lowest levels of stigma by friends. Thus, although stigma of cannabis industry workers by their friends appeared to be rather uncommon, its occurrence may have the most deleterious effects for workers and organizations.

My results also suggested that cannabis industry workers work longer hours during busy weeks than during typical weeks (H2). However, I note that this hypothesis was modified prior to data analysis due to methodological restrictions to test my original hypothesis (i.e., that cannabis industry workers responsible for harvesting plants would report the longest working hours during harvest times, in comparison to working hours during other times). Given that my sample included workers from a variety of jobs and work environments in the cannabis industry, I worded the survey questions to avoid job-specific work experiences (e.g., only grow facility workers would be able to answer questions about work hours during harvest times), and instead asked respondents to indicate how many hours they work in typical weeks and busy weeks to incorporate experiences across all jobs. Although it would be very interesting to compare typical and peak hours for growhouse workers, managing the length of the survey prevented the 
incorporation of variables to truly assess this. Thus, my results are generally intuitive (i.e., working more during busy weeks is not unexpected), but still provide the understanding that cannabis industry work demands (or, at least, work hours) are not consistent across time and may fluctuate. For example, my descriptive results indicated that a majority of respondents (73\%) work less than 40 hours in typical weeks, but just over half of respondents (52\%) work more than 40 hours in busy weeks, with some respondents (6\%) working more than 60 hours in busy weeks. Respondents also worked extra hours almost 5 days/month, and nearly $20 \%$ said that working extra hours was a requirement for their job. Future research might incorporate these findings into hypotheses and study design, to assess the causes of extra work (e.g., during harvest times, holiday/seasonal sales, etc.), differences in work hours across jobs (e.g., by incorporating questions regarding work experiences for specific jobs in the cannabis industry), and potential short- and long-term outcomes of increased workload at busy times.

Although there is a need for future research regarding cannabis industry workers' experiences during typical and busy weeks, my study can provide some initial insight. Specifically, my analysis suggested that respondents who worked long hours during both typical and busy weeks were significantly less satisfied and more burned out than respondents who did not work long hours during such weeks (H6). Although no such differences were found with regard to respondents' organizational commitment or turnover intentions, the mean differences for turnover intentions approached statistical significance $(p=.057)$ and thus may warrant further investigation in future research. These findings were similar regardless of whether the long working hours occurred during typical or busy weeks, suggesting that these findings are consistent throughout fluctuations in workload (i.e., the "business" of that particular week). However, given that my study involved a cross-sectional survey, future research might also 
longitudinally investigate such fluctuations in cannabis industry worker experiences to assess for variability in perceptions of stressors, outcomes, and supports over time and respective "business."

In addition to the impact of stigma experiences and work hours, my results indicated that job insecurity (H4) and role ambiguity (H5) each relate to individual and work-related outcomes for cannabis industry workers. When cannabis industry workers perceive job insecurity, my results suggested that such perceptions relate to moderately lower job satisfaction and affective organizational commitment, as well as moderately higher turnover intentions and burnout. Additionally, perceptions of role ambiguity may moderately relate to lower job satisfaction and weakly relate to lower organizational commitment, higher turnover intentions, and higher burnout.

After assessing the aforementioned relations among study variables, I also analyzed my data to investigate potential buffer effects on these relations. In other words, I sought to determine whether the presence of certain supports, including job control (H7), perceived organizational support (H8), meaningful work (H9), and employability (H10), could mitigate negative outcomes for cannabis industry workers when they experience or perceive certain stressors. Although a large proportion of my analyses were non-significant, I found a number of interesting buffer effects that may have important implications for cannabis industry workers and organizations. Specifically, job control, POS, and MW each significantly moderated at least two hypothesized relations between stressors and outcomes. However, employability did not buffer the relations between job insecurity and either job satisfaction (H10a) or turnover intentions (H10b). Although the incremental variance explained (i.e., $\Delta R^{2}$ ) by all buffer effects was fairly small (i.e., $<.03$, or explaining less than $3 \%$ of variance), these effects may provide initial 
implications for cannabis industry workers and organizations. I next interpret and discuss the various significant buffer effects that I found in this study.

First, my results suggested that the negative relation between perceived stigma and job satisfaction was buffered by workers' perceptions of job control (H7a; Figure 1) and perceived organizational support (H8a; Figure 5), but only when the source of stigma was "friends" and not "family" or "society." In other words, if cannabis industry workers perceive stigma from friends and correspondingly perceive lower job satisfaction than they would otherwise (i.e., if they did not perceive such stigma), then providing workers with more job control and/or organizational support may help to boost workers' job satisfaction. Although stigma from friends was the lowest reported stigma perception among cannabis industry workers, I found that it was the most deleterious for workers and organizations (i.e., through moderate relations to lower job satisfaction and higher turnover intentions). Thus, providing job control and organizational support to workers might be especially beneficial for cannabis workers and organizations when workers perceive stigma by friends.

As I described previously, long working hours may be a prevalent concern among cannabis industry workers that relates to decreased job satisfaction. Fortunately, I found a number of significant buffer effects on this relation. Specifically, during busy weeks, I found that the negative relation between long working hours and job satisfaction was buffered by job control (H7h; Figure 2), perceived organizational support (H8h; Figure 6), and meaningful work (H9h; Figure 10). Additionally, I found that meaningful work also buffered the negative relation between long working hours and job satisfaction in typical weeks (H9h; Figure 9). Given that roughly $27 \%$ of the sample worked long hours during typical weeks and $52 \%$ worked long hours during busy weeks, this finding may be of particular interest to cannabis industry workers and 
organizations. For example, organizations may take extra care to provide support to workers during busy weeks, in the forms of job control and organizational support, to alleviate reduced job satisfaction among employees. Additionally, workers who perceive their work as meaningful might experience such a buffer effect when working long hours, regardless of whether the long hours occur during busy or typical weeks. To provide such a buffer effect, organizations might increase job control by allowing workers to rotate jobs, set their own break schedules, work at their own pace, or have a role in decision-making. Additionally, organizational support could be reinforced through recognition of employees, verbal support, or any other approach to ensuring that workers perceive support from the organization. Finally, meaningful work could be promoted by emphasizing the impact that cannabis industry workers may have on certain populations, such as those with chronic illnesses or conditions who choose to self-medicate with cannabis and/or cannabis products.

Interestingly, job control also buffered the relations between long working hours (in busy weeks) and both turnover intentions (positive; H7i; Figure 3) and affective organizational commitment (negative; H7j; Figure 4). In other words, cannabis industry workers who reported working more than 41 hours/week during busy weeks may have also experienced lower levels of job satisfaction (H7h; Figure 2) and organizational commitment, as well as higher intent to leave their jobs, but having control over their jobs buffered these relations and partially diminished negative outcomes. Phrased yet another way, when cannabis industry personnel work more than 40 hours during busy weeks, their perceptions of job satisfaction, organizational commitment, and turnover intentions depend upon how much control they have over their job. When workers work long hours during busy weeks and experience high levels of job control, they may be expected to also experience lower turnover intentions and higher job satisfaction and 
organizational commitment than workers who experience low job control while working long hours in busy weeks. Interestingly, the figures for $\mathrm{H} 7 \mathrm{~h}, \mathrm{H} 7 \mathrm{i}$, and $\mathrm{H} 7 \mathrm{j}$ all suggest that workers who do not work long hours during busy weeks, but who do experience high job control, might actually be expected to report more negative outcomes than those who experience low job control. Specifically, the figures suggest that workers with high job control and who do not work long hours during busy weeks may report slightly lower job satisfaction, lower affective organizational commitment, and higher turnover intentions. Although speculative, I suggest that this might be indicative of some sort of "boredom effect", in which cannabis industry workers thrive in the presence of high job control while working more than 40 hours/week in busy weeks, but may become bored or disinterested with work in the presence of high job control without long hours. I encourage future research to further investigate this buffering effect of job control, to assess for discrepancies in outcomes among cannabis workers during busy weeks. Additionally, I note that there were no significant main effects of long working hours (during busy weeks) on turnover intentions (H7i; Table 9) or organizational commitment (H7j; Table 10) at any step of hierarchical regression analyses, which is generally consistent with the nonsignificant independent samples $t$-test results in Hypothesis 6. However, job control did exhibit significant main effects on both turnover intentions and organizational commitment during Step 2 of each respective analysis, and the main effect then became non-significant during Step 3 of each analysis, which suggests a moderation effect (Tabachnick \& Fidell, 2013). Given the nonsignificance in $\mathrm{H6}$ and the main effects of job control on turnover intentions in H7i, I interpret and present these results with caution to the reader. Future research may be necessary to accurately interpret the relation between long working hours (in busy weeks) and turnover intentions or organizational commitment. However, if there is indeed a relation between long 
working hours (in busy weeks) and these two variables, my results suggest that providing workers with control over their jobs may mitigate the potential negative consequences of higher turnover intentions or lower organizational commitment.

Finally, I found two other significant instances when meaningful work operated as a buffer for cannabis industry workers. Specifically, meaningful work buffered the negative relation between role ambiguity and job satisfaction (H9e; Figure 8), and also buffered the negative relation between job insecurity and job satisfaction (H9c; Figure 7). Thus, when cannabis industry workers perceive role ambiguity or job insecurity, they may report lower job satisfaction than they would in the absence of such perceptions. However, workers that perceive their work as meaningful may be less susceptible to the reduction in job satisfaction. In other words, cannabis industry workers that believe their work is meaningful, in the presence of role ambiguity or job insecurity, may experience higher levels of job satisfaction than workers in the same context who do not view their work as meaningful.

\section{Comparison to Existent Theory and Research}

This project primarily applied Occupational Health Psychology (OHP) theories and principles to the cannabis industry of Colorado. OHP focuses on the protection and promotion of the health, safety, and well-being of workers in their respective organizations. Given the newness of the cannabis industry, there was no industry or occupation with which worker experiences could be directly compared when generating research questions and hypotheses. As such, I primarily drew upon existing OHP theories and models to develop this project, such as the jobdemands resources model (JDR; Demerouti et al., 2001) and the allostatic load model (McEwen, 1998). Although the allostatic load model suggests that cannabis industry workers may experience strain as a result of allostatic load during peak harvest times, my data do not enable 
such an analysis (i.e., due to sampling from a variety of occupations in the industry at various points in time); as such, I primarily focus on the JDR in this context. The JDR generally suggests that workers experience demands on the job (requiring some degree of sustained effort by the worker), which can be fulfilled through the utilization of resources (either external or internal) that are available to the worker (Demerouti et al., 2001). Accordingly, the JDR posits that an imbalance between demands and resources leads to either positive or negative outcomes. Schaufeli and Teris (2014) described that, when workers experience high levels of job demands, strain or negative health outcomes may occur. Conversely, Schaufeli and Teris described that high levels of resources may lead to positive outcomes, such as increased motivation and productivity.

When comparing my study results to the JDR model, initial support for the JDR may seem apparent. To elaborate, one might consider general stressors in this study to be demands of the job (e.g., long working hours), with outcomes as indicators of strain among cannabis industry workers (e.g., low job satisfaction). For example, my results indicated that a cannabis industry worker who works long hours (i.e., a job demand) perceived significantly lower levels of job satisfaction (i.e., the workers experienced strain) than workers working normal hours (H6). However, job control (a job resource) "buffered" (i.e., moderated) the relation between long working hours and job satisfaction, such that individuals working long hours reported higher job satisfaction when they perceived higher job control. Conversely, my results suggested that individuals working long hours would report lower job satisfaction when they perceived less job control. Therefore, the JDR initially appeared to be an appropriate framework for this context, as the imbalance of demands and resources among cannabis industry workers coincided with strain in many instances. However, this was not always the case, as I found a number of non-significant 
buffer effects and generally unsupported hypotheses. Thus, I next describe a more in-depth assessment of my overall results in the context of the JDR model.

In my study, I included a number of variables that could be considered to be representative of demands, resources, or strain among cannabis industry workers. First, my data and results suggested that cannabis industry workers may not experience rather high job demands. In this study, I conceptualized job demands as general job tasks (e.g., grow work, retail sales, etc.), long working hours (especially during busy weeks, as evidenced by my results), working in a stigmatized industry, and holding jobs that are repetitive in nature, ambiguous, and/or lacking in security. My results generally suggested that cannabis industry workers do not experience high perceptions of stigma (from family, friends, or society), job insecurity, or role ambiguity, but do experience long working hours to some degree.

Additionally, my findings suggested that cannabis industry workers are generally exposed to a relatively high degree of supports and resources on the job, which thus may be utilized to fulfill the demands of cannabis industry work. For example, in this study I included such constructs as meaningful work for cannabis industry personnel, perceptions of organizational support, having control over one's job, and a sense of employability at other cannabis industry organizations if workers were to lose their jobs for any reason. Cannabis industry workers reported moderate or high perceptions of all of these supports.

Finally, my results suggested a general lack of strain among cannabis industry workers. Specifically, cannabis industry workers reported moderately low levels of burnout and turnover intentions, both of which were below the scale midpoint. Respondents also reported high levels of job satisfaction and affective organizational commitment. 
Taken in conjunction, my results generally suggest that there is 1) a lack of strain for cannabis industry workers, 2) relatively low job demands beyond fluctuating work schedules and long working hours, and 3) relatively high levels of supports and resources available to fulfill the demands of their jobs. Thus, there appears to be an imbalance of demands and resources for cannabis industry workers, such that there are high levels of resources and low job demands. As Schaufeli and Taris (2014) suggested, such an imbalance should lead to higher levels of worker productivity and motivation within the context of the JDR model. Among my study variables, I did not include any constructs or measures regarding productivity or motivation among cannabis industry workers. Furthermore, I may have potentially failed to assess strain, demands, or resources in a comprehensive manner (i.e., there may be external variables that I failed to measure). Thus, I am unable to adequately determine if my results provide support for the JDR model.

Given the ambiguity of my results, I deduced a number of possible scenarios which may explain my findings in the context of the JDR model. Specifically, I propose the following possible explanations. First, the lack of strain among cannabis industry workers is due to a balance between demands and resources among cannabis industry workers, such that cannabis industry workers are exposed to a higher level of demands than found in this study (e.g., due to non-representative findings or demands beyond the scope of this project). For example, although my results do not clearly indicate the presence of physical workplace hazards, I cautiously suggested that there are hazards present in the workplace that respondents failed to recognize due to inadequate training or misunderstanding the survey content. If physical workplace hazards do exist, then cannabis industry workers might be exposed to additional demands as a result, such as increased mental or physical effort to adequately fulfill job tasks while avoiding injury or harm. 
Future research is necessary to investigate other potential demands for cannabis industry workers.

Second, my results are reflective of the cannabis industry, in that workers generally experience relatively low strain, relatively low job demands, and relatively high resources on the job. As a result of this imbalance between demands and resources, per the JDR model, cannabis industry workers and organizations experience higher levels of productivity and motivation which could not be assessed by the variables included in this study. Future research is necessary to investigate and measure such outcomes.

Third, although there are inevitably some demands and resources which I did not measure in this study, my results are reflective of the cannabis industry and workers generally experience relatively low strain, relatively low job demands, and relatively high resources on the job. If my results are reflective of the cannabis industry of Colorado, but cannabis industry workers do not experience higher levels of productivity and motivation (as in scenario two), then my results do not provide support for the JDR model and/or the JDR model does not adequately apply to this industry. Future research is necessary to replicate these findings and provide an additional test of the JDR model in this industry.

Given the novelty of the cannabis industry, as well as the lack of prior empirical occupational safety and health investigations in this industry, I do not specifically endorse nor favor any of the above scenarios. Rather, I encourage future research that may further assess the appropriateness of the JDR model to the cannabis industry. Additionally, I also encourage research with measures that may provide an assessment of the allostatic load model in this context. 
Although I cannot make direct comparisons with work in other industries, some parallels can be seen between the cannabis industry and others. For example, similar to the work of Raja and Bhasin (2014) in call centers in India, cannabis industry workers are an emerging, understudied occupational group, and this study was developed accordingly. Although research has compared the cannabis industry to the alcohol and tobacco industries from a public health standpoint (see Pacula et al., 2014), no such comparison has been made in the context of worker experiences on the job. However, work experiences in the cannabis industry may be similar to work in these other industries in some regards. Although little research exists applying OHP to such industries, there is a fair amount of overlap with regard to general occupational health research. For example, some survey respondents expressed concerns about exposure to cannabis dust and aerosols during work tasks; similar concerns have been studied among workers in tobacco processing plants (e.g., Bagwe \& Bhisey, 1993). An additional concern among tobacco industry workers is "green mountain sickness" or "green tobacco sickness" (i.e., nicotine poising from dermal exposure to tobacco plants; Ballard, Ehlers, Freund, Auslander, Brandt, \& Halperin, 1995). Essentially, dermal exposure to tobacco plants elevates levels of nicotine in the body, which can cause physical complications for tobacco workers (Ghosh, Parikh, Gokani, Kashyap, \& Chatterjee, 1979). Although no direct comparison to "green mountain sickness" has arisen thus far in the cannabis industry, dermal exposure to plants and absorption of cannabinoids through the skin is a potential safety hazard that future research might investigate. Related to this, there has been at least one reported incident of respiratory distress among cannabis industry workers, as last year at least one cannabis worker sought medical care in Denver, Colorado (Newman, 2015, personal communication). Also, ergonomic issues associated with tobacco work (e.g., continuous bending of the spine when handling plants, repetitive motions, handling plants 
and potentially toxic chemicals, etc.; May, 2009) are likely to occur in the cannabis industry as well. Finally, Arcury and Quandt (2006) described the need for research in the tobacco industry regarding the health effects of exposure to pesticides among tobacco workers, as well as the effects of growing tobacco on personal use of tobacco (i.e., are those who grow tobacco more/less likely to use it?); I would encourage similar research in the cannabis industry, given worker exposure to pesticides and the high rates of cannabis use among workers in the industry.

\section{Practical Implications}

Results of this study can provide researchers, practitioners, and regulating agencies with a better understanding of work experiences in the cannabis industry, including potential psychological and physical safety hazards, psychological stressors and outcomes, and workplace supports. For example, cannabis industry workers generally compose a highly satisfied and supportive workforce, with a high perception that management values their health and safety. However, workers also reported vast fluctuations in health and safety training (with 49 respondents indicating that they received no health and safety training at their jobs in the cannabis industry), and also do not perceive the presence of many safety hazards. Of the physical workplace hazards included in the survey, participants generally felt that most were not hazards at their workplace, with ergonomic issues and air quality as the highest concerns (although all were below an average rating of " 3 " on a 1-5 Likert scale). The relatively high variability in responses to each of the included hazards (i.e., all standard deviations $>1$ ) further indicates heterogeneity of health and safety concerns and training among cannabis industry organizations and workers. Based on these results, I provide practical recommendations for industry leaders and organizational members to apply at their worksites to promote and protect the health and safety of all workers. 
First, cannabis industry organizations and management should strive to develop, implement, and evaluate formal health and safety training programs for all cannabis workers. I encourage the cannabis industry to follow evidence-based best practices to maximize training effectiveness, such as those described by Salas, Tannenbaum, Kraiger, and Smith-Jentsch (2012). Specifically, Salas et al. provided recommendations that can be implemented before training (e.g., conducting training needs analyses to diagnose who needs to be trained, on what content, and in what context), during training (e.g., enabling proper trainee mindsets and following instructions appropriately), and after training (e.g., removing obstacles to ensure transfer of training and evaluating training by linking cognitive, affective, and behavioral outcomes to training needs). Ideally, cannabis industry associations or government regulatory agencies (e.g., OSHA) would develop specific training programs that could be standardized and implemented throughout the industry. As no such training programs currently exist, organizations should strive to educate and train cannabis industry workers on the hazards involved with growing (e.g., proper pesticide handling and corresponding personal protective equipment [PPE] best practices, ergonomic issues associated with cramped growhouse spaces and awkward postures, etc.), cultivating (e.g., proper trimming techniques over long shifts, providing PPE to protect against dermal absorption of cannabinoids and other materials through the skin, etc.), and selling cannabis (e.g., emergency preparedness plans in case of robbery or other emergencies, best practices in dealing with customers, etc.). Future research could further investigate the heterogeneity among health and safety awareness and training, and may also seek to incorporate additional health and safety hazards or additional measurement tools (e.g., anthropometric measurements of hand/wrist activity by trimmers, observation of workplace hazards by trained professionals, etc.). 
Second, owners and managers should strive to provide supports to cannabis industry workers that align with the buffer variables included in this study. For example, cannabis organizations may provide high degrees of autonomy or control to workers (e.g., through task rotation, flexible scheduling, and establishing autonomous work groups; Bond \& Bunce, 2001), formally emphasize and implement ways to express support to their workers (e.g., through employee recognition programs, inclusion in decision-making processes, and communication from management; Wayne, Shore, Bommer, \& Tetrick, 2002), and also frame workers' tasks around the greater "purpose" of work in the cannabis industry (e.g., by reframing or recalibrating work tasks to incorporate prosocial values of cannabis work, such as an emphasis on hundreds or thousands of civilians who rely upon cannabis products to self-medicate any of a number of debilitations; Dik, Duffy, \& Eldridge, 2009).

Third, in addition to generally emphasizing and implementing formal organizational support systems, cannabis organizations should especially provide support during busy weeks or periods of time (e.g., during harvest times, holidays, or other market-specific peak work and sales times). My results suggest that long hours worked during these periods may result in more negative outcomes for workers (e.g., lower job satisfaction) and organizations (e.g., higher turnover intentions and lower organizational commitment). However, providing extra emphasis on such supports during busy weeks may buffer these negative outcomes.

Fourth, cannabis industry organizations should implement formal policies and regulations regarding the use of cannabis on the job and while driving motor vehicles. In this sample, a high number of cannabis industry workers report using cannabis, with proportions using before or during work hours and while driving (either during work hours or in their personal time). Pilot study data and qualitative experiences during data collection (e.g., when recruiting participants 
for the study) suggested that many cannabis industry organizations do not enact specific policies regarding the use of cannabis on the job, which has led to instances in which workers were too intoxicated to adequately perform job tasks. By implementing and enforcing formal policies in such regard, organizations may reduce negative outcomes that correspond with intoxication on the job or while operating motor vehicles.

\section{Limitations}

As is the case in all research, this study had several limitations worth noting. First, as described previously, I encountered difficulty in sampling from the large population of cannabis organizations along the Front Range. Given the limited time available for data collection (as grant funding ended on June 30, 2015), I obtained as many responses as I could within that timeframe. Although I used as many approaches and recruitment tactics as possible in the twostage process, I still fell short of the originally desired sample size of 300-500 cannabis industry workers. Additionally, the survey design was anonymous. Therefore, I was not able to identify the organizations for which respondents worked (i.e., respondents did not identify their organizations in the survey) or the exact total number of organizations that were represented in the sample (I estimate 20-40 uniquely represented organizations based on the rate of data collection; see results). The survey was administered anonymously to provide the most confidentiality possible for survey respondents given the novelty of the cannabis industry, the sensitivity of survey topics, and advice from industry partners that requesting identifying information might reduce the response rate. Although this study necessitated an anonymous survey, I encourage future research that incorporates other survey methodology (e.g., confidential, identified survey responses) and statistical analyses (e.g., hierarchical linear modeling; Hofmann, Griffin, \& Gavin, 2000) to gather and interpret more specific organizational 
information. The recruitment survey (i.e., stage one of recruitment) proved to be a useful tool for stratifying organizations across various criteria, but in hindsight may have impeded the rate of data collection due to the time involved administering and analyzing the recruitment survey prior to actual data collection. Stage two of recruitment (i.e., convenience sampling) proved to be the most effective strategy, but time constraints forced the end of data collection relatively soon after undertaking this approach, limiting the sample size. Given the large number of variables included in the survey, in conjunction with the low sample size, I lacked statistical power to test some of the hypotheses in this study. Future research could incorporate additional tactics to solicit participation from cannabis industry workers and increase the sample size, such as increased incentives, more work to partner with business owners and managers, and a larger team of individuals to visit cannabis organizations and recruit workers to participate.

Additionally, the largest boost in the response rate in this study came from distributing keychains and other "marketing tools" (e.g., the project brochure) in accordance with social exchange theory (Emerson, 1976). Therefore, I would encourage future researchers to utilize similar tactics earlier on during data collection.

A second limitation of this study involved the lack of existing research in two areas: 1) with regard to work in the cannabis industry in general; and 2) with regard to perceptions of stigma. Generally speaking, there was a lack of existent literature to base this project upon. As such, I utilized all available empirical and theoretical supports (as described previously). I would encourage future researchers in all fields to address this issue and develop proposals or projects in all regards of cannabis research, especially now at the forefront of the legalization movement. Additionally, there was a lack of research surrounding the concept of perceived stigma, which presented the need to develop a new scale to measure this construct. Although I applied best 
practices in psychometrics and I/O research throughout the scale development process, the need to develop a scale added to the scope of work involved in conducting this project.

A third limitation of the study involves its generalizability. Although data were gathered from cannabis industry workers throughout the front range in Colorado, most participants were recruited in-person at organizations in Denver, Boulder, and Fort Collins. Although the Front Range (and especially Denver) make up the primary "hub" of cannabis organizations in Colorado, the generalizability of my study to businesses across the state of Colorado, or other geographic regions who have legalized cannabis (i.e., Alaska, Oregon, and Washington), is unknown.

A fourth limitation of the study was non-response by participants. Although there were no problematic patterns of missing data in this study, there were still 27 individuals who stopped completing the survey at some point in time. These data were still analyzed, to assess all available information, but ideally I would have a data set with complete responses from all participants. Additionally, the issues presented by the "hacker" (see Appendix S) slowed the data collection and incentive reward process; although this forced a high degree of quality control for the data set (i.e., ensuring that responses were "real" and thorough), this impeded the rate of data collection and ultimately may have limited the sample size.

Finally, an unorthodox but noteworthy limitation of this study is the likelihood that a non-negligible amount of participants were under the influence of cannabis at the time of the survey and I do not know how that may have affected participants' responses to the survey items. In my survey, $58 \%$ of participants had used cannabis sometime in the 8 hours preceding the survey; quantities of cannabis ranged from low doses of "a hit or two" (i.e., one "drag" of smoke) to a very high dose of 1000mg of tetrahydrocannabinol (THC), the primary psychoactive 
chemical in cannabis. (To put this in context, first-time edibles users in $\mathrm{CO}$ are encouraged to try no more than 10mg of THC.) Additionally, $65 \%$ of participants had used cannabis sometime in the 24 hours preceding the survey, in similarly varying quantities. Research in other fields has suggested a number of acute and chronic effects of cannabis use; relevant to this context, cannabis use can lead to anxiety, heightened or exaggerated emotions, and impaired attention and memory (Ashton, 2001). In this study, I asked participants to answer a number of questions, many of which involved some degree of reflection on one's emotions, feelings, or perceptions about some component of their job. Thus, given the effects of cannabis use in relation to the cognitive and emotional processes necessary for survey completion, there is the potential for my survey results and data to be confounded by participants' cannabis use in some way.

\section{Summary and Conclusion}

Colorado citizens voted to legalize cannabis for medical sale and use in November 2000, then again voted to legalize the recreational sale and use of cannabis with the passing of Amendment 64 in November 2012. This resulted in the birth of a rapidly-growing industry (in Colorado and now in other states) about which we know extremely little with regard to worker health, safety, and well-being. This study was the first empirical investigation of the cannabis industry of Colorado from an Occupational Health Psychology (OHP) perspective, and provided a first glimpse at the general demographics and perceptions of workers in the cannabis industry. Study results suggested the presence of various physical and psychological workplace stressors, supports, and outcomes. In comparing these results to the job-demands resources model, results generally suggest that cannabis industry workers experience relatively low strain, relatively low job demands and relatively high resources. Future research is necessary to adequately assess the appropriateness of the JDR model to this industry. Additionally, study results suggest 
heterogeneity among the cannabis industry with regard to health and safety training, awareness, and regulation. Generally speaking, this study provided a general understanding of the cannabis industry of Colorado, key health and safety concerns, and recommendations for cannabis industry organizations and workers to provide numerous supports and training to employees. This study began to answer the question "is the 'grass' greener?" but is only the first of a multitude of steps to understand what work is like for individuals in this growing, budding, and flowering industry. 
Table 1.

Demographics: Participants

\begin{tabular}{|c|c|}
\hline Variable & $\%$ \\
\hline \multicolumn{2}{|l|}{ Gender } \\
\hline Male & $57 \%$ \\
\hline Female & $42 \%$ \\
\hline Other & $1 \%$ \\
\hline \multicolumn{2}{|l|}{ Age } \\
\hline $18-25$ & $36 \%$ \\
\hline $26-30$ & $30 \%$ \\
\hline $31-35$ & $14 \%$ \\
\hline $36-40$ & $10 \%$ \\
\hline $41-45$ & $3 \%$ \\
\hline $46-50$ & $3 \%$ \\
\hline $51+$ & $4 \%$ \\
\hline \multicolumn{2}{|l|}{ Race } \\
\hline Caucasian & $76 \%$ \\
\hline Hispanic/Latino & $7 \%$ \\
\hline Black/African-American & $5 \%$ \\
\hline Native American & $5 \%$ \\
\hline Asian & $2 \%$ \\
\hline Hawaiian/Pacific Islander & $1 \%$ \\
\hline Other & $4 \%$ \\
\hline \multicolumn{2}{|l|}{ Education } \\
\hline High school or GED & $12 \%$ \\
\hline Some college & $40 \%$ \\
\hline 2-year degree & $11 \%$ \\
\hline 4-year degree & $28 \%$ \\
\hline Master's degree & $4 \%$ \\
\hline Professional degree (e.g., J.D.) & $1 \%$ \\
\hline Other & $4 \%$ \\
\hline
\end{tabular}


Table 2.

Demographics: Participants' jobs

Variable

$\%$

Payment Type

Salaried

Paid by the hour

$24 \%$

Other

$74 \%$

$2 \%$

Annual salary/income

$<\$ 25,000$

$40 \%$

$\$ 25,001-30,000$

$28 \%$

$\$ 30,001-35,000$

$12 \%$

$\$ 35,001-40,000$

$6 \%$

$\$ 40,001-45,000$

$3 \%$

$\$ 45,001-50,000$

$2 \%$

$\$ 50,001-55,000$

$1 \%$

$\$ 55,001-60,000$

$2 \%$

$\$ 60,001-65,000$

$2 \%$

$\$ 65,001-70,000$

$0 \%$

$\$ 70,001-75,000$

$1 \%$

$\$ 75,001-80,000$

$1 \%$

$>\$ 80,000$

$2 \%$

Typical work schedule

Day shift

Afternoon shift

$80 \%$

Night shift

$5 \%$

Split shift

$1 \%$

$3 \%$

Irregular shift/on-call

$4 \%$

Rotating shifts

$7 \%$

Do you have any other jobs...

...besides your main job?

Yes

$28 \%$

No

$72 \%$

...outside of the cannabis industry?

Yes

No

$74 \%$ 
Table 3.

Demographics: Participants' organizations

\begin{tabular}{|c|c|c|c|}
\hline Variable & $M$ & $S D$ & Median \\
\hline Years in operation & 4.7 & 1.3 & 5.0 \\
\hline \multirow[t]{2}{*}{ Number of employees } & 39 & 69 & 20 \\
\hline & & & $\%$ \\
\hline \multicolumn{4}{|l|}{ Type of cannabis } \\
\hline Medical only & & & $19 \%$ \\
\hline Recreational only & & & $3 \%$ \\
\hline Both medical and recreational & & & $78 \%$ \\
\hline \multicolumn{4}{|c|}{ Organization's facilities in operation - across ALL locations } \\
\hline Indoor growhouse & & & $77 \%$ \\
\hline Outdoor grow & & & $5 \%$ \\
\hline Greenhouse grow & & & $10 \%$ \\
\hline Dispensary/retail sales facility & & & $71 \%$ \\
\hline Medical & & & $20 \%$ \\
\hline Recreational & & & $4 \%$ \\
\hline Both & & & $76 \%$ \\
\hline Extractions facilities & & & $35 \%$ \\
\hline Manufacturing facilities & & & $26 \%$ \\
\hline None of the above & & & $7 \%$ \\
\hline \multicolumn{4}{|c|}{ Organization's facilities in operation - at PARTICIPANT location } \\
\hline Indoor growhouse & & & $38 \%$ \\
\hline Outdoor grow & & & $3 \%$ \\
\hline Greenhouse grow & & & $4 \%$ \\
\hline Dispensary/retail sales facility & & & $51 \%$ \\
\hline Medical & & & $17 \%$ \\
\hline Recreational & & & $11 \%$ \\
\hline Both & & & $72 \%$ \\
\hline Extractions facilities & & & $9 \%$ \\
\hline Manufacturing facilities & & & $11 \%$ \\
\hline None of the above & & & $9 \%$ \\
\hline
\end{tabular}


Table 4.

Demographics: Participants' cannabis use

\begin{tabular}{|c|c|c|c|}
\hline Variable & & & $\%$ \\
\hline Registered Medical MJ Card holder & & & $66 \%$ \\
\hline \multicolumn{4}{|l|}{ How long have you been a member of the registry? } \\
\hline Less than one year & & & $29 \%$ \\
\hline $1-2$ years & & & $29 \%$ \\
\hline $2-4$ years & & & $20 \%$ \\
\hline 4-7 years & & & $21 \%$ \\
\hline $7-10$ years & & & $0 \%$ \\
\hline $10+$ years & & & $1 \%$ \\
\hline \multicolumn{4}{|l|}{ How long ago did you first try cannabis? } \\
\hline N/A (Never tried) & & & $2 \%$ \\
\hline Less than one year & & & $1 \%$ \\
\hline $1-2$ years & & & $2 \%$ \\
\hline $2-4$ years & & & $3 \%$ \\
\hline 4-7 years & & & $14 \%$ \\
\hline $7-10$ years & & & $18 \%$ \\
\hline $10+$ years & & & $60 \%$ \\
\hline \multicolumn{4}{|l|}{ Frequency of current cannabis use (in any form) } \\
\hline Less than monthly (1-11 times/year) & & & $3 \%$ \\
\hline Less than weekly (1-3 times/month) & & & $1 \%$ \\
\hline Once a week & & & $1 \%$ \\
\hline A couple (1-2) times a week & & & $5 \%$ \\
\hline A few (3-6) times a week & & & $7 \%$ \\
\hline Daily & & & $21 \%$ \\
\hline 2-4 times a day & & & $28 \%$ \\
\hline More than 4 times a day & & & $29 \%$ \\
\hline N/A (Don’t use) & & & $5 \%$ \\
\hline Do you ever use cannabis while driving in your... & & Work time? & Personal time? \\
\hline Yes & & $21 \%$ & $43 \%$ \\
\hline No & & $79 \%$ & $57 \%$ \\
\hline Frequency of cannabis use... & Before work & During work & After work \\
\hline Never & $37 \%$ & $55 \%$ & $8 \%$ \\
\hline Less than monthly & $6 \%$ & $4 \%$ & $4 \%$ \\
\hline 1 to 3 days per month & $7 \%$ & $11 \%$ & $3 \%$ \\
\hline 1 to 2 days per week & $9 \%$ & $5 \%$ & $11 \%$ \\
\hline 3 to 5 days per week & $17 \%$ & $10 \%$ & $21 \%$ \\
\hline 6 to 7 days per week & $23 \%$ & $14 \%$ & $53 \%$ \\
\hline
\end{tabular}


Table 5.

Descriptive statistics for all study variables

\begin{tabular}{lccc}
\hline & $M$ & $S D$ & $\mathrm{~N}$ \\
\hline Stigma - Family & 2.070 & .933 & 201 \\
Stigma - Friends & 1.519 & .675 & 201 \\
Stigma - Society & 2.906 & .898 & 201 \\
Job Insecurity & 1.653 & .715 & 201 \\
Role Ambiguity & 1.536 & .661 & 201 \\
Job Satisfaction & 4.400 & .733 & 211 \\
Turnover Intentions & 2.228 & 1.134 & 211 \\
Affective Organizational Commitment & 4.216 & .845 & 211 \\
Burnout & 2.364 & .912 & 211 \\
Job Control & 3.654 & .873 & 189 \\
Perceived Organizational Support & 3.925 & .987 & 189 \\
Meaningfulness in Work & 4.247 & .749 & 189 \\
Perceived Employability & 3.987 & .736 & 189 \\
Number of hours worked - in typical weeks & 39.19 & 9.17 & 200 \\
Number of hours worked - in busy weeks & 44.58 & 11.15 & 200 \\
\hline
\end{tabular}

Note. Participants responded to all measures using a 1-5 Likert scale (except for hours worked in typical or busy weeks). 
Table 6

Correlations for all study variables

\begin{tabular}{|c|c|c|c|c|c|c|c|c|c|}
\hline & 1 & 2 & 3 & 4 & 5 & 6 & 7 & 8 & 9 \\
\hline 1. Stigma - Family & 1 & & & & & & & & \\
\hline 2. Stigma - Friends & $.410^{* *}$ & 1 & & & & & & & \\
\hline 3. Stigma - Society & $.430^{* *}$ & $.331^{* *}$ & 1 & & & & & & \\
\hline 4. Job Insecurity & $.256^{* *}$ & $.318^{* *}$ & $.216^{* *}$ & 1 & & & & & \\
\hline 5. Role Ambiguity & $.228^{* *}$ & $.324^{* *}$ & $.173^{*}$ & $.393^{* *}$ & 1 & & & & \\
\hline 6. LWH - Typical & .033 & -.041 & .046 & $.188^{* *}$ & .135 & 1 & & & \\
\hline 7. LWH - Busy & .098 & -.047 & .091 & .138 & .133 & $.567^{* *}$ & 1 & & \\
\hline 8. Turnover Intentions & $.205^{* *}$ & $.318^{* *}$ & $.280^{* *}$ & $.341^{* *}$ & $.201^{* *}$ & .135 & .091 & 1 & \\
\hline 9. Burnout & $.291^{* *}$ & $.261^{* *}$ & $.301^{* *}$ & $.425^{* *}$ & $.298^{* * *}$ & $.292^{* *}$ & $.295^{* *}$ & $.611^{* *}$ & 1 \\
\hline 10. Job Satisfaction & $-.173^{*}$ & $-.308^{* *}$ & $-.198^{* *}$ & $-.482^{* *}$ & $-.325^{* *}$ & $-.195^{* *}$ & $-.198^{* *}$ & $-.667^{* *}$ & $-.609^{* *}$ \\
\hline 11. Affective Org. Comm. & -.112 & $-.260^{* *}$ & -.138 & $-.402^{* *}$ & $-.241^{* *}$ & -.010 & -.005 & $-.571^{* *}$ & $-.399^{* *}$ \\
\hline 12. Perceived Org. Support & $-.172^{*}$ & $-.283^{* *}$ & $-.300^{* *}$ & $-.421^{* *}$ & $-.270^{* *}$ & -.105 & -.055 & $-.599^{* *}$ & $-.567^{* *}$ \\
\hline 13. Meaningfulness in Work & $-.249^{* *}$ & $-.333^{* *}$ & $-.279^{* *}$ & $-.355^{* *}$ & $-.234^{* *}$ & .010 & .066 & $-.603^{* *}$ & $-.354^{* *}$ \\
\hline 14. Employability & -.049 & $-.219^{* *}$ & $-.168^{*}$ & $-.217^{* *}$ & $-.236^{* *}$ & .054 & .098 & -.048 & .036 \\
\hline
\end{tabular}

Note. $\mathrm{N}=190-212$; LWH - Typical = long working hours in typical weeks; LWH - Busy = long working hours in busy weeks; Affective Org. Comm. = affective organizational commitment; Perceived Org. Support = perceived organizational support.

$* p<.05$, two-tailed; ** $p<.01$, two-tailed 
Table 6 (cont'd)

Correlations for All Study Variables

\begin{tabular}{lccccc}
\hline & 10 & 11 & 12 & 13 & 14 \\
\hline 10. Job Satisfaction & 1 & & & & \\
11. Affective Org. Comm. & $.668^{* *}$ & 1 & & & \\
12. Perceived Org. Support & $.592^{* *}$ & $.555^{* *}$ & 1 & & \\
13. Meaningfulness in Work & $.562^{* *}$ & $.613^{* *}$ & $.501^{* *}$ & 1 & \\
14. Employability & .092 & $.237^{* *}$ & .137 & $.309^{* *}$ & 1 \\
\hline
\end{tabular}

Note. $\mathrm{N}=190$ - 212; Affective Org. Comm. = affective organizational commitment; Perceived

Org. Support $=$ perceived organizational support.

$* p<.05$, two-tailed; $* * p<.01$, two-tailed 
Table 7.

Hypothesis 7a: Hierarchical regression analyses predicting job satisfaction with perceived stigma (friends) and with job control as a buffer

\begin{tabular}{lccccccc}
\hline \multicolumn{1}{c}{ Variable } & $B$ & $\beta$ & $R^{2}$ & $\Delta R^{2}$ & Adjusted $R^{2}$ & $\Delta F$ & $d f$ \\
\hline Step 1 & & & .107 & .102 & $22.376^{* * *}$ & 187 \\
Stigma - Friends & $-.348^{* * *}$ & $-.327 * * *$ & & & & & \\
Step 2 & & & .185 & .078 & .177 & $17.903 * * *$ & 186 \\
Stigma - Friends & $-.310^{* * *}$ & $-.291 * * *$ & & & & & \\
Job Control & $.236^{* * *}$ & $.282^{* * *}$ & & & & & \\
Step 3 & & & .205 & .020 & .192 & $4.624 *$ & 185 \\
Stigma - Friends & $-.313^{* * *}$ & $-.294 * * *$ & & & & & \\
Job Control & $.239 * * *$ & $.286^{* * *}$ & & & & & \\
Stigma - Friends x Job & $.201 * *$ & $.141^{* * *}$ & & & & & \\
Control & & & & & & & \\
\hline
\end{tabular}

$* p<.05 ; * * p<.01 ; * * * p<.001$ 
Table 8.

Hypothesis 7 : Hierarchical regression analyses predicting job satisfaction with long working hours (busy weeks) and with job control as a buffer

\begin{tabular}{lccccccc}
\hline \multicolumn{1}{c}{ Variable } & $B$ & $\beta$ & $R^{2}$ & $\Delta R^{2}$ & Adjusted $R^{2}$ & $\Delta F$ & $d f$ \\
\hline Step 1 & & & .037 & .031 & $7.074 * *$ & 186 \\
LWH-Busy & $-.280^{* * *}$ & $-.191^{* *}$ & & & & & \\
Step 2 & & & .160 & .124 & .151 & $27.292^{* * *}$ & 185 \\
LWH-Busy & $-.359 * * *$ & $-.246^{* * *}$ & & & & & \\
Job Control & $.297^{* * *}$ & $.356^{* * *}$ & & & & & \\
Step 3 & & & .181 & .020 & .167 & $4.543^{*}$ & 184 \\
LWH-Busy & $-.348^{* *}$ & $-.238^{* *}$ & & & & & \\
Job Control & .142 & .171 & & & & & \\
LWH-Busy x Job & $.247^{*}$ & $.233^{*}$ & & & & & \\
Control & & & & & & \\
\hline
\end{tabular}

Note. LWH-Busy = long working hours (busy weeks).

$* p<.05 ; * * p<.01 ; * * * p<.001$ 
Table 9.

Hypothesis 7i: Hierarchical regression analyses predicting turnover intentions with long working hours (busy weeks) and with job control as a buffer

\begin{tabular}{lccccccc}
\hline \multicolumn{1}{c}{ Variable } & $B$ & $\beta$ & $R^{2}$ & $\Delta R^{2}$ & Adjusted $R^{2}$ & $\Delta F$ & $d f$ \\
\hline Step 1 & & & .007 & - & .001 & 1.267 & 186 \\
LWH-Busy & .185 & .082 & & & & & \\
Step 2 & & & .087 & .080 & .077 & $16.285^{* * * *}$ & 185 \\
LWH-Busy & .283 & .126 & & & & & \\
Job Control & $-.367 * * *$ & $-.287^{* * *}$ & & & & & \\
Step 3 & & & .117 & .030 & .102 & $6.164 *$ & 184 \\
LWH-Busy & .261 & .116 & & & & & \\
Job Control & -.081 & -.063 & & & & & \\
LWH-Busy x Job & $-.460 * * *$ & $-.381 * * *$ & & & & & \\
Control & & & & & & & \\
\hline
\end{tabular}

Note. LWH-Busy = long working hours (busy weeks).

$* p<.05 ; * * p<.01 ; * * * p<.001$ 
Table 10.

Hypothesis 7j: Hierarchical regression analyses predicting affective organizational commitment with long working hours (busy weeks) and with job control as a buffer

\begin{tabular}{lccccccc}
\hline \multicolumn{1}{c}{ Variable } & $B$ & $\beta$ & $R^{2}$ & $\Delta R^{2}$ & Adjusted $R^{2}$ & $\Delta F$ & $d f$ \\
\hline Step 1 & & & .000 & - & -.005 & .005 & 186 \\
LWH-Busy & .009 & .005 & & & & & \\
Step 2 & & & .173 & .173 & .164 & $38.760^{* * *}$ & 185 \\
LWH-Busy & -.101 & -.059 & & & & & \\
Job Control & $.411^{* * *}$ & $.421^{* * *}$ & & & & & \\
Step 3 & & & .208 & .034 & .195 & $8.00^{* * *}$ & 184 \\
LWH-Busy & -.083 & -.048 & & & & & \\
Job Control & .175 & .180 & & & & & \\
LWH-B x JC & $.378^{* *}$ & $.303^{* *}$ & & & & & \\
\hline
\end{tabular}

Note. LWH-Busy = long working hours (busy weeks); JC = job control.

$* p<.05 ; * * p<.01 ; * * * p<.001$ 
Table 11.

Hypothesis 8a: Hierarchical regression analyses predicting job satisfaction with perceived stigma (friends) and with perceived organizational support as a buffer.

\begin{tabular}{lccccccc}
\hline \multicolumn{1}{c}{ Variable } & $B$ & $\beta$ & $R^{2}$ & $\Delta R^{2}$ & Adjusted $R^{2}$ & $\Delta F$ & $d f$ \\
\hline $\begin{array}{l}\text { Step 1 } \\
\text { Stigma - Friends }\end{array}$ & $-.348^{* * *}$ & $-.327^{* * *}$ & .107 & - & .102 & $22.376^{* * *}$ & 187 \\
Step 2 & & & .378 & .272 & .372 & $81.256^{* * *}$ & 186 \\
Stigma - Friends & $-.184^{* *}$ & $-.173^{* *}$ & & & & & \\
POS & $.402^{* * *}$ & $.543^{* * *}$ & & & & & \\
Step 3 & & & .398 & .020 & .388 & $6.088^{*}$ & 185 \\
Stigma - Friends & $-.148^{*}$ & $-.139^{*}$ & & & & & \\
POS & $.398^{* * *}$ & $.537^{* * *}$ & & & & & \\
Stigma - Friends x & $.129 *$ & $.145^{*}$ & & & & & \\
POS & & & & & & \\
\hline
\end{tabular}

Note. POS = perceived organizational support.

$* p<.05 ; * * p<.01 ; * * * p<.001$ 
Table 12.

Hypothesis 8h: Hierarchical regression analyses predicting job satisfaction with long working hours (busy weeks) and with perceived organizational support as a buffer.

\begin{tabular}{lccccccc}
\hline \multicolumn{1}{c}{ Variable } & $B$ & $\beta$ & $R^{2}$ & $\Delta R^{2}$ & Adjusted $R^{2}$ & $\Delta F$ & $d f$ \\
\hline Step 1 & & & .037 & - & .031 & $7.074 * *$ & 186 \\
LWH-Busy & $-.280^{* *}$ & $-.191 * *$ & & & & & \\
Step 2 & & & .381 & .344 & .374 & $102.783 * * *$ & 185 \\
LWH-Busy & $-.232 * *$ & $-.159 * *$ & & & & & \\
POS & $.433^{* * *}$ & $.587 * * *$ & & & & & \\
Step 3 & & & .397 & .016 & .387 & & \\
LWH-Busy & $-.236^{* *}$ & $-.162^{* *}$ & & & & & \\
POS & $.318^{* * *}$ & $.432^{* * *}$ & & & & & \\
LWH-Busy x & $.193 *$ & $.201 *$ & & & & & \\
POS & & & & & & \\
\hline
\end{tabular}

Note. LWH-Busy = long working hours (busy weeks); POS = perceived organizational support.

$* p<.05 ; * * p<.01 ; * * * p<.001$ 
Table 13.

Hypothesis 9c: Hierarchical regression analyses predicting job satisfaction with job insecurity and with meaningful work as a buffer.

\begin{tabular}{lccccccc}
\hline \multicolumn{1}{c}{ Variable } & $B$ & $\beta$ & $R^{2}$ & $\Delta R^{2}$ & Adjusted $R^{2}$ & $\Delta F$ & $d f$ \\
\hline Step 1 & & & .252 & - & .248 & $62.954 * * *$ & 187 \\
Job Insecurity & $-.503 * * *$ & $-.502 * * *$ & & & & & \\
Step 2 & & & .421 & .169 & .414 & $54.214 * * *$ & 186 \\
Job Insecurity & $-.346 * * *$ & $-.346^{* * *}$ & & & & & \\
MW & $.429 * * *$ & $.439 * * *$ & & & & & \\
Step 3 & & & .440 & .019 & .431 & $6.407 *$ & \\
Job Insecurity & $-.296 * * *$ & $-.296 * *$ & & & & & \\
MW & $.424 * * *$ & $.434 * * *$ & & & & & \\
JI x MW & $.174 *$ & $.149 *$ & & & & & \\
\hline
\end{tabular}

Note. $\mathrm{JI}=$ job insecurity; $\mathrm{MW}=$ meaningful work.

$* p<.05 ; * * p<.01 ; * * * p<.001$ 
Table 14.

Hypothesis $9 e$ : Hierarchical regression analyses predicting job satisfaction with role ambiguity and with meaningful work as a buffer.

\begin{tabular}{lccccccc}
\hline \multicolumn{1}{c}{ Variable } & \multicolumn{1}{c}{$B$} & $\beta$ & $R^{2}$ & $\Delta R^{2}$ & Adjusted $R^{2}$ & $\Delta F$ & $d f$ \\
\hline Step 1 & & & .127 & - & .123 & $27.304 * * *$ & 187 \\
Role Ambiguity & $-.394^{* * *}$ & $-.357^{* * *}$ & & & & & \\
Step 2 & & & .370 & .242 & .363 & $71.554^{* * *}$ & 186 \\
Role Ambiguity & $-.263^{* * *}$ & $-.239^{* * *}$ & & & & & \\
MW & $.494^{* * *}$ & $.506^{* * *}$ & & & & & \\
Step 3 & & & .383 & .014 & .373 & $4.079 *$ & 185 \\
Role Ambiguity & $-.235^{* *}$ & $-.213^{* *}$ & & & & & \\
MW & $.491^{* * *}$ & $.503^{* * *}$ & & & & & \\
RA x MW & $.158^{*}$ & $.119^{*}$ & & & & & \\
\hline
\end{tabular}

Note. $\mathrm{RA}=$ role ambiguity; $\mathrm{MW}=$ meaningful work.

$* p<.05 ; * * p<.01 ; * * * p<.001$ 
Table 15.

Hypothesis 9h: Hierarchical regression analyses predicting job satisfaction with long working hours (typical or busy weeks) and with meaningful work as a buffer.

\begin{tabular}{|c|c|c|c|c|c|c|c|}
\hline Variable & $B$ & $\beta$ & $R^{2}$ & $\Delta R^{2}$ & Adjusted $R^{2}$ & $\Delta F$ & $d f$ \\
\hline Step 1 & & & .056 & - & .051 & $11.020 * *$ & 186 \\
\hline LWH-Typical & $-.378 * *$ & $-.237 * *$ & & & & & \\
\hline Step 2 & & & .384 & .328 & .377 & $98.511 * * *$ & 185 \\
\hline LWH-Typical & $-.388 * * *$ & $-.242 * * *$ & & & & & \\
\hline MW & $.556 * * *$ & $.573 * * *$ & & & & & \\
\hline Step 3 & & & .415 & .031 & .405 & $9.647 * *$ & 184 \\
\hline LWH-Typical & $-.390 * * *$ & $-.244 * * *$ & & & & & \\
\hline MW & $.438 * * *$ & $.451 * * *$ & & & & & \\
\hline LWH-T x MW & $.363 * *$ & $.213 * *$ & & & & & \\
\hline Step 1 & & & .037 & - & .031 & $7.074 * *$ & 186 \\
\hline LWH-Busy & $-.280 * *$ & $-.191 * *$ & & & & & \\
\hline Step 2 & & & .378 & .341 & .371 & $101.046^{* * *}$ & 185 \\
\hline LWH-Busy & $-.336 * * *$ & $-.230 * * *$ & & & & & \\
\hline MW & $.568 * * *$ & $.585 * * *$ & & & & & \\
\hline Step 3 & & & .394 & .016 & .384 & $4.942 *$ & 184 \\
\hline LWH-Busy & $-.333 * * *$ & $-.228 * * *$ & & & & & \\
\hline MW & $.430 * * *$ & $.443 * * *$ & & & & & \\
\hline LWH-B x MW & $.250 *$ & $.191 *$ & & & & & \\
\hline
\end{tabular}

Note . LWH-Typical = long working hours (typical weeks); LWH-Busy = long working hours (busy weeks); MW = meaningful work.

$* p<.05 ; * * p<.01 ; * * * p<.001$ 


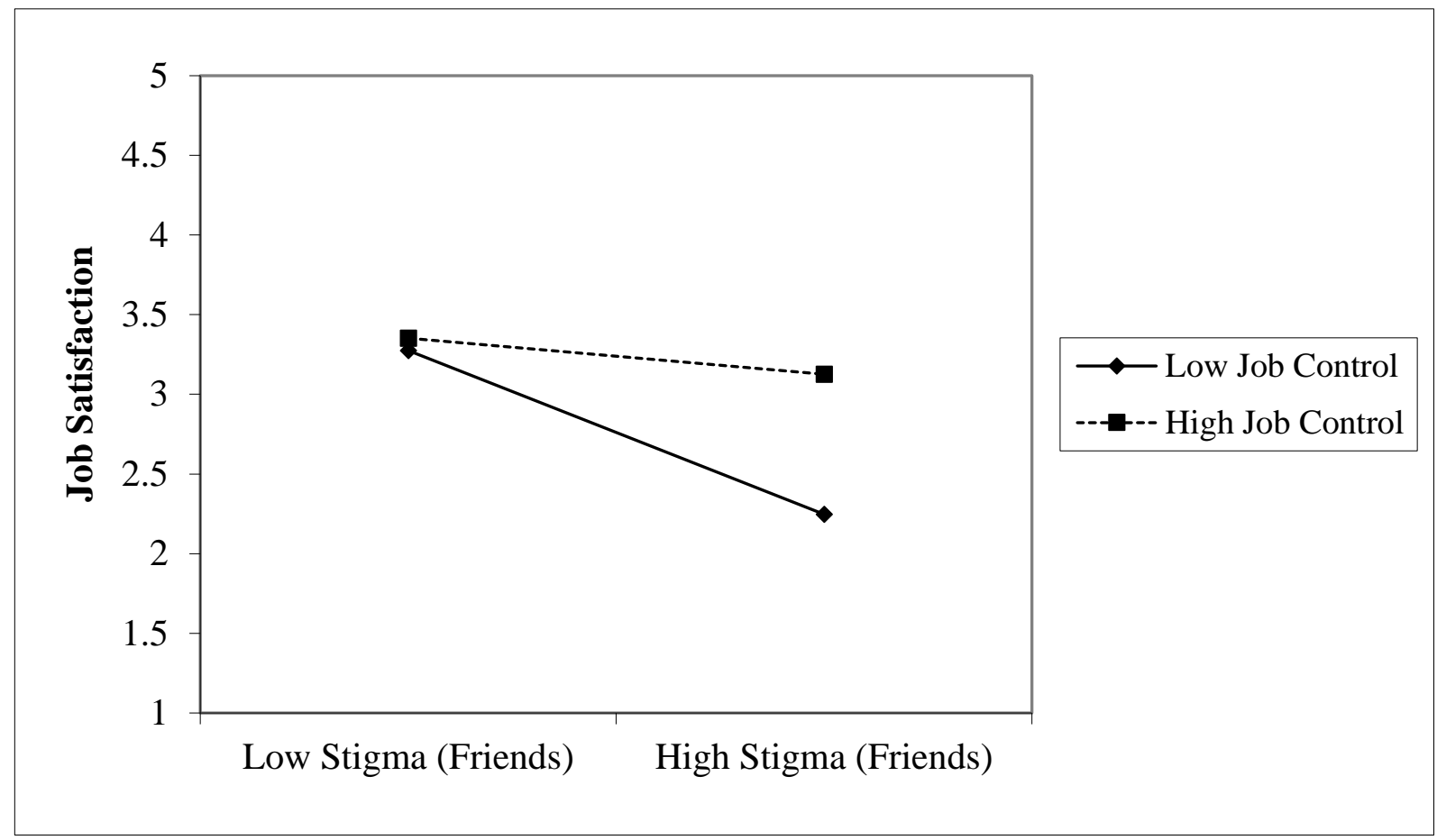

Figure 1. Hypothesis 7a: The significant buffering effect of job control on the relationship between stigma perceptions (friends) and job satisfaction. 


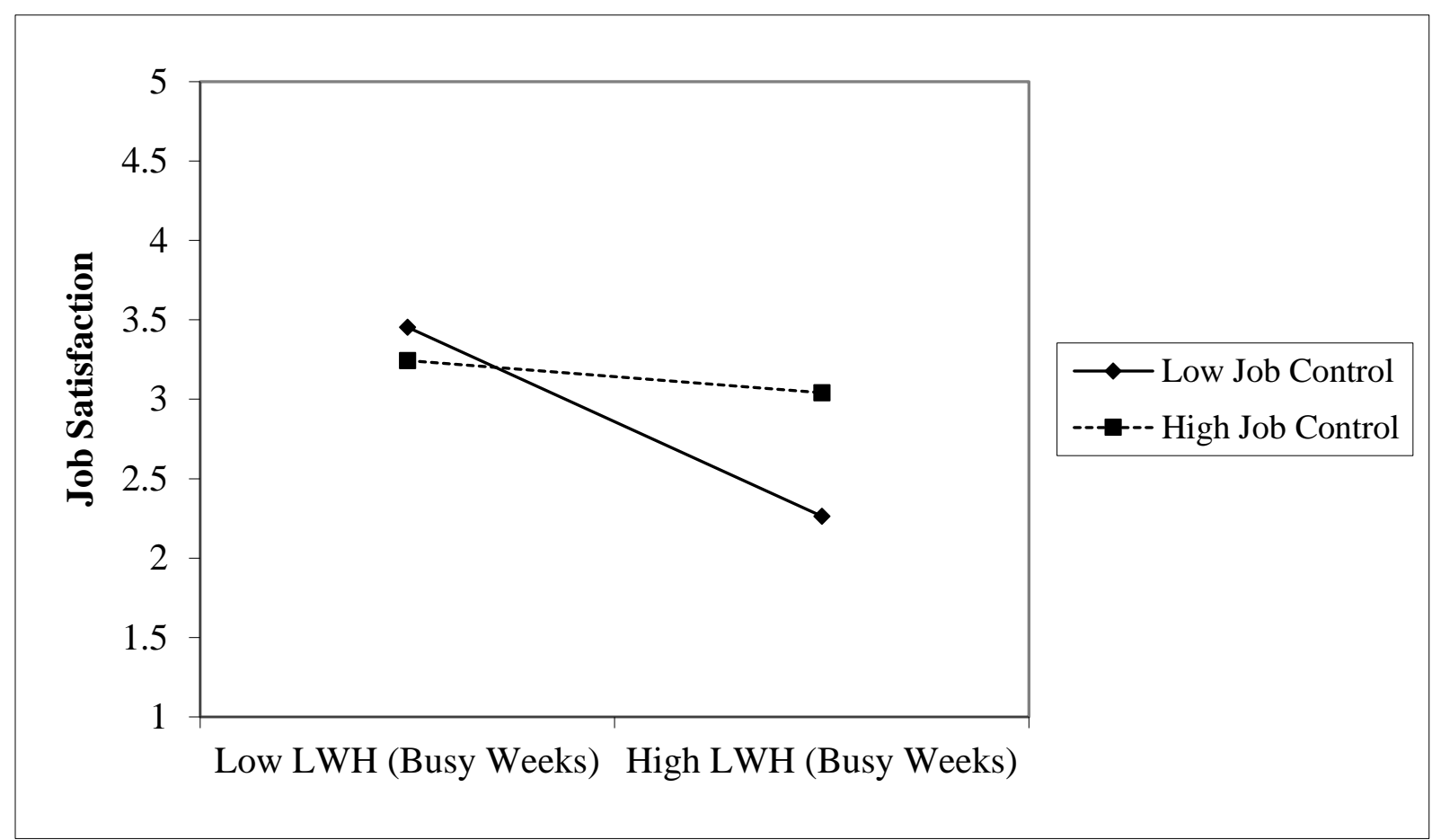

Figure 2. Hypothesis 7h: The significant buffering effect of job control on the relationship between long working hours (busy weeks) and job satisfaction. 


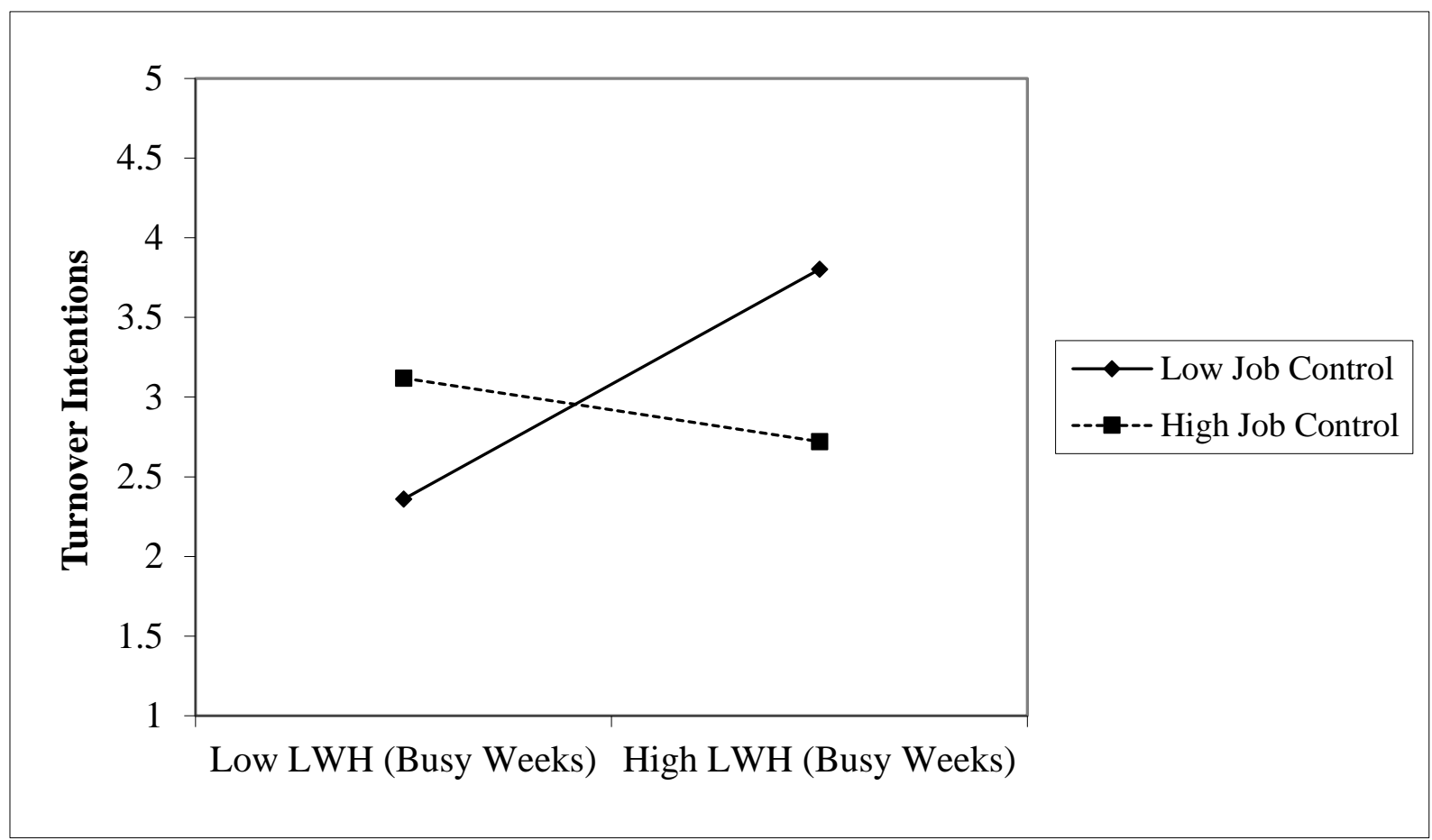

Figure 3. Hypothesis 7i: The significant buffering effect of job control on the relationship between long working hours (busy weeks) and turnover intentions. 


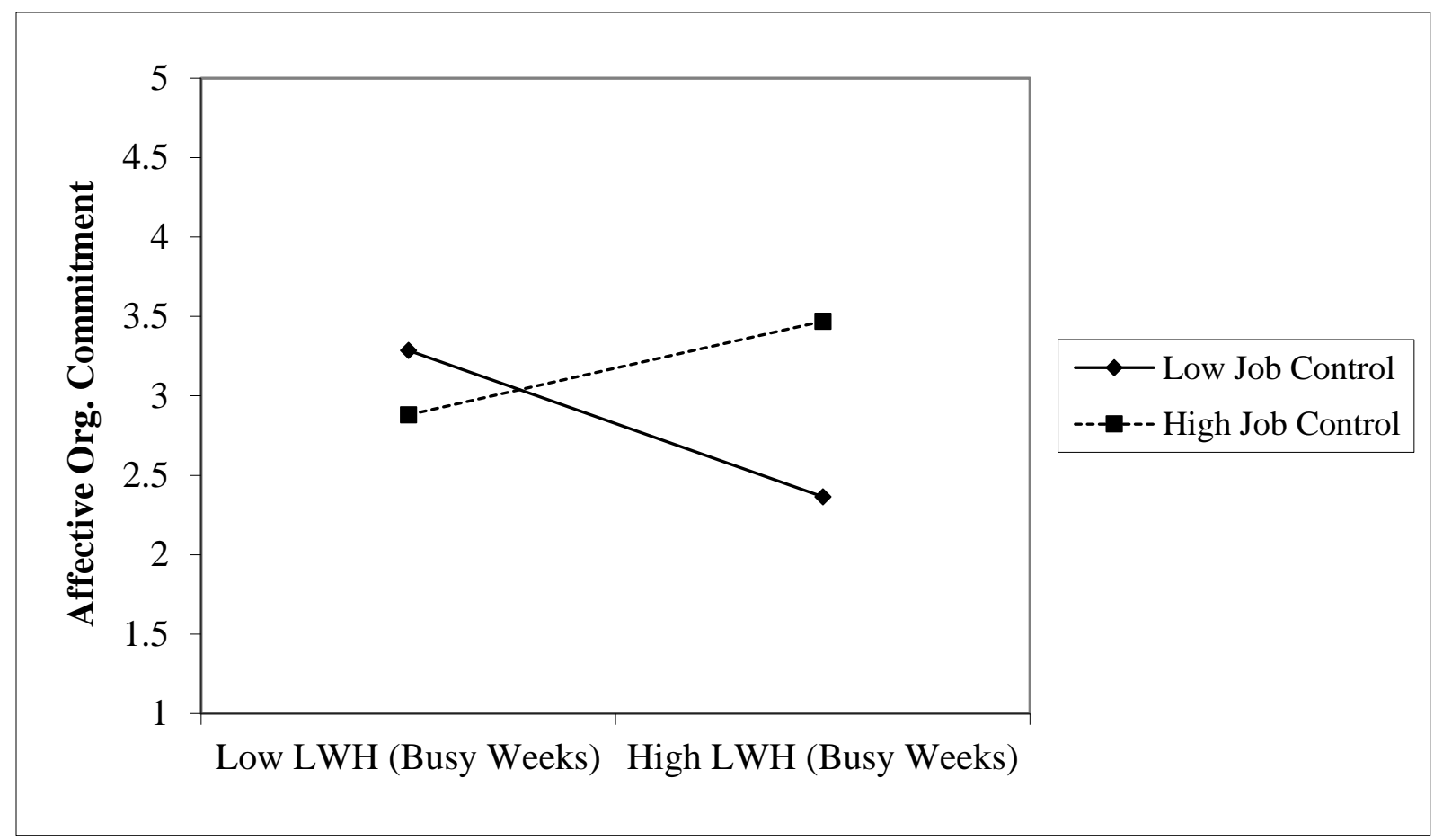

Figure 4. Hypothesis 7j: The significant buffering effect of job control on the relationship between long working hours (busy weeks) and affective organizational commitment. 


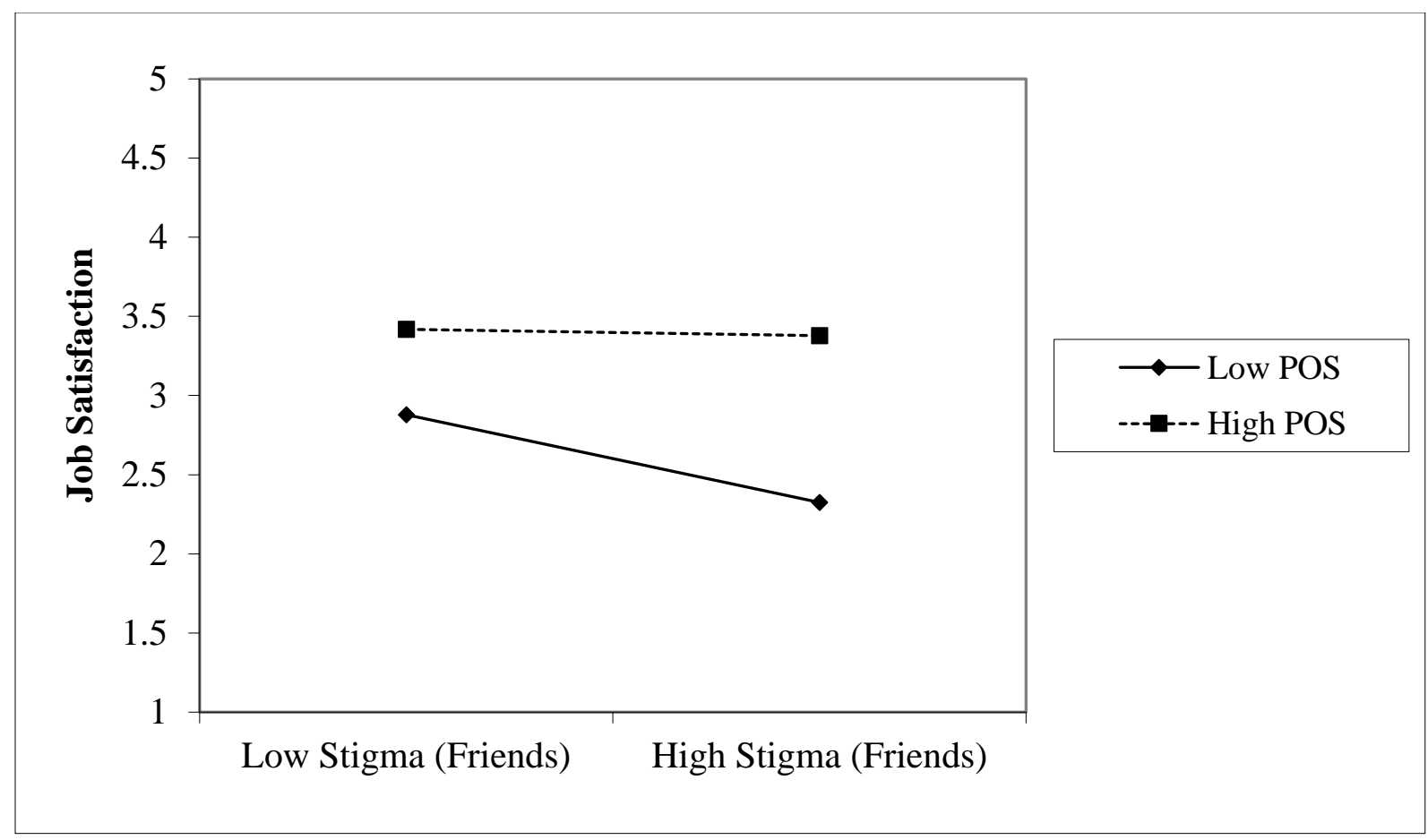

Figure 5. Hypothesis 8a: The significant buffering effect of perceived organizational support (POS) on the relationship between stigma perceptions (friends) and job satisfaction. 


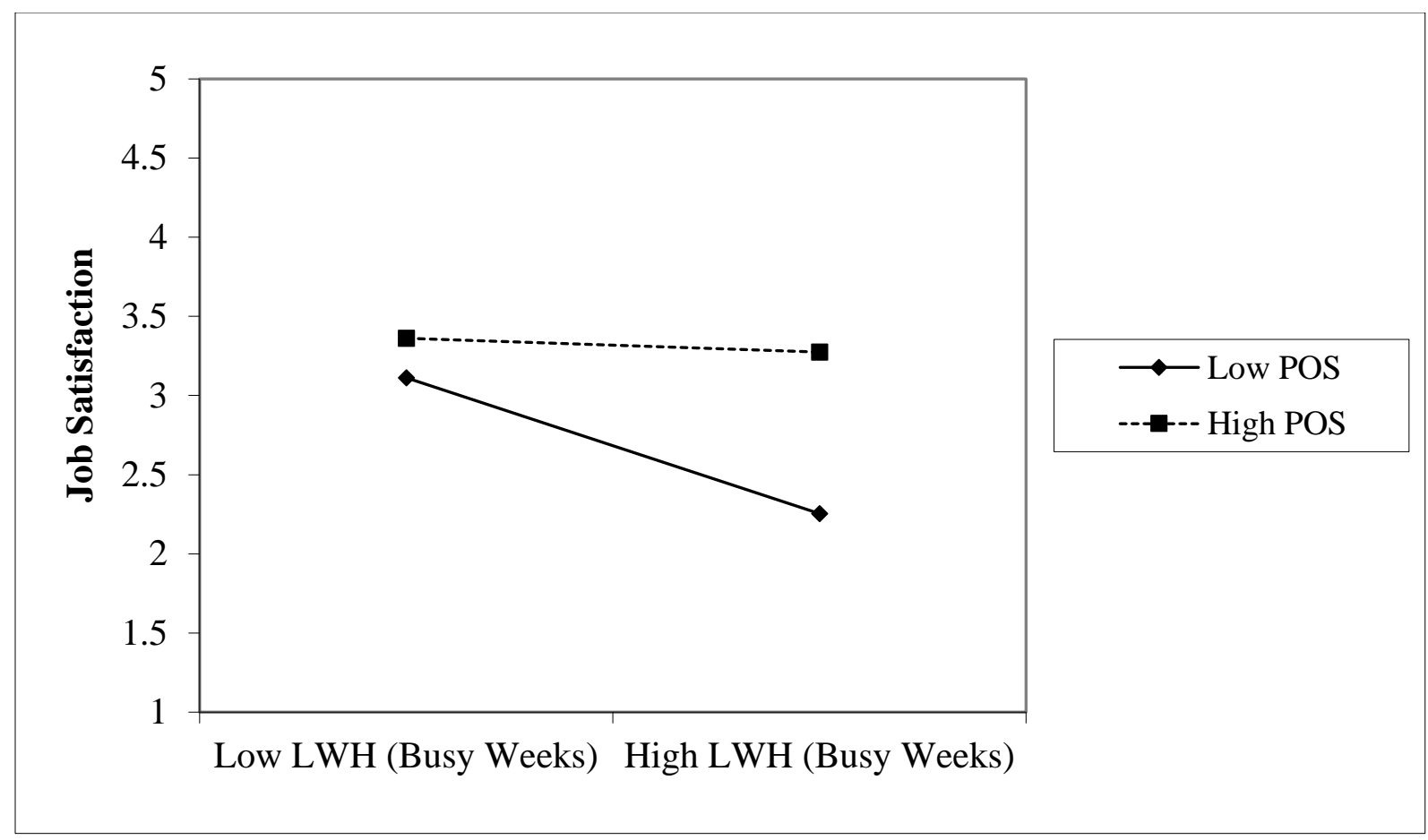

Figure 6. Hypothesis $8 \mathrm{~h}$ : The significant buffering effect of perceived organizational support (POS) on the relationship between long working hours (busy weeks) and job satisfaction. 


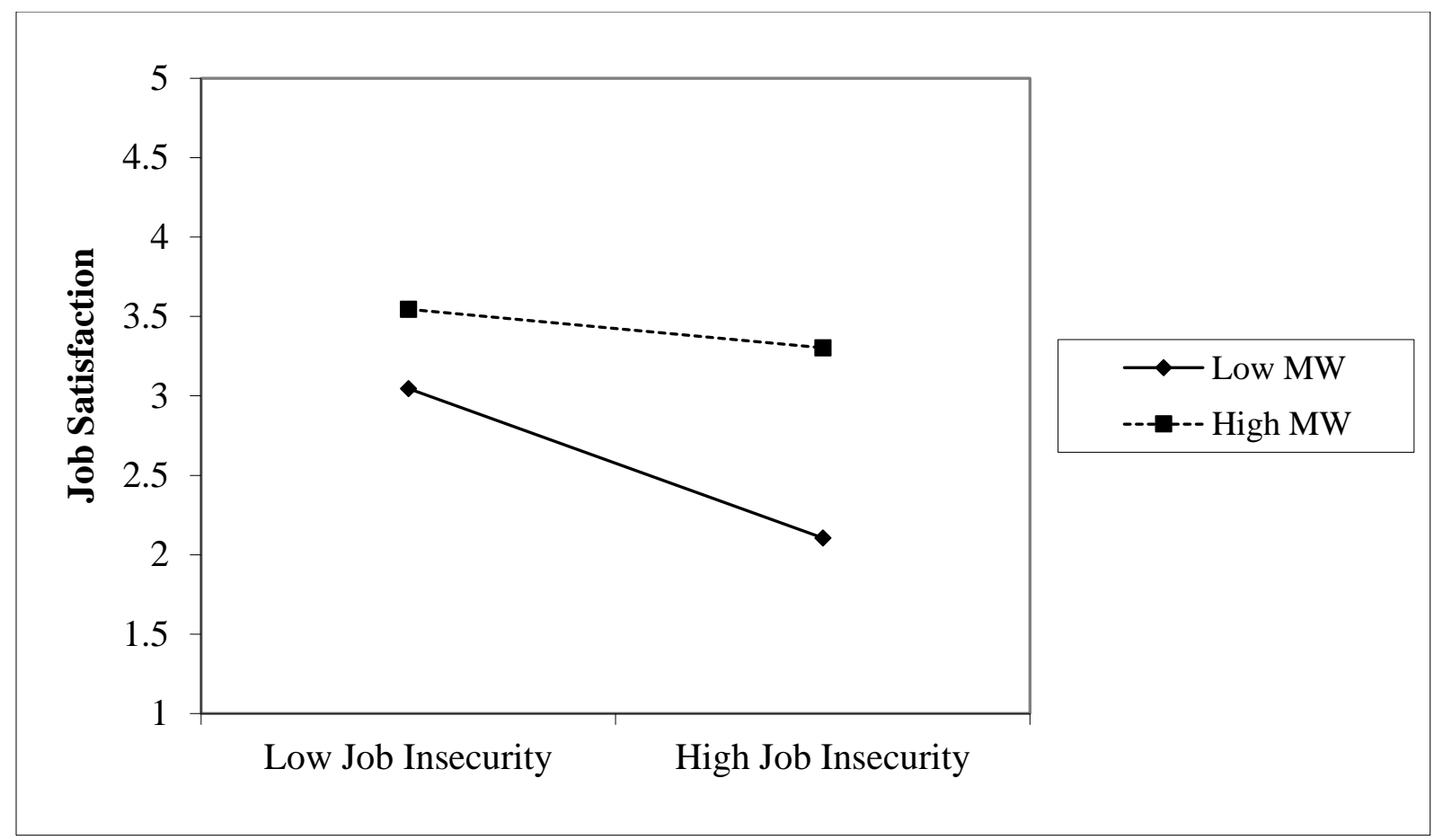

Figure 7. Hypothesis 9c: The significant buffering effect of meaningful work (MW) on the relationship between job insecurity and job satisfaction. 


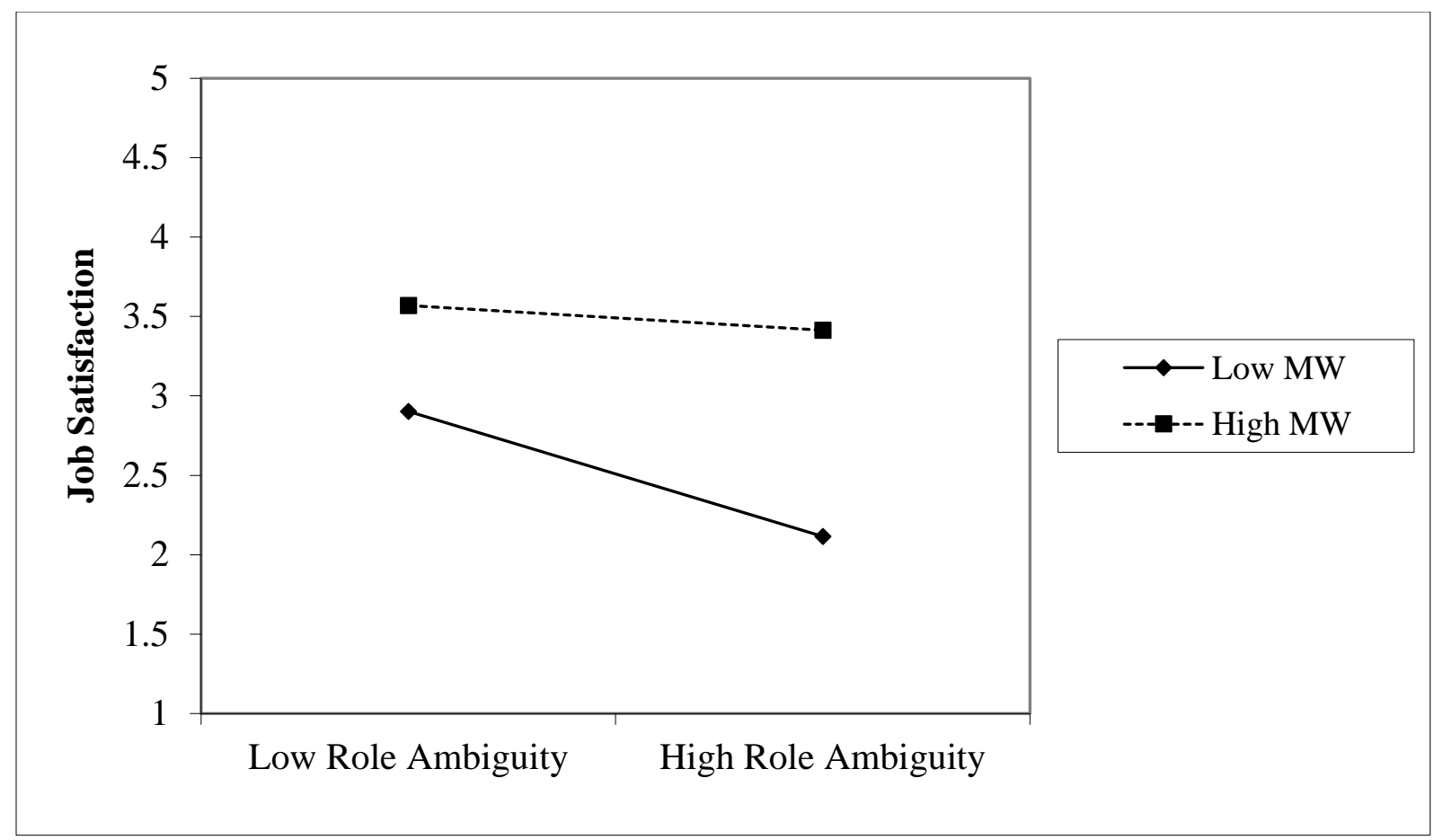

Figure 8. Hypothesis 9e: The significant buffering effect of meaningful work (MW) on the relationship between role ambiguity and job satisfaction. 


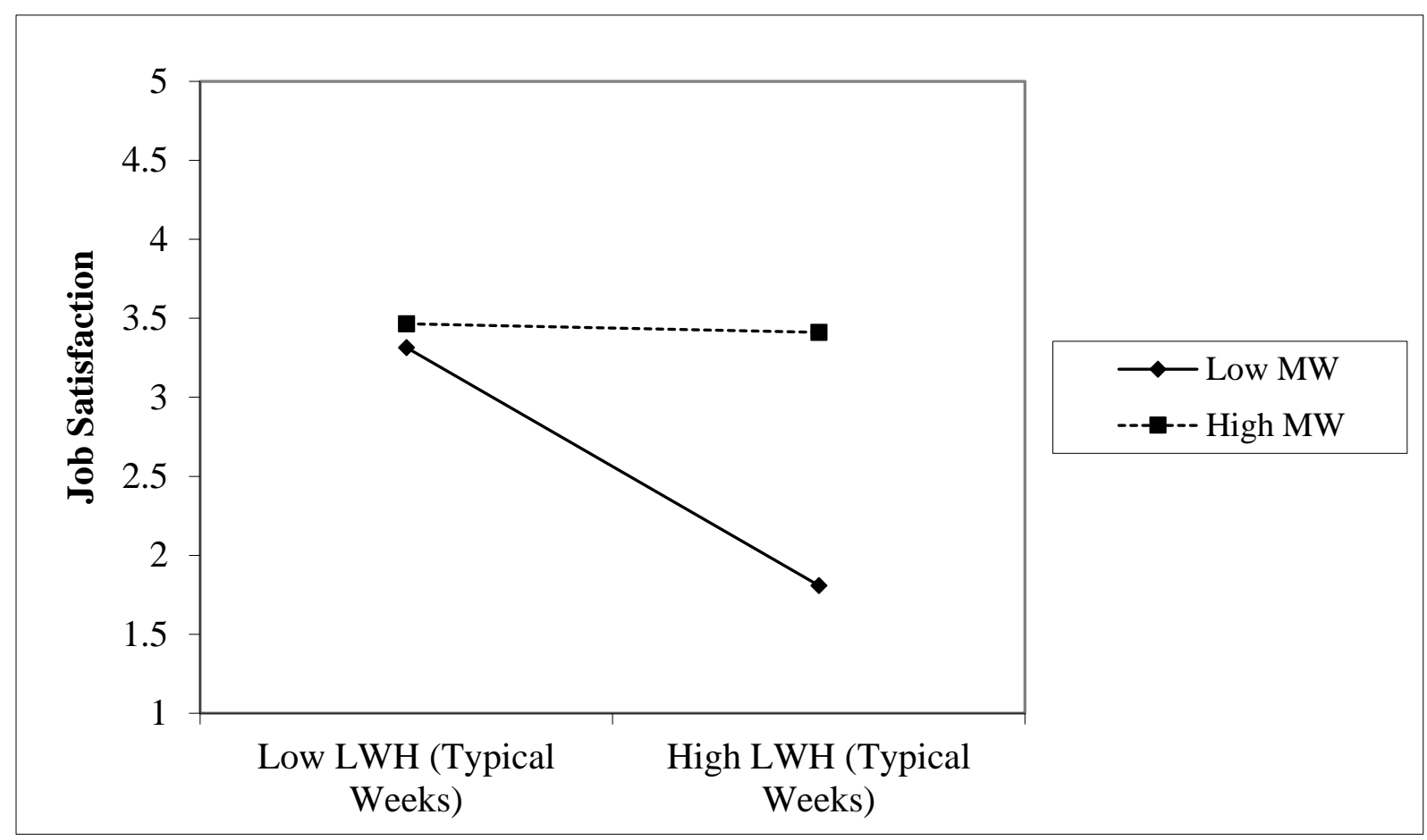

Figure 9. Hypothesis 9h-Typical Weeks: The significant buffering effect of meaningful work (MW) on the relationship between long working hours (typical weeks) and job satisfaction. 


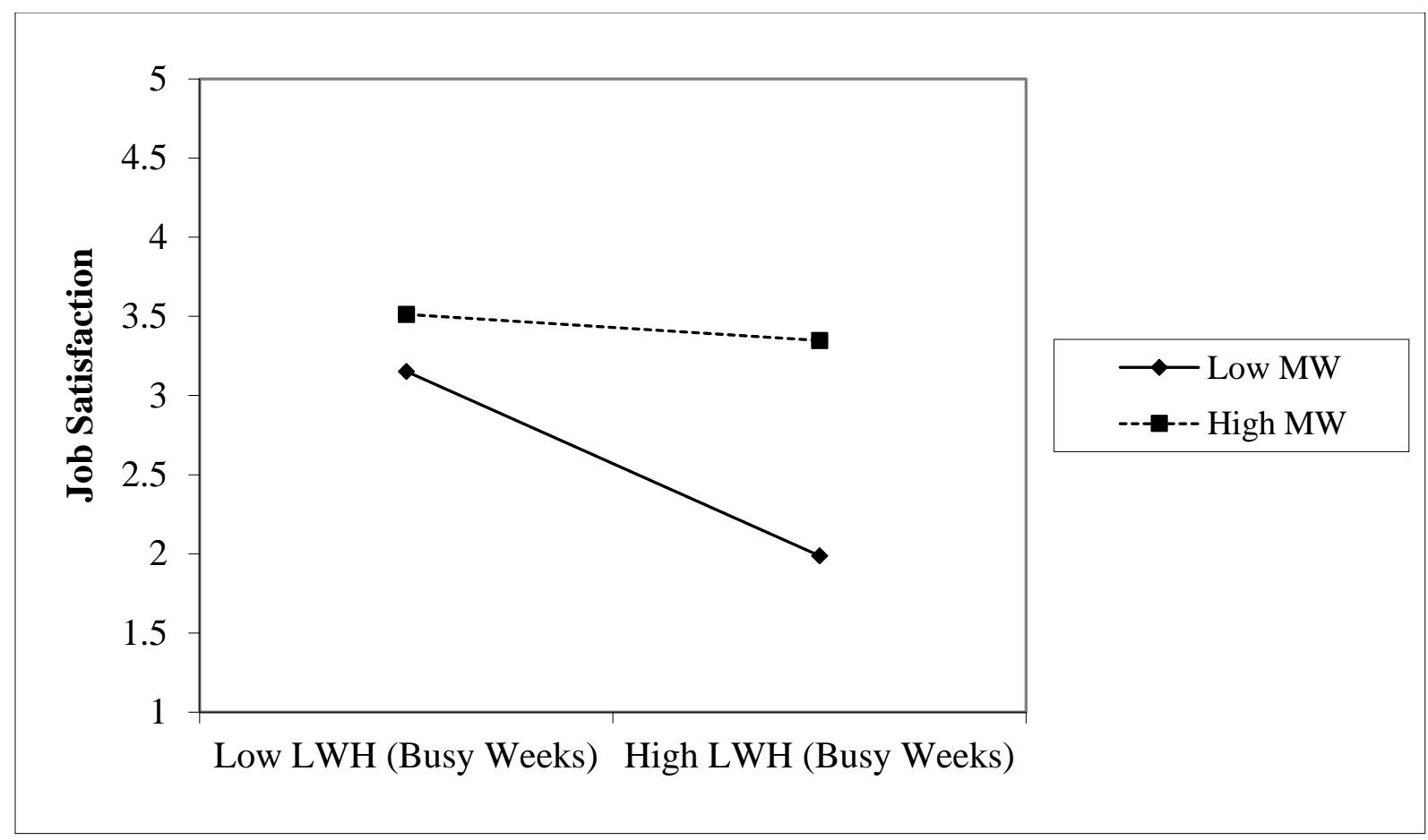

Figure 10. Hypothesis 9h - Busy Weeks: The significant buffering effect of meaningful work (MW) on the relationship between long working hours (busy weeks) and job satisfaction. 


\section{References}

Abramis, D. J. (1994). Work role ambiguity, job satisfaction, and job performance: Metaanalyses and review. Psychological Reports, 75, 1411-1433.

doi:10.2466/pr0.1994.75.3f.1411

Adkins, J. A. (1999). Promoting organizational health: The evolving practice of occupational health psychology. Professional Psychology: Research and Practice, 30, 129-137. doi:10.1037/0735-7028.30.2.129

Aguinis, H., Gottfredson, R. K., \& Joo, H. (2013). Best-practice recommendations for defining, identifying, and handling outliers. Organizational Research Methods, 16, 270-301. doi:10.1177/1094428112470848

Allen, N. J., \& Meyer, J. P. (1990). The measurement and antecedents of affective, continuance and normative commitment to the organization. Journal of Occupational Psychology, 63, 1-18. doi: 10.1111/j.2044-8325.1990.tb00506.x

Arcury, T. A., \& Quandt, S. A. (2006). Health and social impacts of tobacco production. Journal of Agromedicine, 11(3-4), 71-81. doi:10.1300/J096v11n03_08

Arthur, M. B., \& Rousseau, D. M. (Eds.). (2001). The boundaryless career: A new employment principle for a new organizational era. Oxford University Press.

Ashforth, B. E., \& Kreiner, G. E. (1999). "How can you do it?": Dirty work and the challenge of constructing a positive identity. Academy of Management Review, 24, 413-434. doi:10.5465/AMR.1999.2202129

Ashforth, B. E., \& Kreiner, G. E. (2013). Profane or profound? Finding meaning in dirty work. In B. J. Dik, Z. S. Byrne, \& M. F. Steger (Eds.), Purpose and Meaning in the Workplace (pp. 127-150). Washington, DC: American Psychological Association. 
Ashton, C. H. (2001). Pharmacology and effects of cannabis: A brief review. The British Journal of Psychiatry, 178, 101-106. doi:10.1192/bjp.178.2.101

Aziri, B. (2011). Job satisfaction: A literature review. Management Research and Practice, 3(4), 77-86. Retrieved from http://www.mrp.ase.ro/no34/f7.pdf

Bagwe, A. N., \& Bhisey, R. A. (1993). Occupational exposure to tobacco and resultant genotoxicity in bidi industry workers. Mutation Research/Genetic Toxicology, 299, 103109. doi:10.1016/0165-1218(93)90087-T

Bakker, A. B., \& Demerouti, E. (2007). The job demands-resources model: State of the art. Journal of Managerial Psychology, 22, 309-328. doi:10.1108/02683940710733115

Ballard, T., Ehlers, J., Freund, E., Auslander, M., Brandt, V., \& Halperin, W. (1995). Green tobacco sickness: occupational nicotine poisoning in tobacco workers. Archives of Environmental Health: An International Journal, 50, 384-389.

doi:10.1080/00039896.1995.9935972

Baran, B. E., Shanock, L., \& Miller, L. R. (2012). Advancing organizational support theory into the twenty-first century world of work. Journal of Business and Psychology, 27, 123-147. doi:10.1007/s10869-011-9236-3

Berntson, E., \& Marklund, S. (2007). The relationship between perceived employability and subsequent health. Work \& Stress, 21, 279-292. doi:10.1080/02678370701659215

Bond, F. W., \& Bunce, D. (2001). Job control mediates change in a work reorganization intervention for stress reduction. Journal of Occupational Health Psychology, 6, 290-302. doi:10.1037/1076-8998.6.4.290

Bosch, G. (1999). Working time: Tendencies and emerging issues. International Labour Review, 138, 131-149. doi:10.1111/j.1564-913X.1999.tb00063.x 
Bottorff, J. L., Bissell, L. J., Balneaves, L. G., Oliffe, J. L., Capler, N. R., \& Buxton, J. (2013). Perceptions of cannabis as a stigmatized medicine: a qualitative descriptive study. Harm Reduction Journal, 10(2), 1-10. doi:10.1186/1477-7517-10-2

Bowling, N. A., \& Hammond, G. D. (2008). A meta-analytic examination of the construct validity of the Michigan Organizational Assessment Questionnaire Job Satisfaction Subscale. Journal of Vocational Behavior, 73, 63-77. doi: 10.1016/j.jvb.2008.01.004

Brauchli, R., Bauer, G. F., \& Hämmig, O. (2014). Job autonomy buffers the impact of work-life conflict on organizational outcomes: A large-scale cross-sectional study among employees in Switzerland. Swiss Journal of Psychology, 73, 77-86. doi:10.1024/1421$0185 / \mathrm{a} 000126$

Breaugh J. A., \& Colihan, J. P. (1994). Measuring facets of job ambiguity: Construct validity evidence. Journal of Applied Psychology, 79, 191-202. http://dx.doi.org/10.1037/00219010.79.2.191

Cammann, C., Fichman, M., Jenkins, G. D., \& Klesh, J. (1983). Michigan Organizational Assessment Questionnaire. In S. E. Seashore, E. E. Lawler, P. H. Mirvis, \& C. Cammann (Eds.), Assessing organizational change: A guide to methods, measures, and practices (pp. 71-138). New York: Wiley-Interscience

Cammann, C., Fichman, M., Jenkins, D., \& Klesh, J. (1979). The Michigan Organizational Assessment Questionnaire. Unpublished manuscript, University of Michigan, Ann Arbor.

Cannon, W. B. (1932). The wisdom of the body (2 ${ }^{\text {nd }}$ ed.). New York, NY: Norton.

Caruso, C., Bushnell, T., Eggerth, D., Heitmann, A., Kojola, B., Newman, K., \& ... Vila, B. (2006). Long working hours, safety, and health: Toward a National Research Agenda. American Journal of Industrial Medicine, 49, 930-942. doi:10.1002/ajim.20373 
Chan, D. (1998). Functional relations among constructs in the same content domain at different levels of analysis: A typology of composition models. Journal of Applied Psychology, 83(2), 234-246. http://dx.doi.org/10.1037/0021-9010.83.2.234

Cheng, G. H. L., \& Chan, D. K. S. (2008). Who suffers more from job insecurity? A metaanalytic review. Applied Psychology: An International Review, 57, 272-303. doi:10.1111/j.1464-0597.2007.00312.x

Cohen, J. (1992). A power primer. Psychological bulletin, 112, 155-159. http://dx.doi.org/10.1037/0033-2909.112.1.155

Colorado Department of Revenue [CDOR]. (2016a). Marijuana Enforcement Division (MED) Licensed Facilities. Retrieved February 15, 2016 from https://www.colorado.gov/pacific/enforcement/med-licensed-facilities

Colorado Department of Revenue [CDOR]. (2016b). Colorado Marijuana Tax Data. Retrieved January 19, 2016 from https://www.colorado.gov/pacific/revenue/colorado-marijuanatax-data

Cordell, K. C. (2014, May). Tangled web. 5280, 21(11), 96-101; 166-174.

Cortina, J. M. (1993). What is coefficient alpha? An examination of theory and applications. Journal of Applied Psychology, 78, 98-104. http://dx.doi.org/10.1037/0021-9010.78.1.98

Curran, P. J., West, S. G., \& Finch, J. F. (1996). The robustness of test statistics to nonnormality and specification error in confirmatory factor analysis. Psychological methods, 1, 16. http://dx.doi.org/10.1037/1082-989X.1.1.16

Daniels, K., \& Guppy, A. (1994). Occupational stress, social support, job control, and psychological well-being. Human Relations, 47, 1523-1544. doi:10.1177/001872679404701205 
De Cuyper, N., Bernhard-Oettel, C., Berntson, E., Witte, H. D., \& Alarco, B. (2008).

Employability and employees' well-being: Mediation by job insecurity. Applied Psychology, 57, 488-509. doi: 10.1111/j.1464-0597.2008.00332.x

De Cuyper, N., Van der Heijden, B. I., \& De Witte, H. (2011). Associations between perceived employability, employee well-being, and its contribution to organizational success: a matter of psychological contracts? The International Journal of Human Resource Management, 22, 1486-1503. doi:10.1080/09585192.2011.561962

Dedobbeleer, N., \& Béland, F. (1991). A safety climate measure for construction sites. Journal of Safety Research, 22, 97-103. doi:10.1016/0022-4375(91)90017-P

Demerouti, E., Bakker, A. B., Nachreiner, F., \& Schaufeli, W. B. (2001). The job demandsresources model of burnout. Journal of Applied Psychology, 86, 499-512. http://dx.doi.org/10.1037/0021-9010.86.3.499

Dik, B. J., Duffy, R. D., \& Eldridge, B. M. (2009). Calling and vocation in career counseling: Recommendations for promoting meaningful work. Professional Psychology: Research and Practice, 40, 625-632. doi:10.1037/a0015547

Drennan, J. (2003). Cognitive interviewing: verbal data in the design and pretesting of questionnaires. Journal of Advanced Nursing, 42, 57-63. doi:10.1046/j.13652648.2003.02579.x

Duffy, R. D., \& Dik, B. J. (2013). Research on calling: What have we learned and where are we going? Journal of Vocational Behavior, 83, 428-436. doi:10.1016/j.jvb.2013.06.006

Eisenberger, R., Armeli, S., Rexwinkel, B., Lynch, P. D., \& Rhoades, L. (2001). Reciprocation of perceived organizational support. Journal of Applied Psychology, 86, 42-51. doi:10.1037/0021-9010.86.1.42 
Eisenberger, R., Fasolo, P., \& Davis-LaMastro, V . (1990). Perceived organizational support and employee diligence, commitment, and innovation. Journal of Applied Psychology, 75, 51-59. http://dx.doi.org/10.1037/0021-9010.75.1.51

Eisenberger, R., Huntington, R. H., \& Sowa, S. (1986). Perceived Organizational Support. Journal of Applied Psychology, 71, 500-507. http://dx.doi.org/10.1037/00219010.71.3.500

Emerson, R. M. (1976). Social exchange theory. Annual Review of Sociology, 2, 335-362. Retrieved from http://www.jstor.org/stable/2946096

Fabrigar, L. R., Wegener, D. T., MacCallum, R. C., \& Strahan, E. J. (1999). Evaluating the use of exploratory factor analysis in psychological research. Psychological Methods, 4, 272 299. http://dx.doi.org/10.1037/1082-989X.4.3.272

Fishbein, M., \& Ajzen, I. (1975). Belief, attitude, intention and behavior: An introduction to theory and research. Reading, MA: Addison-Wesley.

Ganster, D. C., \& Perrewé, P. L. (2011). Theories of occupational stress. In J. Quick \& L. E. Tetrick (Eds.), Handbook of Occupational Health Psychology (2nd ed.) (pp. 37-53). Washington, DC, US: American Psychological Association.

Ganster, D. C., \& Rosen, C. C. (2013). Work stress and employee health: A multidisciplinary review. Journal of Management, 39, 1085-1122. doi:10.1177/0149206313475815

Ghosh, S. K., Parikh, J. R., Gokani, V. N., Kashyap, S. K., \& Chatterjee, S. K. (1979). Studies on occupational health problems during agricultural operation of Indian tobacco workers: a preliminary survey report [Abstract]. Journal of Occupational and Environmental Medicine, 21, 45-47. 
Giddens, A. (1991). Modernity and self-identity: Self and society in the late modern age. Stanford University Press.

Glendon, A. I., \& Stanton, N. A. (2000). Perspectives on safety culture. Safety Science, 34, 193214. doi:10.1016/S0925-7535(00)00013-8

Gliem, J. A., \& Gliem, R. R. (2003, October 8-10). Calculating, interpreting, and reporting Cronbach's alpha reliability coefficient for Likert-type scales. Paper presented at the Midwest Research-to-Practice Conference in Adult, Continuing, and Community Education, Columbus, OH. Retrieved from http://hdl.handle.net/1805/344

George, J. M., \& Jones, G. R. (1996). The experience of work and turnover intentions: Interactive effects of value attainment, job satisfaction, and positive mood. Journal of Applied Psychology, 81, 318-325. doi:10.1037/0021-9010.81.3.318

Goffman E (1963). Stigma. Englewood Cliffs, NJ: Prentice-Hall.

Golden, L., \& Wiens-Tuers, B. (2005). Mandatory overtime work in the United States: who, where, and what? Labor Studies Journal, 30, 1-25. doi:10.1177/0160449X0503000102

Golden, L., \& Wiens-Tuers, B. (2006). To your happiness? Extra hours of labor supply and worker well-being. The Journal of Socio-Economics, 35, 382-397. doi:10.1016/j.socec.2005.11.039

Golden, L., \& Wiens-Tuers, B. (2008). Overtime work and wellbeing at home. Review of Social Economy, 66, 25-49. doi:10.1080/00346760701668495

Good, L. K., Sisler, G. F., \& Gentry, J. W. (1988). Antecedents of turnover intentions among retail management personnel [Abstract]. Journal of Retailing, 64, 295-314.

Greenhalgh, L., \& Rosenblatt, Z. (1984). Job insecurity: Toward conceptual clarity. Academy of Management Review, 9, 438-448. doi:10.5465/AMR.1984.4279673 
Griffin, M. A., \& Neal, A. (2000). Perceptions of safety at work: a framework for linking safety climate to safety performance, knowledge, and motivation. Journal of Occupational Health Psychology, 5, 347-358. http://dx.doi.org/10.1037/1076-8998.5.3.347

Grönlund, A. (2007). More Control, Less Conflict? Job Demand-Control, Gender and WorkFamily Conflict. Gender, Work \& Organization, 14, 476-497. doi:10.1111/j.14680432.2007.00361.x

Harris, K. J., Wheeler, A. R., \& Kacmar, K. M. (2009). Leader-member exchange and empowerment: Direct and interactive effects on job satisfaction, turnover intentions, and performance. The Leadership Quarterly, 20, 371-382. doi:10.1016/j.leaqua.2009.03.006

Hathaway, A. D., Comeau, N. C., \& Erickson, P. G. (2011). Cannabis normalization and stigma: Contemporary practices of moral regulation. Criminology \& Criminal Justice: An International Journal, 11, 451-469. doi:10.1177/1748895811415345.

Hayes, L. J., O’Brien-Pallas, L., Duffield, C., Shamian, J., Buchan, J., Hughes, F., ... \& Stone, P. W. (2012). Nurse turnover: A literature review - An update. International Journal of Nursing Studies, 49, 887-905. doi:10.1016/j.jpurstu.2011.10.001

Headd, B. (2001). Business Success: Factors leading to surviving and closing successfully. Center for Economic Studies, US Department of Commerce, Bureau of the Census.

Hecht, L. M. (2001). Role conflict and role overload: Different concepts, different consequences. Sociological Inquiry, 71, 111-121. doi:10.1111/j.1475682X.2001.tb00930.x

Hofmann, D. A., Griffin, M., \& Gavin, M. (2000). The application of hierarchical linear modeling to organizational research. In K. J. Klein \& S. W. J. Kozlowski (Eds.), 
Multilevel theory, research, and methods in organizations: Foundations, extensions, and new directions (pp. 467-511). San Francisco: Jossey-Bass

Hoppock, R. (1935). Job satisfaction. Oxford, England: Harper.

Hughes, E. C. (1951). Work and the self. In J. H. Rohrer \& M. Sherif (Eds.), Social Psychology at the Crossroads (pp. 312-323). New York: Harper \& Brothers.

Hulbert-Williams, N. J., Morrison, V. V., Wilkinson, C. C., \& Neal, R. D. (2013). Investigating the cognitive precursors of emotional response to cancer stress: Re-testing Lazarus's Transactional Model. British Journal of Health Psychology, 18, 97-121. doi:10.1111/j.2044-8287.2012.02082.x

Ironson, G. H., Smith, P. C., Brannick, M. T., Gibson, W. M., \& Paul, K. B. (1989).

Construction of a Job in General scale: A comparison of global, composite, and specific measures. Journal of Applied Psychology, 74, 193-200. doi:10.1037/0021-9010.74.2.193

Jackson, S. E., \& Schuler, R. S. (1985). A meta-analysis and conceptual critique of research on role ambiguity and role conflict in work settings. Organizational Behavior and Human Decision Processes, 36, 16-78. doi:10.1016/0749-5978(85)90020-2

Johnson, J. V., \& Lipscomb, J. (2006). Long working hours, occupational health and the changing nature of work organization. American Journal of Industrial Medicine, 49, 921929. doi:10.1002/ajim.20383

Judge, T. A., Parker, S., Colbert, A. E., Heller, D., \& Ilies, R. (2001). Job satisfaction: A crosscultural review. In N. Anderson, D. S. Ones, H. K. Sinangil, \& C. Viswesvaran (Eds.), Handbook of industrial, work, and organizational psychology (pp. 25-52). Thousand Oaks, CA: Sage. 
Kahn, R. L., Wolfe, D. M., Quinn, R. P., Snoek, J. D., \& Rosenthal, R. A. (1964). Organizational stress: Studies in role conflict and ambiguity. Oxford, England: John Wiley \& Sons, Inc.

Kamdron, T. (2005). Work motivation and job satisfaction of Estonian higher officials. International Journal of Public Administration, 28, 1211-1240. doi:10.1080/01900690500241085

Karasek, R., \& Therorell, T. (1992). Healthy work: stress, productivity, and the reconstruction of working life. Basic books.

Kath, L. M., Stichler, J. F., Ehrhart, M. G., \& Schultze, T. A. (2013). Predictors and outcomes of nurse leader job stress experienced by AWHONN members. Journal of Obstetric, Gynecologic, \& Neonatal Nursing, 42, E12-E25. doi:10.1111/j.1552-6909.2012.01430.x

Kaur, D., Sambasivan, M., \& Kumar, N. (2013). Effect of spiritual intelligence, emotional intelligence, psychological ownership and burnout on caring behaviour of nurses: a crosssectional study. Journal of Clinical Nursing, 22, 3192-3202. doi:10.1111/jocn.12386

Keim, A. C., Landis, R. S., Pierce, C. A., \& Earnest, D. R. (2014). Why do employees worry about their jobs? A meta-analytic review of predictors of job insecurity. Journal of Occupational Health Psychology, 19, 269-290. doi:10.1037/a0036743

Kortum, E., \& Leka, S. (2014). Tackling psychosocial risks and work-related stress in developing countries: The need for a multilevel intervention framework. International Journal of Stress Management, 21, 7-26. doi:10.1037/a0035033

Kristensen, T. S., Borritz, M., Villadsen, E., \& Christensen, K. B. (2005). The Copenhagen Burnout Inventory: A new tool for the assessment of burnout. Work \& Stress, 19, 192207. doi:10.1080/02678370500297720 
Krull, J. L., \& MacKinnon, D. P. (2001). Multilevel modeling of individual and group level mediated effects. Multivariate Behavioral Research, 36, 249-277. doi:10.1207/S15327906MBR3602_06

Lazarus, R. S., \& Folkman, S. (1984). Stress, appraisal, and coping. New York, NY: Springer Publishing Company, Inc.

Locke, E. A. (1976). The nature and causes of job satisfaction. In M. D. Dunnette (Ed.), Handbook of industrial and organizational psychology (pp. 1293-1349). Chicago: Rand McNally.

Maslach, C., Schaufeli, W. B., \& Leiter, M. P. (2001). Job burnout. Annual review of psychology, 52, 397-422. doi:10.1146/annurev.psych.52.1.397

May, J. J. (2009). Occupational injury and illness in farmworkers in the eastern United States. In S. A. Quandt \& T. A. Arcury (Eds.), Latino farmworkers in the eastern United States (pp. 71-101). New York, NY: Springer.

McEwen, B. S. (1998). Stress, adaptation, and disease: Allostasis and allostatic load. Annals of the New York Academy of Sciences, 840, 33-44. doi:10.1111/j.1749-6632.1998.tb09546.x

McGonagle, A. K., \& Barnes-Farrell, J. L. (2013). Chronic illness in the workplace: stigma, identity threat and strain. Stress and Health, 30, 310-321. doi:10.1002/smi.2518

Meriac, J. P., Slifka, J. S., \& LaBat, L. R. (2015). Work ethic and grit: An examination of empirical redundancy. Personality and Individual Differences, 86, 401-405. doi:10.1016/j.paid.2015.07.009

Meyer, J. P., \& Allen, N. J. (1991). A three-component conceptualization of organizational commitment. Human Resource Management Review, 1, 61-89. doi:10.1016/10534822(91)90011-Z 
Meyer, J. P., Stanley, D. J., Herscovitch, L., \& Topolnytsky, L. (2002). Affective, continuance, and normative commitment to the organization: A meta-analysis of antecedents, correlates, and consequences. Journal of Vocational Behavior, 61, 20-52. doi:10.1006/jvbe.2001.1842

Mishra, S., \& Bhatnagar, D. (2010). Linking emotional dissonance and organizational identification to turnover intention and emotional well-being: A study of medical representatives in India. Human Resource Management, 49, 401-419. doi:10.1002/hrm.20362

Mohamed, S. (2002). Safety climate in construction site environments. Journal of Construction Engineering and Management, 128, 375-384. http://dx.doi.org/10.1061/(ASCE)07339364(2002)128:5(375)

Nagy, M. S. (2002). Using a single-item approach to measure facet job satisfaction. Journal of Occupational \& Organizational Psychology, 75, 77-86. doi:10.1348/096317902167658

National Agriculture, Forestry, and Fishing Agenda. (2008). Retrieved from http://www.cdc.gov/niosh/nora/comment/agendas/agforfish/pdfs/AgForFishDec2008.pdf

National Institute for Occupational Safety and Health [NIOSH]. (2013). The national occupational research agenda. Retrieved September 1, 2014, from http://www.cdc.gov/niosh/nora/default.html

National Manufacturing Agenda. (2010). Retrieved from http://www.cdc.gov/niosh/nora/comment/agendas/manuf/pdfs/ManufJune2010.pdf National Organization for the Reformation of Marijuana Laws [NORML]. (2016). State info. Retrieved February 14, 2016 from http://norml.org/states 
National Wholesale and Retail Trade Agenda (2009). Retrieved from

http://www.cdc.gov/niosh/nora/comment/agendas/wholrettrade/pdfs/WholRetTradeOct20 09.pdf

Neal, A., \& Griffin, M. A. (2006). A study of the lagged relationships among safety climate, safety motivation, safety behavior, and accidents at the individual and group levels. Journal of Applied Psychology, 91, 946-953. http://dx.doi.org/10.1037/00219010.91.4.946

Neal, A., Griffin, M. A., \& Hart, P. M. (2000). The impact of organizational climate on safety climate and individual behavior. Safety Science, 34, 99-109. doi:10.1016/S0925$7535(00) 00008-4$

Nelson, D. L., \& Simmons, B. L. (2011). Savoring eustress while coping with distress: The holistic model of stress. In J. Quick \& L. E. Tetrick (Eds.), Handbook of Occupational Health Psychology (2nd ed.) (pp. 55-74). Washington, DC, US: American Psychological Association.

Pacula, R. P., Kilmer, B., Wagenaar, A. C., Chaloupka, F. J., \& Caulkins, J. P. (2014). Developing public health regulations for marijuana: Lessons from alcohol and tobacco. American Journal of Public Health, 104, 1021-1028. doi:10.2105/AJPH.2013.301766

Pinel, E. C. (1999). Stigma consciousness: The psychological legacy of social stereotypes. Journal of Personality and Social Psychology, 76, 114-128. doi:10.1037/0022-3514.76.1.114

Podsakoff, P. M., MacKenzie, S. B., Lee, J. Y., \& Podsakoff, N. P. (2003). Common method biases in behavioral research: a critical review of the literature and recommended 
remedies. Journal of Applied Psychology, 88, 879-903. http://dx.doi.org/10.1037/00219010.88.5.879

Quick, J. C., Quick, J. D., Nelson, D. L., \& Hurrell, J. J. (1997). Preventive stress management in organizations. Washington, D.C.: American Psychological Association. http://dx.doi.org/10.1037/10238-000

Raja, J., \& Bhasin, S. (2014). Health issues amongst call center employees, an emerging occupational group in India. Indian Journal of Community Medicine, 39, 175-177. doi:10.4103/0970-0218.137156

Rantanen, J. (2011). The future. In T. L. Guidotti, J. Rantanen, S. Lehtinen, K. Takahashi, D. Koh, R. Mendes, ... S. G. Rose (Eds.), Global Occupational Health (pp. 560-569). New York, NY, US: Oxford University Press. doi:10.1093/acprof:oso/9780195380002.003.0031

Reichers, A. E. (1985). A review and reconceptualization of organizational commitment. The Academy of Management Review, 10, 465-476. doi:10.2307/258128

Rhoades, L., \& Eisenberger, R. (2002). Perceived organizational support: A review of the literature. Journal of Applied Psychology, 87, 698-714. doi:10.1037/0021-9010.87.4.698

Rhoades, L., Eisenberger, R., \& Armeli, S. (2001). Affective commitment to the organization: The contribution of perceived organizational support. Journal of Applied Psychology, 86, 825-836. http://dx.doi.org/10.1037/0021-9010.86.5.825

Richter, P., \& Hacker, W. (1998). Belastung und Beanspruchung: Stress, Ermüdung und Burnout im Arbeitsleben [Workload and strain: Stress, fatigue, and burnout in working life]. Heidelberg, Germany: Asanger. 
Ringen, K. and Stafford, E. J. (1996), Intervention research in occupational safety and health: Examples from construction. American Journal of Industrial Medicine, 29, 314-320. doi:10.1002/(SICI)1097-0274(199604)29:4<314::AID-AJIM7>3.0.CO;2-O

Rizzo, J. R., House, R. J., \& Lirtzman, S. I. (1970). Role conflict and ambiguity in complex organizations. Administrative Science Quarterly, 150-163. doi:10.2307/2391486

Rogers, B. (2006). The National Occupational Research Agenda-The Second Decade of NORA. AAOHN Journal 54(4), 153. Retrieved from http://search.proquest.com/docview/219334820?pq-origsite=gscholar

Rubin, D. B., \& Little, R. J. (2002). Statistical analysis with missing data. Hoboken, NJ: John Wiley \& Sons, Inc.

Rusbult, C. E., Martz, J. M., \& Agnew, C. R. (1998). The investment model scale: Measuring commitment level, satisfaction level, quality of alternatives, and investment size. Personal Relationships, 5, 357-387. doi:10.1111/j.1475-6811.1998.tb00177.x

Salas, E., Tannenbaum, S. I., Kraiger, K., \& Smith-Jentsch, K. A. (2012). The science of training and development in organizations: What matters in practice. Psychological Science in the Public Interest, 13, 74-101. doi: 10.1177/1529100612436661

Sapolsky, R. M. (1994). Why zebras don't get ulcers. New York: W.H. Freeman.

Sauter, S. L., Murphy, L. R., \& Hurrell, J. J. (1990). Prevention of work-related psychological disorders: A national strategy proposed by the National Institute for Occupational Safety and Health (NIOSH). American Psychologist, 45, 1146-1158. http://dx.doi.org/10.1037/0003-066X.45.10.1146

Scharlach, A. E. (2001). Role strain among working parents: Implications for workplace and community. Community, Work \& Family, 4, 215-230. doi:10.1080/713658929 
Schaufeli, W. B., \& Taris, T. W. (2014). A critical review of the job demands-resources model: Implications for improving work and health. In G. F. Bauer \& O. Hämmig (Eds.), Bridging occupational, organizational and public health: A transdisciplinary approach (pp. 43-68). New York, NY: Springer Science. doi:10.1007/978-94-007-5640-3_4

Seashore, S. E., Lawler, E. E., Mirvis, P., \& Cammann, C. (1982). Observing and measuring organizational change: A guide to field practice. NY: John Wiley \& Sons, Inc..

Selye, H. (1955). Stress and disease. The Laryngoscope, 65, 500-514. doi:10.1288/00005537195507000-00002

Shields, M. (1999). Long working hours and health. Health Reports-Statistics Canada, 11, 3348. Retrieved from http://www.ncbi.nlm.nih.gov/pubmed/10618741

Silla, I., De Cuyper, N., Gracia, F. J., Peiró, J. M., \& De Witte, H. (2009). Job insecurity and well-being: Moderation by employability. Journal of Happiness Studies, 10, 739-751. doi:10.1007/s10902-008-9119-0

Smith, P. C., Kendall, L., \& Hulin, C. L. (1969). The measurement of satisfaction in work and retirement: A strategy for the study of attitudes. Chicago: Rand McNally.

Smith, C. S., Tisak, J., Hahn, S. E., \& Schmeider, R. A. (1997). The measurement of job control. Journal of Organizational Behavior, 18, 225-237. Retrieved from http://www.jstor.org/stable/3100142

Sorerholm, S. C. (2006). National Occupational Research Agenda. Cross-sector research in the second decade. In NORA Symposium. Presented at the 2006 National Occupational Research Agenda Symoposium, Washington, DC. Retrieved from http://www. cdc. gov/niosh/nora/symp06/pdfs/cross06present.pdf. 
Sparks, K., Faragher, B., \& Cooper, C. L. (2001). Well-being and occupational health in the 21st century workplace. Journal of Occupational and Organizational Psychology, 74, 489509. doi:10.1348/096317901167497

Sparks, J. R., \& Schenk, J. A. (2001). Explaining the effects of transformational leadership: An investigation of the effects of higher-order motives in multilevel marketing organizations. Journal of Organizational Behavior, 22, 849-869. doi:10.1002/job.116

Spector, P. E. (1986). Perceived control by employees: A meta-analysis of studies concerning autonomy and participation at work. Human Relations, 39, 1005-1016. doi:10.1177/001872678603901104

Spurgeon, A., Harrington, J. M., \& Cooper, C. L. (1997). Health and safety problems associated with long working hours: A review of the current position. Occupational and Environmental Medicine, 54, 367-375. doi:10.1136/oem.54.6.367

Steel, R. P., \& Ovalle, N. K. (1984). A review and meta-analysis of research on the relationship between behavioral intentions and employee turnover. Journal of Applied Psychology, 69, 673-686. http://dx.doi.org/10.1037/0021-9010.69.4.673

Steele, J. P., Rupayana, D. D., Mills, M. J., Smith, M. R., Wefald, A., \& Downey, R. G. (2012). Relative importance and utility of positive worker states: A review and empirical examination. The Journal of Psychology: Interdisciplinary and Applied, 146, 617-650. doi:10.1080/00223980.2012.665100

Steger, M. R., Dik, B. J., \& Duffy, R. D. (2012). Measuring meaningful work: The work and meaning inventory (WAMI). Journal of Career Assessment, 20(3), 322-337. doi:10.1177/1069072711436160 
Stellman, J. M. (Ed.). (1998). Encyclopaedia of occupational health and safety (4 ${ }^{\text {th }}$ Ed.). Geneva, Switzerland: International Labour Organization.

Sterling, P., \& Eyer, J. (1988). Allostasis: a new paradigm to explain arousal pathology. In S.

Fisher \& J. Reason (Eds.), Handbook of Life Stress, Cognition, and Health (pp. 629-659). New York, NY: Wiley.

Sverke, M., \& Hellgren, J. (2002). The nature of job insecurity: Understanding employment uncertainty on the brink of a new millennium. Applied Psychology, 51, 23-42. doi:10.1111/1464-0597.0077z

Sverke, M., Hellgren, J., \& Näswall, K. (2002). No security: A meta-analysis and review of job insecurity and its consequences. Journal of Occupational Health Psychology, 7, 242-264. doi:10.1037/10768998.7.3.242

Tabachnick, B. G., \& Fidell, L. S. (2013). Using multivariate statistics (6 ${ }^{\text {th }}$ ed.). New Jersey: Pearson Education.

Tetrick, L. E., \& Quick, J. (2011). Overview of occupational health psychology: Public health in occupational settings. In J. Quick, L. E. Tetrick (Eds.), Handbook of Occupational Health Psychology (2nd ed.) (pp. 3-20). Washington, DC, US: American Psychological Association.

Thompson, C. A., \& Prottas, D. J. (2006). Relationships among organizational family support, job autonomy, perceived control, and employee well-being. Journal of Occupational Health Psychology, 11, 100-118. doi:10.1037/1076-8998.10.4.100

Truxillo, D. M., Cadiz, D. M., Bauer, T. N., \& Erdogan, B. (2013). Reactions to employer policies regarding prescription drugs and medical marijuana: the role of safety 
sensitivity. Journal of Business and Psychology, 28, 145-158. doi:10.1007/s10869-0129276-3

Uehata, T. (1991). Long working hours and occupational stress-related cardiovascular attacks among middle-aged workers in Japan. Journal of Human Ergology, 20, 147-153. http://doi.org/10.11183/jhe1972.20.147

Vandenberghe, C., Bentein, K., \& Stinglhamber, F. (2004). Affective commitment to the organization, supervisor, and work group: Antecedents and outcomes. Journal of Vocational Behavior, 64, 47-71. doi:10.1016/S0001-8791(03)00029-0

Vander Elst, T., De Witte, H., \& De Cuyper, N. (2014). The Job Insecurity Scale: A psychometric evaluation across five European countries. European Journal of Work and Organizational Psychology, 23, 364-380. doi:10.1080/1359432X.2012.745989

Venkataramani, V., Labianca, G. J., \& Grosser, T. (2013). Positive and negative workplace relationships, social satisfaction, and organizational attachment. Journal of Applied Psychology, 98, 1028-1039. http://dx.doi.org/10.1037/a0034090

Virga, D. (2015). Job insecurity and job satisfaction: the mediating effect of psychological capital. Psihologia Resurselor Umane, 13, 206-216. Retrieved from http://pru.apio.ro/index.php/prujournal/article/view/396

Viswesvaran, C., Sanchez, J. I., \& Fisher, J. (1999). The role of social support in the process of work stress: A meta-analysis. Journal of Vocational Behavior, 54, 314-334. doi:10.1006/jvbe.1998.1661

Vroom, V. H. (1964). Work and motivation. New York: Wiley.

Warren, J. A., \& Johnson, P. J. (1995). The impact of workplace support on work-family role strain. Family Relations, 44, 163-169. doi:10.2307/584803 
Watson, D., Clark, L. A., \& Tellegen, Al. (1988). Development and validation of brief measure of positive and negative affect: The PANAS scales. Journal of Personality and Social Psychology, 54, 1063-1070. http://dx.doi.org/10.1037/0022-3514.54.6.1063

Wayne, S. J., Shore, L. M., Bommer, W. H., \& Tetrick, L. E. (2002). The role of fair treatment and rewards in perceptions of organizational support and leader-member exchange. Journal of Applied Psychology, 87, 590-598. doi:10.1037/0021-9010.87.3.590 
Appendices 
Appendix A: Project Brochure (Outside)

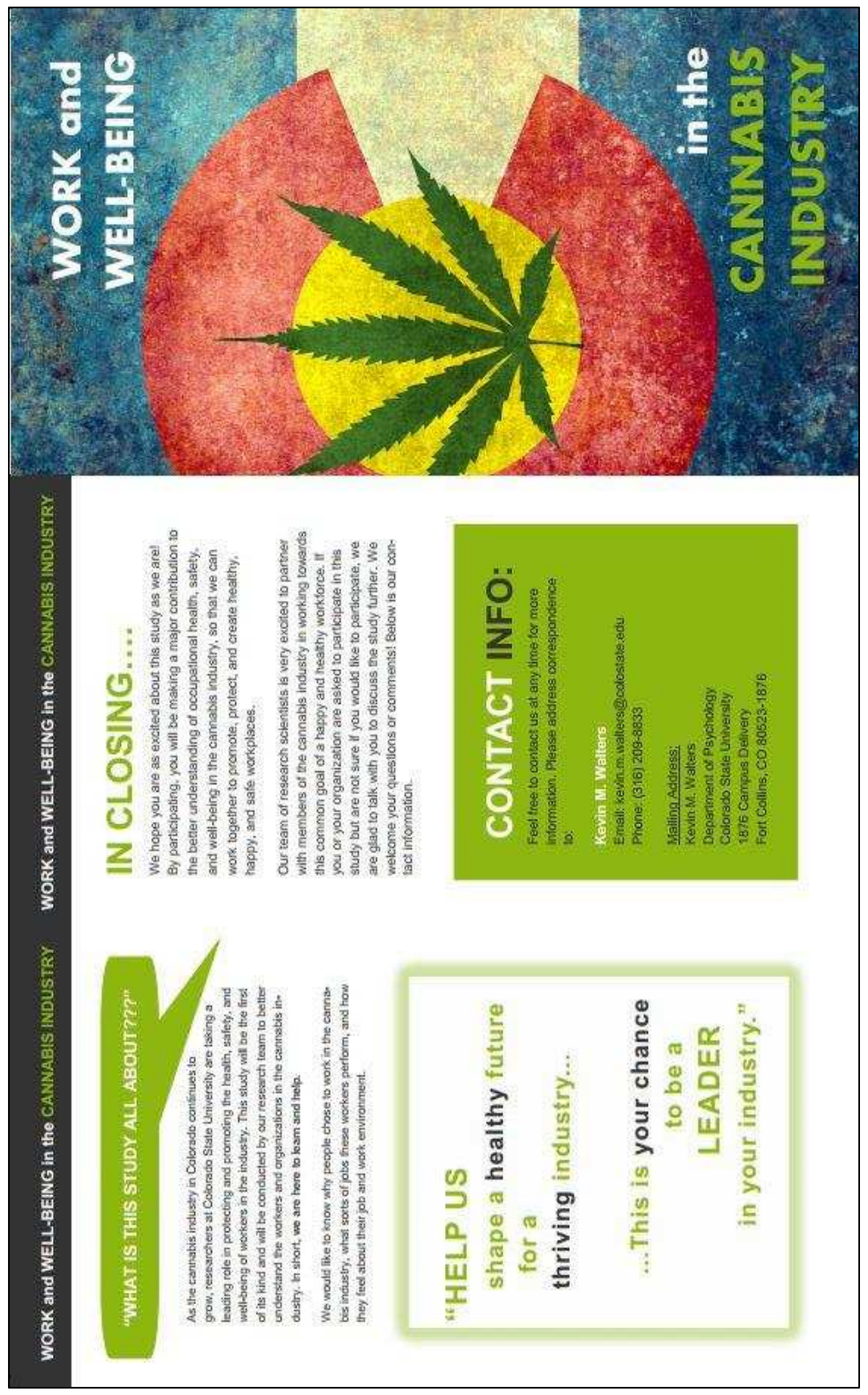




\section{Appendix A: Project Brochure (Inside)}

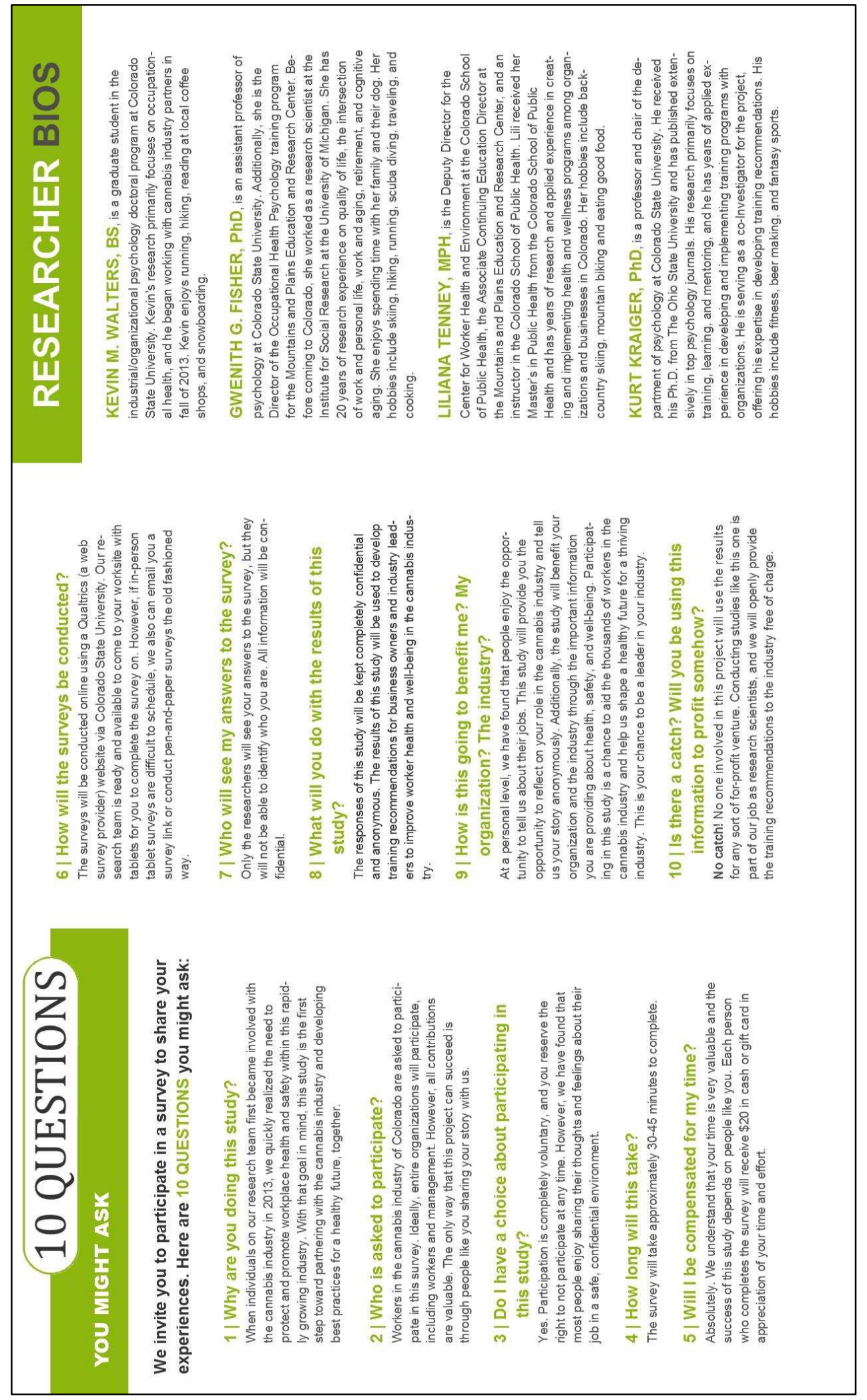




\section{Appendix B: Steps for Stigma Scale Validation}

Steps for Establishing Evidence of Validity for a New Measure of Perceived Stigma of Work in the Cannabis Industry (Fisher, Walters, \& Menger, in preparation)

1. Review relevant literature

2. Adapt scale items based on existing measures

3. Generate new items

4. Rate items for content validity

5. Administer items to pilot sample

a. Include measures to assess discriminant validity (e.g., Big Five, negative affectivity)

b. Include measures to assess criterion-related validity (e.g., job satisfaction, affective commitment)

6. Review descriptive statistics and psychometric characteristics (e.g., item analysis, reliability analysis, factor structure)

7. Select items for inclusion in final survey of cannabis industry workers 


\section{Appendix C: Measure of Perceived Stigma of Work in the Cannabis Industry}

Fisher, Walters, \& Menger (in preparation)

1. I am concerned that my family judges me for the type of work I do.

2. My family gossips about me behind my back because I work in the cannabis industry.

3. My choice to work in the cannabis industry has been scrutinized by my family.

4. My family has a negative view of people who work in the cannabis industry.

5. I am concerned that my friends judge me for the type of work I do.

6. My friends gossip about me behind my back because I work in the cannabis industry.

7. My choice to work in the cannabis industry has been scrutinized by my friends.

8. My friends have a negative view of people who work in the cannabis industry.

9. I am concerned that society judges me for the type of work I do.

10. I think that workers in the cannabis industry are stigmatized by society.

11. My choice to work in the cannabis industry has been scrutinized by people in general.

12. Society has a negative view of people who work in the cannabis industry.

Note. Items were rated on a 1 to 5 scale where $1=$ Strongly Disagree, $2=$ Somewhat Disagree, $3=$ Neither Agree nor Disagree, $4=$ Somewhat Agree, $5=$ Strongly Agree. Items refer to stigma from three sources, including: 1) family (items 1-4); 2) friends (items 5-8); and 3) society in general (items 9-12). Original scale items were developed from from the Pinel (1999) Stigma Consciousness Scale, from the McGonagle \& Barnes-Farrell (2013) Identity Threat measure, and one newly generated item. 


\section{Appendix D: Job Insecurity Scale}

(Vander Elst, De Witte, \& De Cuyper, 2014)

1. Chances are, I will soon lose my job.

2. I am sure I can keep my job.

3. I feel insecure about the future of my job.

4. I think I might lose my job in the near future.

Note. . Items are rated on a 1 to 5 scale where $1=$ Strongly Disagree, $2=$ Somewhat Disagree, 3

$=$ Neither Agree nor Disagree, $4=$ Somewhat Agree, $5=$ Strongly Agree . 


\section{Appendix E: Breaugh \& Colihan Role Ambiguity Scale}

(Breaugh \& Colihan, 1994)

1. I am certain how to go about getting my job done (the methods to use).

2. I know what is the best way (approach) to go about getting my work done.

3. I know how to get my work done (what procedures to use).

Note. Items are rated on a 1 to 5 scale where $1=$ Strongly Disagree, $2=$ Somewhat Disagree, 3

$=$ Neither Agree nor Disagree, $4=$ Somewhat Agree, $5=$ Strongly Agree . 


\section{Appendix F: Measure of Long Working Hours}

1. What is the average number of hours you work during a typical week?

2. What is the average number of hours you work during a typical week during busy weeks?

3. How many days per month do you work extra hours beyond your usual schedule?

4. When you work extra hours on your main job, is it mandatory (required by your employer)?

Note. Items 1-3 will be open-ended text boxes in which respondents can enter a numerical value. Item 4 will be "Yes/No" question. Items 1-2 are derived from the work of Shields (1999). Items 3-4 are derived from the work of Golden and Wines-Tuers (2008). 


\section{Appendix G: Neal \& Griffin Safety Climate Measure}

(Neal \& Griffin, 2000)

1. Management is concerned for the safety of employees.

2. Management places a strong emphasis on workplace health and safety.

3. Safety is given a high priority by management

4. Management considers safety to be important.

5. There is frequent communication about safety issues in this workplace.

6. Employees are able to discuss their concerns about safety issues with line management.

7 There is sufficient opportunity to discuss and deal with safety issues in meetings.

8. There is open communication about safety issues within this workplace.

9. Employees are regularly consulted about workplace health and safety issues.

10. Safety issues are given a high priority in training programs.

11. Workplace health and safety training covers the types of situations that employees encounter in their job

12. Employees receive comprehensive training in workplace health and safety issues.

13. Employees have sufficient access to workplace health and safety training programs.

14. There are significant dangers inherent in the workplace.

15. The physical work environment is safe.

16. Employees are frequently exposed to risky situations.

Note. Items are rated on a 1 to 5 scale where $1=$ Strongly Disagree, $2=$ Somewhat Disagree, 3

= Neither Agree nor Disagree, $4=$ Somewhat Agree, 5 = Strongly Agree. Items 1-4 measure

"Management Values"; items 5-9 measure "Communication"; items 10-13 measure

"Training"; and items 14-16 measure "Physical Work Environment." 


\section{Appendix H: Measure of Perceptions of Physical Safety in the Cannabis Industry}

1. Please rate the extent to which you agree or disagree that each of the following items is a problematic issue in your workplace. In other words, do you view each of the following items as hazardous to your health?

a. Physical safety (that is, your overall sense of security)

b. Air quality

c. Respiratory issues (such as due to breathing in aerosols from plants)

d. Absorbing chemicals through skin (such as through touching plants while trimming)

e. Ergonomic issues (such as wrist or hand issues due to trimming for long periods of time)

f. Slips, trips, and fall hazards

g. Temperature from lighting systems (such as burns resulting from overhead plant lighting)

h. Exposure to pesticides

2. Are there any other characteristics of your workplace that you view as hazardous to your health? If so, how hazardous would you rate in using the same scale as above?

Note. Items 1a-1h are rated on a 1 to 5 scale where $1=$ Strongly Disagree, $2=$ Somewhat Disagree, $3=$ Neither Agree nor Disagree, $4=$ Somewhat Agree, $5=$ Strongly Agree. Item 2 will be open-ended with a corresponding 1-5 Likert scale. 
Appendix I: Michigan Organizational Assessment Questionnaire Job Satisfaction Subscale

(Cammann, Fichman, Jenkins, \& Klesh, 1979)

1. All in all I am satisfied with my job.

2. In general, I don't like my job

3. In general, I like working here.

Note. Items are rated on a 1 to 5 scale where 1 = Strongly Disagree, 2 = Somewhat Disagree, 3 $=$ Neither Agree nor Disagree, $4=$ Somewhat Agree, $5=$ Strongly Agree. 


\section{Appendix J: Turnover Intentions Scale}

(Seashore, Lawler, Mirvis, \& Cammann, 1982)

1. I have seriously thought about leaving my current organiztion.

2. I would prefer another job to the one I have now.

3. If I have my way, I won't be working for this organization a year from now.

Note. Items are rated on a 1 to 5 scale where 1 = Strongly Disagree, 2 = Somewhat Disagree, 3

$=$ Neither Agree nor Disagree, 4 = Somewhat Agree, $5=$ Strongly Agree. 


\section{Appendix K: Affective Commitment Scale}

(Allen \& Meyer, 1990; Rhoades, Eisenberger, \& Armeli, 2001)

1. I am proud to tell others I work at my company/organization.

2. I feel personally attached to my company/organization.

3. I feel a strong sense of belonging to my company/organization.

Note. Items are rated on a 1 to 5 scale where $1=$ Strongly Disagree, $2=$ Somewhat Disagree, 3

$=$ Neither Agree nor Disagree, 4 = Somewhat Agree, $5=$ Strongly Agree. 


\section{Appendix L: Copenhagen Work Burnout Inventory}

(Kristensen, Borritz, Villadsen, \& Christensen, 2005)

1. Is your work emotionally exhausting?

2. Do you feel burned out because of your work?

3. Does your work frustrate you?

4. Do you feel worn out at the end of a working day?

5. Are you exhausted in the morning at the thought of another day at work?

6. Do you feel that every working hour is tiring for you?

7. Do you have enough energy for family and friends during leisure time?

Note. Items 1-3 are rated on a 1 to 5 scale where $1=$ To a very low degree, $2=$ To a low degree, $3=$ Somewhat, $4=$ To a high degree, $5=$ To a very high degree. Items 4-7 are rated on a 1 to 5 scale where $1=$ Never/Almost Never, $2=$ Seldom, $3=$ Sometimes, $4=$ Often, and $5=$ Always. 


\section{Appendix M: Job Control - Decision Authority}

(Smith, Tisak, Hahn, \& Schmieder, 1997)

1. My job allows me to make a lot of decisions on my own.

2. I have a lot of say about what happens on my job.

3. On my job, I have very little freedom to decide how I work.

Note. Items are rated on a 1 to 5 scale where $1=$ Strongly Disagree, $2=$ Disagree, $3=$ Neither Agree nor Disagree, $4=$ Agree, and $5=$ Strongly Agree. 


\section{Appendix N: Survey of Perceived Organizational Support}

(Eisenberger, Huntington, Hutchinson, \& Sowa, 1986)

1. Help is available from my organization when I have a problem.

2. My organization really cares about my well-being.

3. My organization shows a lot of concern for me.

4. My organization strongly considers my goals and values.

Note. Items are rated on a 1 to 5 scale where $1=$ Strongly Disagree, $2=$ Disagree, $3=$ Neither Agree nor Disagree, $4=$ Agree, and $5=$ Strongly Agree. Items 1-4 measure perceived organizational support, items 5-7 measure supervisor social support, and items 8-10 measure coworker social support. 


\section{Appendix O: Work as Meaning Inventory}

(Steger, Dik, \& Duffy, 2012)

1. I have found a meaningful career.

2. I view my work as contributing to my personal growth.

3. My work really makes no difference to the world.

4. I understand how my work contributes to my life's meaning.

5. I have a good sense of what makes my job meaningful.

6. I know my work makes a positive difference in the world.

7. My work helps me better understand myself.

8. I have discovered work that has a satisfying purpose.

9. My work helps me make sense of the world around me.

10. The work I do serves a greater purpose.

Note. Items are rated on a 1 to 5 scale where $1=$ Absolutely Untrue, $2=$ Mostly Untrue, $3=$ Neither True nor Untrue, $4=$ Mostly True, and $5=$ Absolutely True. Items 1, 4, 5, and 8 measure the "Positive Meaning" dimension; items 2, 7, and 9 measure the "Meaning-Making through Work" dimension; and a subtracted rating for item 3 from a value of 6 , summed with items 6 and 10 measure the "Greater Good Motivations" dimension. Aggregate scores measure overall Meaningful Work. 


\section{Appendix P: Measure of Perceived Employability}

(Berntson \& Marklund, 2007)

1. My competence is sought after in the labor market.

2. I have a contact network that I can use to get a new (equivalent or better) job.

3. I know of other organizations/companies where I could get work.

4. My personal qualities make it easy for me to get a new (equivalent or better) job in a different company/organization.

5. My experience is in demand on the labour market.

Note. Items are rated on a 1 to 5 scale where $1=$ Strongly Disagree, $2=$ Somewhat Disagree, 3 $=$ Neither Agree nor Disagree, $4=$ Somewhat Agree, $5=$ Strongly Agree. 


\section{Appendix Q: Negative Affectivity Scale}

(from PANAS; Watson, Clark, \& Tellegen, 1988)

Please read the following list of thoughts and emotions and indicate how often you

GENERALLY FEEL THIS WAY; that is, HOW YOU FEEL ON AVERAGE:

1. Scared

2. Afraid

3. Upset

4. Distressed

5. Jittery

6. Nervous

7. Ashamed

8. Guilty

9. Irritable

10. Hostile

Note. Items are rated on a 1 to 5 scale where $1=$ Strongly Disagree, $2=$ Somewhat Disagree, 3

$=$ Neither Agree nor Disagree, $4=$ Somewhat Agree, $5=$ Strongly Agree. 


\section{Appendix R: Demographics and Cannabis Use}

1. What is your gender?
a. Male
b. Female

2. What is your age?
a. $18-25$
b. $26-30$
c. $31-35$
d. $36-40$
e. $41-45$
f. $46-50$
g. 51-55
h. $56-60$
i. $61+$

3. What is your race/ethnicity? (Please mark all that apply)
- Caucasian
- Black/African-American
- Hispanic/Latino
- Native American
- Asian
- Hawaiian/Pacific Islander
o Other

4. What is your highest level of education?
a. High school or GED
b. Some college
c. 2 year degree
d. 4-year degree
e. Master's degree
f. Doctoral degree
g. Professional degree (e.g, JD)

5. In your main job, are you salaried, paid by the hour, or what?
a. Salaried
b. Paid by the hour
c. Other (please specify:

6. What is your annual salary/income from your main job in the cannabis industry?
a. $<\$ 25,000$
b. $\$ 25,001-30,000$
c. $\$ 30,001-35,000$ 


\section{Appendix R (cont'd)}
d. $\$ 35,001-40,000$
e. $\$ 40,001-45,000$
f. $\$ 45,001-50,000$
g. $\$ 50,001-55,000$
h. \$55,001-60,000
i. $\$ 60,001-65,000$
j. $\$ 65,001-70,000$
k. $\$ 70,001-75,000$
1. $\$ 75,001-80,000$
m. $\$ 80,000$

7. Which of the following best describes your usual work schedule?
a. Day shift
b. Afternoon shift
c. Night shift
d. Split shift
e. Irregular shift/on-call
f. Rotating shifts

8. How long has your organization been operating/in business? years and months (drop down box for each category)

9. How many employees work for your organization at your location?

10. Which of the following facilities does your organization currently have in operation across all locations?
a. Indoor growhouse (e.g., in a warehouse)
b. Outdoor grow
c. Greenhouse grow operation
d. Dispensary/Retail sales facility (if yes, please specify which type of cannabis)
e. Medical
f. Recreational
g. Both
h. Extraction facilities
i. Manufacturing facilities (e.g., for cannabis edibles)

11. Which of the following facilities does your organization currently have in operation at YOUR work location?
a. Indoor growhouse (e.g., in a warehouse)
b. Outdoor grow
c. Greenhouse grow operation
d. Dispensary/Retail sales facility (if yes, please specify which type of cannabis) 


\section{Appendix R (cont'd)}
e. Medical
f. Recreational
g. Both
h. Extraction facilities
i. Manufacturing facilities (e.g., for cannabis edibles)

12. Which type of cannabis does your organization work with?
a. Medical only
b. Recreational only
c. Both medical and recreational

13. Do you have any other jobs besides your main job or do any other work for pay?
a. Yes
b. No

14. Do you have any other jobs outside of the cannabis industry?
a. Yes
b. No

\section{Cannabis Use:}

15. Are you part of Colorado's Medical Marijuana Registry (do you own a Red Card)?
a. Yes
b. No

16. How often do you CURRENTLY use Cannabis (in any form)?
a. N/A (Don't use)
b. Less than monthly (1-11 times/year)
c. Less than weekly (1-3 times/month)
d. Once a week
e. A couple (1-2) times a week
f. A few (3-6) times a week
g. Daily
h. 2-4 times a day
i. More than 4 times a day

17. How long ago did you first try cannabis?
a. N/A (Never tried)
b. Less than one year
c. 1-2 years 


\section{Appendix R (cont'd)}
d. 2-4 years
e. 4-7 years
f. 7-10 years
g. $10+$ years

18. During the past two months, how often do you typically use cannabis or cannabis products before work - within two hours of starting work?
a. Never
b. Less than monthly
c. 1 to 3 days per month
d. 1 to 2 days per week
e. 3 to 5 days per week
f. 6 to 7 days per week

19. During the past two months, how often do you typically use cannabis or cannabis products during work (including on breaks or while working)?
a. Never
b. Less than monthly
c. 1 to 3 days per month
d. 1 to 2 days per week
e. 3 to 5 days per week
f. 6 to 7 days per week

20. During the past two months, how often do you typically use cannabis or cannabis products after work (within two hours of finishing work)?
a. Never
b. Less than monthly
c. 1 to 3 days per month
d. 1 to 2 days per week
e. 3 to 5 days per week
f. 6 to 7 days per week

21. During your work day, do you ever drive while under the influence of cannabis or cannabis products?
a. Yes
b. No

22. If you ever drive while under the influence of cannabis or cannabis products during your work day, in what context do you do so? (please check all that apply)

O On the way to work

○ During work hours (e.g., to work sites, running work-related errands, etc.)

$\circ$ On the way home from work 


\section{Appendix R (cont'd)}

23. In your personal non-work time, do you ever drive while under the influence of cannabis or cannabis products?
a. Yes
b. No 


\section{Appendix S: Description of "Hacker" Response Identification and Deletion Process}

Throughout data collection, I viewed responses on a rolling basis to provide incentives to study participants. When analyzing responses, I quickly noticed that certain responses appeared to be problematic, and also oriented around a similar pattern. Qualtrics automatically provides estimated locations of the IP addresses of respondents; when analyzing the data, I first noticed that these problematic responses all portrayed IP address locations from around the world, in locations not targeted for our sample (as this study was limited to participants in the state of Colorado). After identifying this first pattern in the data, I then identified numerous other criteria indicating a pattern in responses, including: a) incredibly short response times (e.g., ranging from a few seconds to less than 5 minutes); b) bogus email addresses included in the dataset using random strings of letters, which continuously appeared in a similar format across separate respondents (e.g., xndxwlxy@gmail.com); c) false phone numbers in the data set (originally, the area code of phone numbers was from around the world. Eventually, area codes were switched to the Denver area, but phone numbers were found to be false after I attempted to call the phone number for survey verification); d) random strings of letters and words inputted as responses to open-ended questions; e) copied/pasted responses to open-ended questions across multiple different individual respondents (indicating that these responses were likely originated by one particular individual or group of individuals, who pasted responses in multiple different survey windows); f) occupations and industries that represented jobs outside of the cannabis industry (e.g., engineer, architect, estimator, etc.); g) generic occupations and duties which were also copied and pasted across numerous separate responses (e.g., a "finance manager" whose tasks involved "preparation of the final plan, supervise the operation and use of funds" and a 
"marketing director" whose tasks involved "The definition, planning and design of product function").

Additionally, in two separate circumstances, overall responses fit several of the above criteria, but responses to the open-ended questions about job and job tasks appeared to be legitimate responses. For example, in one particular response, the individual reported their job as "Cannabis Laboratory Technician" with job tasks listed as "Set up cannabis testing facility / Assist in choosing appropriate testing equipment / Testing of cannabis products for potency, pesticides, molds, biologicals, etc." (this is the exact response, including slash-marks). The very exact and descriptive nature of these job tasks appeared suspicious, and deviated in overall tone from the vast majority of responses to date. To investigate these suspicions further, I copied and pasted the job tasks into a Google search and discovered that the responses were actually copied and pasted from an online job posting for a "Cannabis Laboratory Technician". In the other instance, responses were copied verbatim from a job posting for a "Grower's Assistant" (deidentified PDF versions of these job postings are available upon request). Given the exact wording copied from the job posting, as well as the responses satisfying several other aforementioned criteria, these responses were determined to be false. All false responses satisfying some or all of the above criteria were removed from the dataset. 